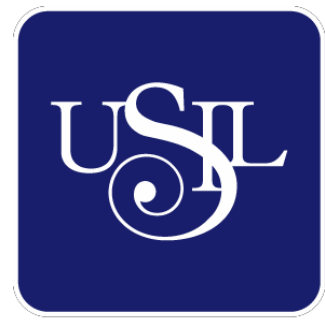

UNIVERSIDAD

SAN IGNACIO

DE LOYOLA

FACULTAD DE INGENIERÍA

Carrera de Ingeniería Industrial

\title{
IMPACTO DE UNA MEJORA DE LA GESTIÓN DE INVENTARIOS EN EL NIVEL DE SERVICIO DE UNA EMPRESA LUMINARIA
}

\author{
Tesis para optar el Título Profesional de Ingeniero \\ Industrial
}

GIANELLA DEL CASTILLO RAMOS

(0000-0002-8997-6995)

CARLA FARFÁN NARAZA

(0000-0002-0935-1160)

Asesor:

Dr. Pedro Pablo Rosales López

(0000-0002-8115-6431)

Lima - Perú

2021 


\title{
JURADO DE LA SUSTENTACION ORAL
}

\author{
Presidente
}

Jurado 1

Jurado 2

Entregado el:



Graduando

Graduando
Aprobado por:

Asesor de Tesis: 


\section{UNIVERSIDAD SAN IGNACIO DE LOYOLA FACULTAD DE INGENIERÍA DECLARACIÓN DE AUTENTICIDAD}

Yo, Gianella Del Castillo Ramos, identificado con DNI № 74128685, Bachiller del Programa Académico de la Carrera de Ingeniería Industrial de la Facultad de Ingeniería de la Universidad San Ignacio de Loyola, presento mi tesis titulada:

"IMPACTO DE UNA MEJORA DE LA GESTIÓN DE INVENTARIOS EN EL NIVEL DE SERVICIO DE UNA EMPRESA LUMINARIA".

Declaro en honor a la verdad, que el trabajo de tesis es de mi autoría; que los datos, los resultados y su análisis e interpretación, constituyen mi aporte. Todas las referencias han sido debidamente consultadas y reconocidas en la investigación.

En tal sentido, asumo la responsabilidad que corresponda ante cualquier falsedad u ocultamiento de la información aportada. Por todas las afirmaciones ratifico lo expresado, a través de mi firma correspondiente.

Lima, 21 de enero de 2021

Gianella Del Castillo Ramos

DNI 74128685 


\section{UNIVERSIDAD SAN IGNACIO DE LOYOLA \\ FACULTAD DE INGENIERÍA DECLARACIÓN DE AUTENTICIDAD}

Yo, Carla Farfán Naraza, identificado con DNI № 46639716, Bachiller del Programa Académico de la Carrera de Ingeniería Industrial de la Facultad de Ingeniería de la Universidad San Ignacio de Loyola, presento mi tesis titulada:

"IMPACTO DE UNA MEJORA DE LA GESTIÓN DE INVENTARIOS EN EL NIVEL DE SERVICIO DE UNA EMPRESA LUMINARIA".

Declaro en honor a la verdad, que el trabajo de tesis es de mi autoría; que los datos, los resultados y su análisis e interpretación, constituyen mi aporte. Todas las referencias han sido debidamente consultadas y reconocidas en la investigación.

En tal sentido, asumo la responsabilidad que corresponda ante cualquier falsedad u ocultamiento de la información aportada. Por todas las afirmaciones ratifico lo expresado, a través de mi firma correspondiente.

Lima, 21 de enero de 2021

Carla Farfán Naraza

DNI 46639716 


\section{Epígrafe}

"Mediante el trabajo ha sido como la mujer ha podido franquear la distancia que la separa del hombre. El trabajo es lo único que puede garantizarle una libertad completa"

- Simone de Beauvoir 
INDICE

RESUMEN 15

ABSTRACT

16

INTRODUCCIÓN 17

PROBLEMA DE LA INVESTIGACIÓN

IDENTIFICACIÓN DEL PROBLEMA

$\begin{array}{ll}\text { FORMULACIÓN DEL PROBLEMA } & 27\end{array}$

$\begin{array}{ll}\text { Problema general } & 27\end{array}$

$\begin{array}{ll}\text { Problemas específicos } & 27\end{array}$

$\begin{array}{lr}\text { MARCO REFERENCIAL } & 27\end{array}$

$\begin{array}{ll}\text { ANTECEDENTES } & 27\end{array}$

$\begin{array}{ll}\text { Nacionales. } & 27\end{array}$

Internacionales. $\quad 30$

ESTADO DEL ARTE $\quad 32$

MARCO TEÓRICO $\quad 34$

Definición de inventarios. $\quad 34$

Definición gestión de inventarios. $\quad 34$

Objetivo de la gestión de inventarios. $\quad 36$

Control de inventarios. $\quad 36$

Rotación de inventarios. $\quad 37$

Inventario de seguridad.

Gestión de stocks. 38

Exactitud de registro de inventarios. 38

Punto de reorden. 39

Lote económico de pedido. 39

Clasificación ABC. $\quad 40$

Nivel de servicio $\quad 41$

Entregas perfectas $\quad 41$

Entregas a tiempo 42

Devoluciones $\quad 42$

Tiempo de ciclo de pedido 43 
$\begin{array}{lr}\text { OBJETIVOS DE LA INVESTIGACIÓN } & 44\end{array}$

OBJETIVO GENERAL $\quad 44$

OBJETIVOS ESPECÍFICOS $\quad 44$

JUSTIFICACIÓN DE LA INVESTIGACIÓN $\quad 44$

$\begin{array}{ll}\text { TEÓRICA } & 44\end{array}$

PRÁCTICA $\quad 44$

SOCIAL $\quad 45$

ECONÓMICA

HIPOTESIS $\quad 46$

HIPÓTESIS GENERAL $\quad 46$

HIPÓTESIS ESPECIFICAS $\quad 46$

$\begin{array}{lr}\text { MATRIZ DE CONSISTENCIA } & 47\end{array}$

$\begin{array}{ll}\text { MARCO METODOLÓGICO } & 48\end{array}$

$\begin{array}{lr}\text { Metodología } & 48\end{array}$

PARADIGMA $\quad 48$

$\begin{array}{lr}\text { ENFOQUE } & 48\end{array}$

MÉTODO 48

$\begin{array}{lr}\text { VARIABLE } & 49\end{array}$

$\begin{array}{lr}\text { INDEPENDIENTE } & 49\end{array}$

Mejora de la gestión de inventarios $\quad 49$

DEPENDIENTE $\quad 50$

Nivel de servicio. $\quad 50$

POBLACIÓN Y MUESTRA

POBLACIÓN

MUESTRA

UNIDAD DE ANÁLISIS

INSTRUMENTOS Y TÉCNICAS

PROCEDIMIENTO Y MÉTODO DE ANÁLISIS 53 
PROCEDIMIENTO

MÉTODO DE ANÁLISIS $\quad 64$

Análisis descriptivo $\quad 64$

Análisis inferencial $\quad 65$

$\begin{array}{ll}\text { RESULTADOS } & 66\end{array}$

$\begin{array}{ll}\text { ENTREGAS PERFECTAS } & 66\end{array}$

ENTREGAS A TIEMPO

DEVOLUCIONES $\quad 76$

TIEMPO DE CICLO $\quad 81$

$\begin{array}{ll}\text { DISCUSIÓN } & 87\end{array}$

$\begin{array}{ll}\text { CONCLUSIONES } & 89\end{array}$

$\begin{array}{lr}\text { RECOMENDACIONES } & 90\end{array}$

$\begin{array}{lc}\text { SUGERENCIAS } & 93\end{array}$

$\begin{array}{lr}\text { REFERENCIAS } & 94\end{array}$ 


\section{INDICE DE TABLAS}

Tabla 1 Análisis por qué de bajo nivel de servicio - medio ambiente 21

Tabla 2 Análisis por qué bajo nivel de servicio - materiales, métodos y procedimientos 22

Tabla 3 Análisis por qué de bajo nivel de servicio - mano de obra y medida 23

Tabla 4 Matriz de consistencia. $\quad 47$

Tabla 5 Matriz de operacionalización de la variable nivel de servicio 51

Tabla 6 Aplicación de las 5S: Iniciativa mejora de desempeño de almacén 54

Tabla 7 Rotación de inventario por sub-familias $\quad 55$

Tabla 8 Clasificación $A B C \quad 58$

Tabla 9 Cuadro resumen de clasificación $A B C \quad 59$

Tabla 10 Muestreo Aleatorio Pre-test 65

Tabla 11 Muestreo Aleatorio Pre-test 65

Tabla 12 Entregas Perfectas Pre-test - Mayo 2019

Tabla 13 Estadística Descriptiva de Entregas Perfectas Pre-test - Mayo 2019.

Tabla 14 Prueba de Normalidad de Entregas Perfectas Pre-test - Mayo 2019

Tabla 15 Entregas Perfectas Post-test - Octubre $2019 \quad 68$

Tabla 16 Estadística Descriptiva de Entregas Perfectas Post-test - Octubre 2019

Tabla 17 Prueba de Normalidad de Entregas Perfectas Post-test-Octubre 2019

Tabla 18. Comparativo Pre-test Post-test de Entregas Perfectas. 70

Tabla 19 Entregas a Tiempo Pre-test - Mayo 2019

Tabla 20 Estadística Descriptiva de Entregas a Tiempo Pre-test - Mayo 2019

Tabla 21 Prueba de Normalidad de Entregas a Tiempo Pre-test - Mayo 2019

Tabla 22 Entregas a Tiempo Post-test - Octubre 2019

Tabla 23 Estadística Descriptiva de Entregas a Tiempo Post-test - Octubre 2019

Tabla 24 Prueba de Normalidad de Entregas a Tiempo Post-test - Octubre 2019

Tabla 25 Comparativo entre Pre-test y Post-test de Entregas a Tiempo 75

Tabla 26 Devoluciones Pre-test - Mayo 2019

Tabla 27 Estadística Descriptiva de Devoluciones Pre-test - Mayo 2019

Tabla 28 Prueba de Normalidad de Devoluciones Pre-test - Mayo 2019

Tabla 29 Devoluciones Post-test - Octubre 2019

Tabla 30 Estadística Descriptiva de Devoluciones Post-test - Octubre 2019

Tabla 31 Prueba de Normalidad de Devoluciones Post-test - Octubre 2019

Tabla 32 Comparativo Pre-test Post-test de Devoluciones 80 
Tabla 33 Tiempo de Ciclo Pre-test - Mayo 2019

Tabla 34 Estadística Descriptiva de Tiempo de Ciclo Pre-test - Mayo 2019

Tabla 35 Prueba de Normalidad de Tiempo de Ciclo Pre-test - Mayo 2019

Tabla 36 Tiempo de Ciclo Post-test - Octubre 2019

Tabla 37 Estadística Descriptiva de Tiempo de Ciclo Post-test - Octubre 2019

Tabla 38 Prueba de Normalidad de Tiempo de Ciclo Post-test - Octubre 2019

Tabla 39 Comparativo entre Pre-test y Post-test de Tiempo de Ciclo 85

Tabla 40 Dimensiones del Nivel de Servicio de una empresa luminaria. 86 


\section{INDICE DE FIGURAS}

Figura 1. Diagrama de Ishikawa $\quad 20$

Figura 2. Porcentaje de entregas perfectas. $\quad 24$

Figura 3. Porcentaje de entregas a tiempo. 25

Figura 4. Número de devoluciones. $\quad 26$

Figura 5. Ciclo de pedido. $\quad 26$

Figura 6. Metodología 5S $\quad 54$

Figura 7. Rotación de inventarios por sub-familia $\quad 56$

Figura 8. Clasificación ABC 59

Figura 9. DOP recepción de mercadería. $\quad 62$

$\begin{array}{ll}\text { Figura 10. Matriz de programación de capacitación. } & 63\end{array}$

Figura 11. Diseño de la investigación $\quad 64$

Figura 12. Prueba U de Mann - Whitney de Entregas Perfectas $\quad 70$

Figura 13. Prueba de U Mann - Whitney para Entregas a Tiempo 75

Figura 14. Prueba U de Mann - Whitney de Devoluciones $\quad 80$

Figura 15. Prueba de U Mann - Whitney para Tiempo de Ciclo 85 


\section{INDICE DE ANEXOS}

Anexo I. Matriz de operacionalización.

Anexo II: Rotación de inventario por SKU

102

Anexo III. Indicadores de política de revisión continua de inventarios.

109

Anexo IV: Pruebas estadísticas del Ratio Entregas Perfectas Pre-Test

113

Anexo V: Pruebas estadísticas del Ratio Entregas Perfectas Post-Test

116

Anexo VI: Pruebas estadísticas del Ratio Entregas a Tiempo Pre-Test

119

Anexo VII: Pruebas estadísticas del Ratio Entregas a Tiempo Post-Test

122

Anexo VIII: Pruebas estadísticas del Ratio de Devoluciones Pre-Test

125

Anexo IX: Pruebas estadísticas del Ratio de Devoluciones Post-Test

128

Anexo X: Data de Tiempo de Ciclo

Anexo XI: Pruebas estadísticas del Tiempo de Ciclo Pre-Test

Anexo XII: Pruebas estadísticas del Tiempo de Ciclo Post-Test 


\section{Dedicatoria}

Dedicamos a nuestros familiares y amigos por su apoyo brindado durante la realización de esta investigación, gracias por la confianza y motivación a seguir adelante. 


\section{Agradecimiento}

Nuestro agradecimiento a la Universidad San Ignacio de Loyola que nos brindó los conocimientos necesarios para elaborar la presente investigación.

A la experta en la materia Fiorela Farfán por su paciencia entrega y valiosos consejos.

A nuestros colegas que nos facilitaron acceso a literatura y por darnos siempre apoyo.

A la empresa por darnos las facilidades y la información de manera oportuna en el planteamiento inicial y durante el desarrollo de nuestra tesis.

En especial a nuestras familias por el soporte incondicional para el logro de nuestros objetivos. 


\section{RESUMEN}

El presente trabajo de investigación ha sido desarrollado en una empresa luminaria, dedicada a la importación, venta y distribución de tecnología de iluminación LED. Para la empresa en muy importante la relación con sus clientes, sobre todo, en el mercado tan competitivo. De esta forma, y dado el giro del negocio, dentro de los procesos que más generan valor son los correspondientes a la gestión de inventario. En los cuales detectaron diversas deficiencias a corregir.

De esta manera, la relación con el cliente resultante del manejo de inventarios es diagnosticada mediante el indicador nivel de servicio, para incrementarlo se planteó una mejora en la gestión de inventarios. Para ello se utilizaron diversas herramientas como son la clasificación $A B C$, rotación de inventarios, EOQ, stock de seguridad, punto de re-orden, $5 S$, planes de capacitación y revisión de procesos.

Con la finalidad de verificar la hipótesis de la presente investigación con diseño cuasiexperimental, se precedió a evaluar las dimensiones del nivel de servicio, antes y después de la mejora en la gestión de inventarios. Obteniéndose resultados favorables.

En conclusión, la mejora de la gestión de inventarios tuvo un impacto positivo en el nivel de servicio. No obstante, cabe señalar, que sin el compromiso de todo el capital humano dentro de la organización no se hubieran obtenido los mismos resultados.

Palabras claves: Nivel de servicio, gestión de inventario, clasificación ABC. 


\begin{abstract}
This research has been developed in a company dedicated to import lighting products, sale and distribution of LED lighting technology. For the company the customer's relationship is very important, especially in their highly competitive market. This way, and given the turn of the business, within the processes that generate most value are those corresponding to inventory management. In which they detected several deficiencies to correct.

This way, the relationship with the client resulting from inventory management is diagnosed through the service level indicator, to increase it, an improvement in inventory management was proposed. For this, many tools were used such as $A B C$ classification, inventory rotation, $E O Q$, safety stock, reorder point, $5 S$, training plans and process examination.

In order to verify the hypothesis of the current investigation with a quasi-experimental design, it was preceded to evaluate the dimensions of service level, before and after the improvement in inventory management. Obtaining satisfactory results.

In conclusion, the improvement in inventory management had a positive impact on the service level. However, it should be noted that without the commitment of all the human resources of the organization, the same results would not have been obtained.
\end{abstract}

Keywords: Service level, inventory management, $A B C$ classification. 


\section{INTRODUCCIÓN}

La empresa objeto de investigación se dedica a la comercialización de productos de iluminación con tecnología LED, los cuales son importados de China. La empresa tiene como estrategia de negocio diferenciarse mediante un servicio de calidad, brindando todo lo que el cliente requiera en el momento exacto, lo que implica un gran esfuerzo de parte del área logística en coordinación con ventas, todo ello con el objetivo de brindar un alto nivel de servicio.

La empresa presenta diversas deficiencias en la gestión de inventarios, lo que ocasiona quiebres de stock, lo cual impacta directamente en el nivel de servicio. Ello debido a la falta de clasificación de sus inventarios, al inadecuado cálculo de los indicadores en el área de almacén y falta de capacitación del personal. En consecuencia, existe un desbalance en el aprovisionamiento.

Por lo tal, en la presente tesis se pudo probar la forma en que impacta la mejora de la gestión de inventarios en el nivel de servicio, es decir, cómo manejar los procesos correctamente dentro de la organización repercute directamente en la percepción que tiene el cliente respecto al servicio brindado. 


\section{PROBLEMA DE LA INVESTIGACIÓN}

\section{Identificación del problema}

La empresa luminaria en cuestión cuenta con 6 años en el mercado como importadora y distribuidora de iluminación de tecnología LED; productos que proveen ahorro de energía, alta eficiencia y nitidez en los colores, la empresa desarrolla sus actividades en todo el Perú, con centro de operaciones en Lima.

El actual gerente comercial, comenzó en la década de los noventa como socio en una empresa importadora de productos de iluminación, llaves termo magnéticas y tableros, luego de que el gobierno peruano, en el año 2010, abriera el mercado peruano a las importaciones con China. Rápidamente adquirió los conocimientos en importación y junto a un capital familiar se independizó y creo la empresa luminaria en el año 2013.

En un principio la empresa manejaba una estructura básica, con un gerente general, un jefe de ventas, un asistente administrativo y dos trabajadores en área de despacho. La gerencia tenía la labor de las importaciones y hacía la proyección de compras de manera instintiva y no con una medición exacta, aquello, junto a una sobrecarga laboral causó roturas de stock en muchas oportunidades. Luego de unos años, al crecer el radio de operación era preciso ampliar la planilla y buscar la optimización de costos y cantidades de aprovisionamiento por lo que se agregó un jefe de logística, quien tenía a su cargo las compras y despachos de mercadería. En un futuro, se adicionaron al personal un jefe de compras, quien tiene actualmente a su cargo las importaciones y su proyección.

En un inicio fue beneficiosa la incorporación del nuevo integrante, hubo mejoras en las compras, menores costos por el manejo de promociones con proveedores, créditos con proveedores, innovación en portafolio de productos tecnológicos y en consecuencia en las entregas. Sin embargo, la empresa aún no cuenta con una buena gestión de abastecimiento en la actualidad, lo cual le lleva a enfrentar problemas en el nivel de servicio al cliente. La empresa distribuidora entra en periodos en los que no tiene cantidad suficiente de un determinado producto (o varios) y, por lo tanto, no puede abastecer la demanda de sus clientes y crea entregas incompletas (imperfectas), la cual genera pérdidas monetarias.

Actualmente la empresa cuenta con un asistente de almacén, quien está encargado del control de inventarios de forma física, cuenta con el módulo de almacén en el sistema SIE 
(Sistema integral empresarial), ERP (enterprise resource planning) que le permite tener stock de productos actualizado y mantener ratios de rotación de inventarios según su valor, ingresar los conteos físicos de productos y supervisar la manipulación de los productos. La data del historial de los últimos meses le permite al jefe de compras programar adquisiciones tomando en cuenta el ciclo de importación de aproximadamente tres meses por embarque. No obstante, el área sigue teniendo problemas con establecer puntos de reorden por tipo de productos, no cuenta con clasificación de los mismo y no mantiene un orden de trabajo adecuado, esto genera fluctuación en los niveles de inventario. Adicionalmente, se ha observado que la falta de un producto influye en la venta de otros, debido a que se suelen adquirir en familias de productos de distintas variedades, lo cual causa bajas importantes en ventas y resta competitividad a la empresa.

De esta manera, para una mejor visualización del problema y de todas las ramas que ello implica se ha graficado mediante el diagrama de Ishikawa el cual se presenta a continuación. En este sentido, se puede visualizar las causas del problema general motivo de esta investigación, problemas derivados de una ineficiente gestión de inventarios. 


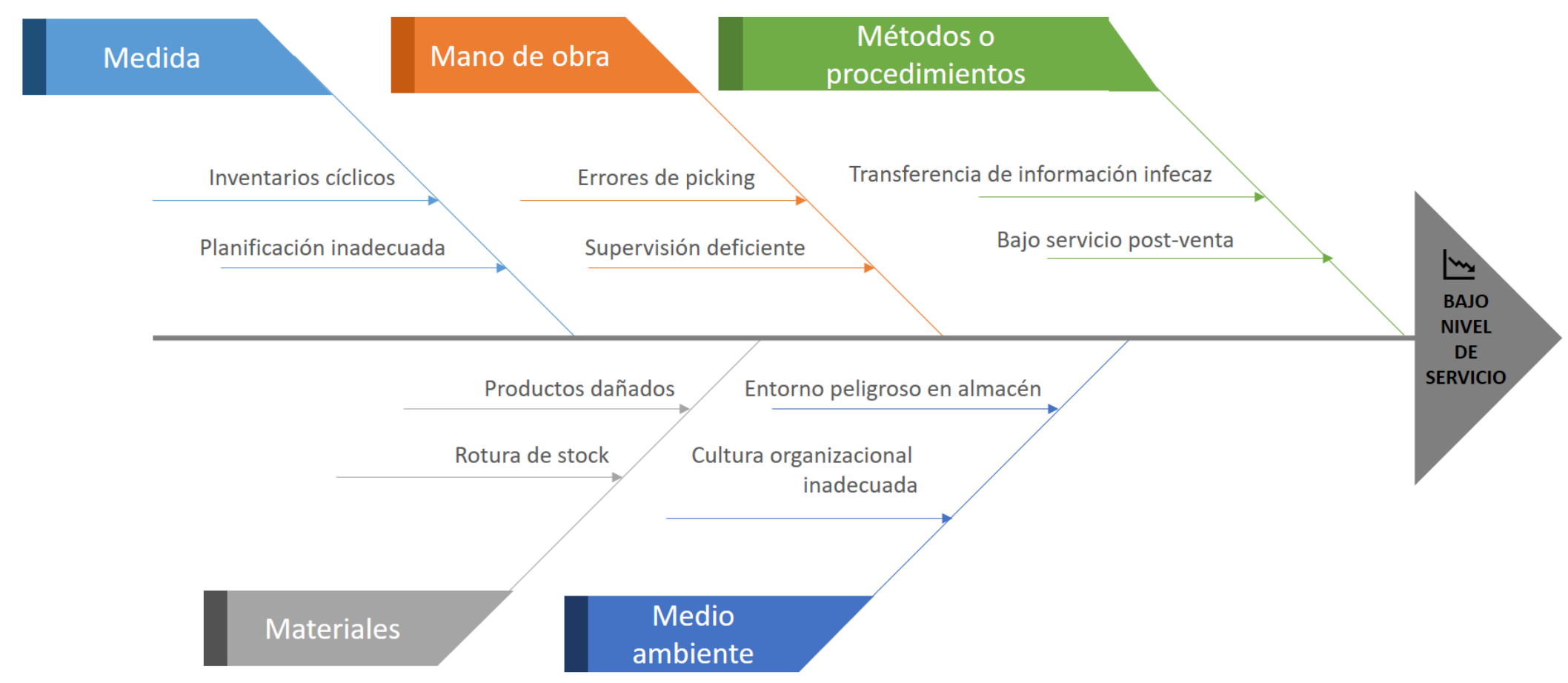

Figura 1. Diagrama de Ishikawa 


\section{Análisis Por Qué: Bajo nivel de servicio en la empresa iluminaria}

Temas: Medio Ambiente - Mano de Obra - Materiales - Métodos - Medida

Tabla 1

Análisis por qué de bajo nivel de servicio - medio ambiente

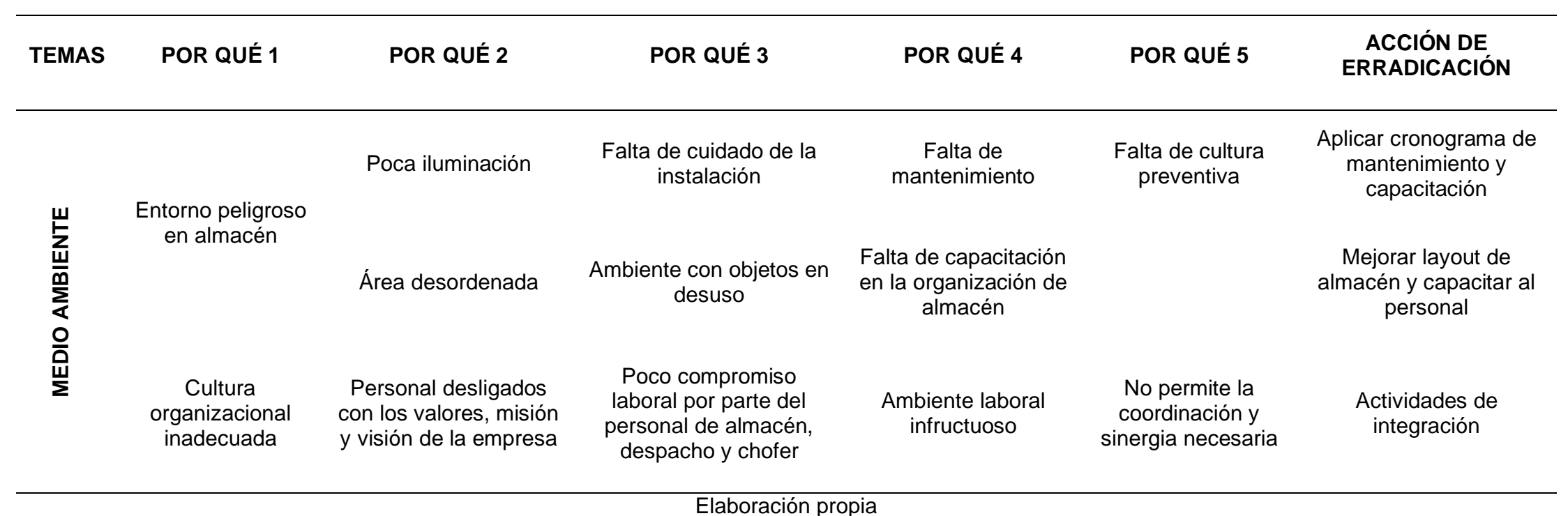


Tabla 2

Análisis por qué bajo nivel de servicio - materiales, métodos y procedimientos

\begin{tabular}{|c|c|c|c|c|c|c|}
\hline TEMAS & POR QUÉ 1 & POR QUÉ 2 & POR QUÉ 3 & POR QUÉ 4 & POR QUÉ 5 & $\begin{array}{c}\text { ACCIÓN DE } \\
\text { ERRADICACIÓN }\end{array}$ \\
\hline \multirow{3}{*}{ 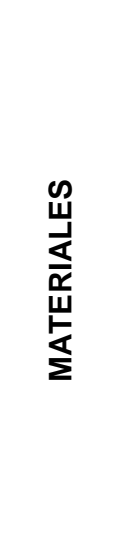 } & & $\begin{array}{l}\text { Falta de identificación de } \\
\text { productos con alta } \\
\text { rotación }\end{array}$ & $\begin{array}{l}\text { Inadecuado cálculo } \\
\text { de punto de re- } \\
\text { orden }\end{array}$ & $\begin{array}{l}\text { Mala gestión } \\
\text { de inventarios }\end{array}$ & & $\begin{array}{l}\text { Mejorar gestión de } \\
\text { inventarios }\end{array}$ \\
\hline & Rotura de stock & $\begin{array}{l}\text { Constante innovación en } \\
\text { el sector luminario }\end{array}$ & $\begin{array}{c}\text { Falta de } \\
\text { actualización y } \\
\text { asistencia a ferias } \\
\text { del sector }\end{array}$ & $\begin{array}{l}\text { Inadecuada } \\
\text { planificación }\end{array}$ & & $\begin{array}{l}\text { Diseñar procedimiento y } \\
\text { cronograma de innovación }\end{array}$ \\
\hline & $\begin{array}{l}\text { Productos } \\
\text { dañados }\end{array}$ & $\begin{array}{l}\text { Localización de } \\
\text { materiales inadecuada }\end{array}$ & $\begin{array}{l}\text { Falta de } \\
\text { organización de } \\
\text { almacén }\end{array}$ & $\begin{array}{l}\text { Mal diseño de } \\
\text { layout }\end{array}$ & $\begin{array}{l}\text { No existe cultura } \\
\text { organizacional sobre } \\
\text { la estandarización }\end{array}$ & $\begin{array}{c}\text { Capacitar a la dirección } \\
\text { para generar políticas } \\
\text { efectivas de } \\
\text { estandarización }\end{array}$ \\
\hline \multirow{2}{*}{ 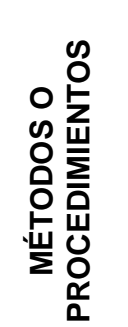 } & $\begin{array}{l}\text { Transferencia de } \\
\text { información } \\
\text { ineficaz }\end{array}$ & $\begin{array}{c}\text { Falta de adecuada } \\
\text { comunicación entre } \\
\text { áreas }\end{array}$ & $\begin{array}{c}\text { Uso inadecuado del } \\
\text { ERP }\end{array}$ & $\begin{array}{l}\text { Personal no } \\
\text { capacitado }\end{array}$ & $\begin{array}{l}\text { Poco interés de la } \\
\text { empresa en el tema }\end{array}$ & $\begin{array}{l}\text { Realizar cronograma de } \\
\text { capacitación al personal }\end{array}$ \\
\hline & $\begin{array}{l}\text { Bajo servicio } \\
\text { post-venta }\end{array}$ & $\begin{array}{c}\text { Vendedores no realizan } \\
\text { seguimiento al cliente } \\
\text { una vez despachado el } \\
\text { producto }\end{array}$ & $\begin{array}{c}\text { Falta de } \\
\text { procedimiento post- } \\
\text { venta estandarizado }\end{array}$ & & & $\begin{array}{l}\text { Estandarización del } \\
\text { procedimiento post-venta y } \\
\text { capacitación a fuerza de } \\
\text { ventas }\end{array}$ \\
\hline
\end{tabular}

Elaboración propia 
Tabla 3

Análisis por qué de bajo nivel de servicio - mano de obra y medida

\begin{tabular}{|c|c|c|c|c|c|c|}
\hline TEMAS & POR QUÉ 1 & POR QUÉ 2 & POR QUÉ 3 & POR QUÉ 4 & POR QUÉ 5 & $\begin{array}{l}\text { ACCIÓN DE } \\
\text { ERRADICACIÓN }\end{array}$ \\
\hline \multirow{2}{*}{ 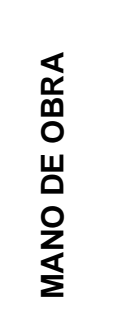 } & $\begin{array}{l}\text { Errores de } \\
\text { picking }\end{array}$ & $\begin{array}{l}\text { Mala organización } \\
\text { en el despacho }\end{array}$ & $\begin{array}{l}\text { Inadecuada priorización } \\
\text { de despachos }\end{array}$ & Inadecuado rotulado & $\begin{array}{c}\text { Uso } \\
\text { inadecuado } \\
\text { del ERP }\end{array}$ & $\begin{array}{l}\text { Capacitación al personal de } \\
\text { almacén }\end{array}$ \\
\hline & $\begin{array}{l}\text { Supervisión } \\
\text { deficiente }\end{array}$ & $\begin{array}{l}\text { Personal de } \\
\text { almacén es el } \\
\text { mismo que realiza } \\
\text { el inventario }\end{array}$ & $\begin{array}{c}\text { Administración considera } \\
\text { que no es necesario } \\
\text { invertir en una tercera } \\
\text { persona }\end{array}$ & $\begin{array}{l}\text { No se cuenta con el } \\
\text { presupuesto para una } \\
\text { tercera persona }\end{array}$ & & $\begin{array}{l}\text { Concientizar a la dirección } \\
\text { sobre el correcto control de } \\
\text { inventarios y capacitación al } \\
\text { personal. }\end{array}$ \\
\hline \multirow{2}{*}{ 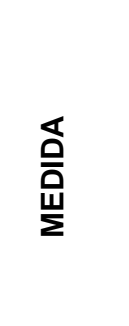 } & $\begin{array}{l}\text { Inventarios } \\
\text { cíclicos }\end{array}$ & $\begin{array}{l}\text { Políticas no } \\
\text { definidas en } \\
\text { almacén }\end{array}$ & Falta de estandarización & $\begin{array}{l}\text { Falta de clasificación } \\
\text { ABC }\end{array}$ & & Mejorar gestión de inventarios \\
\hline & $\begin{array}{l}\text { Planificación } \\
\text { inadecuada }\end{array}$ & $\begin{array}{c}\text { Compras excesivas } \\
\text { o faltantes }\end{array}$ & $\begin{array}{l}\text { Falta de un punto de } \\
\text { reorden y clasificación de } \\
\text { stock }\end{array}$ & $\begin{array}{c}\text { Falta de } \\
\text { estandarización del } \\
\text { procedimiento de } \\
\text { cálculo }\end{array}$ & & $\begin{array}{c}\text { Estandarización de la gestión } \\
\text { de inventarios }\end{array}$ \\
\hline
\end{tabular}


En este sentido, se presenta la necesidad de mejorar la gestión de inventarios actual para tener un mejor nivel de servicio, lo cual se verá traducido en ofrecerle al cliente entregas perfectas, a tiempo, que cumplan con el tiempo estipulado y que no generen la posibilidad a devoluciones.

De esta forma, en lo que respecta a los problemas específicos provenientes de este estudio se han graficado cada uno. Obteniendo un mayor entendimiento en cómo estos problemas afectan a la empresa en sus indicadores.

La empresa ha ido disminuyendo en el porcentaje de entregas perfectas, el siguiente gráfico indica los porcentajes en mediciones quincenales de los meses de enero, febrero y marzo del 2019.

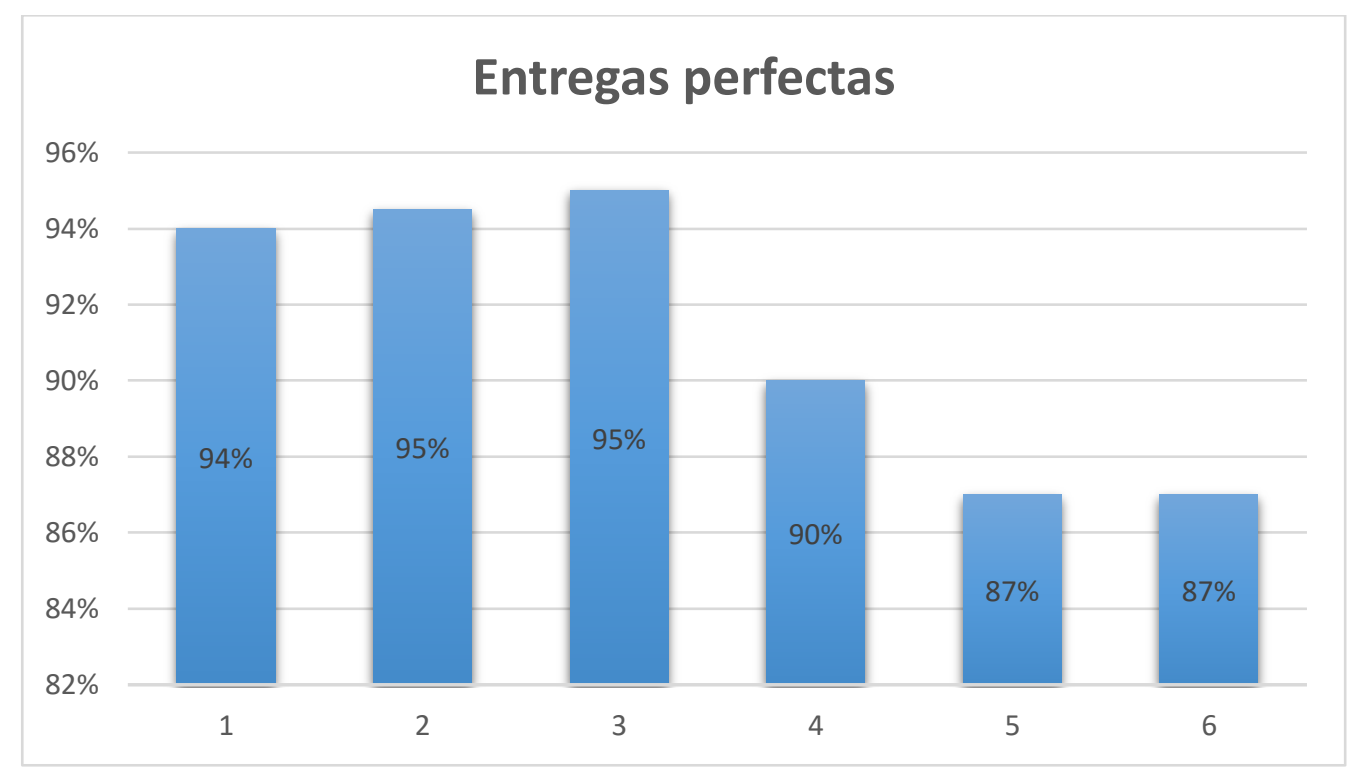

Figura 2. Porcentaje de entregas perfectas. 
La empresa ha ido reduciendo en el porcentaje de entregas a tiempo, el siguiente gráfico indica los porcentajes en mediciones quincenales de enero, febrero y marzo del 2019.

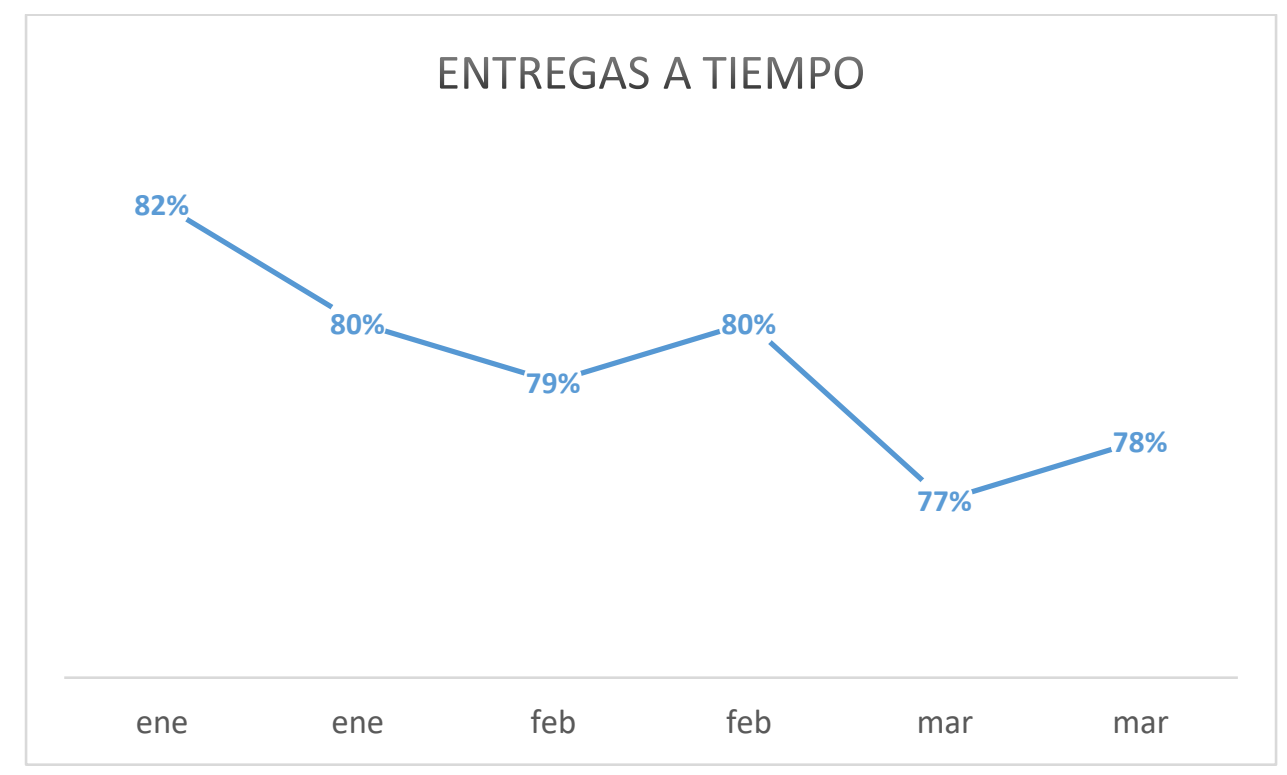

Figura 3. Porcentaje de entregas a tiempo. 
Por el contrario, la empresa ha ido aumentando en el número de devoluciones, el siguiente gráfico indica el número de incidencias totales quincenales de enero, febrero y marzo del 2019.

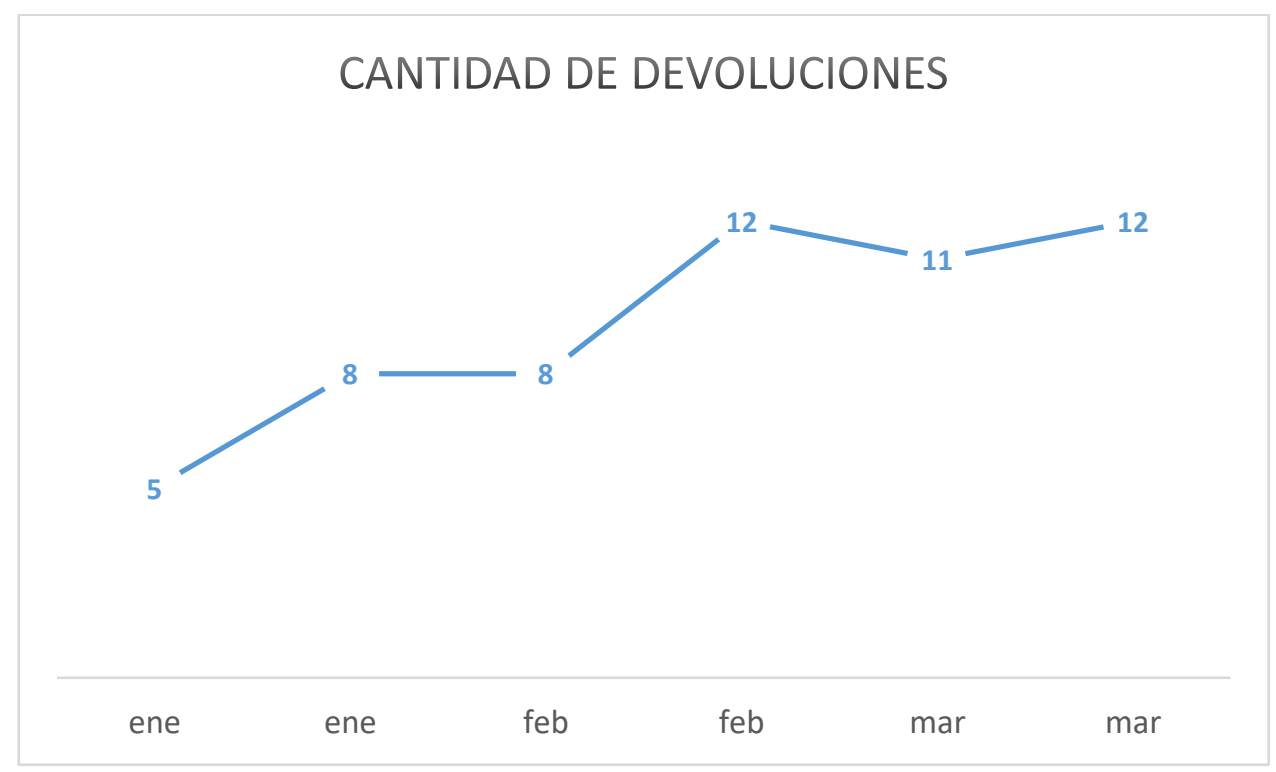

Figura 4. Número de devoluciones.

Por otro lado, ha ido diminuyendo en el número de días adecuados para ciclo de pedido, el siguiente gráfico indica el porcentaje promedio de ciclo de pedido considerado a tiempo quincenales de enero, febrero y marzo del 2019.

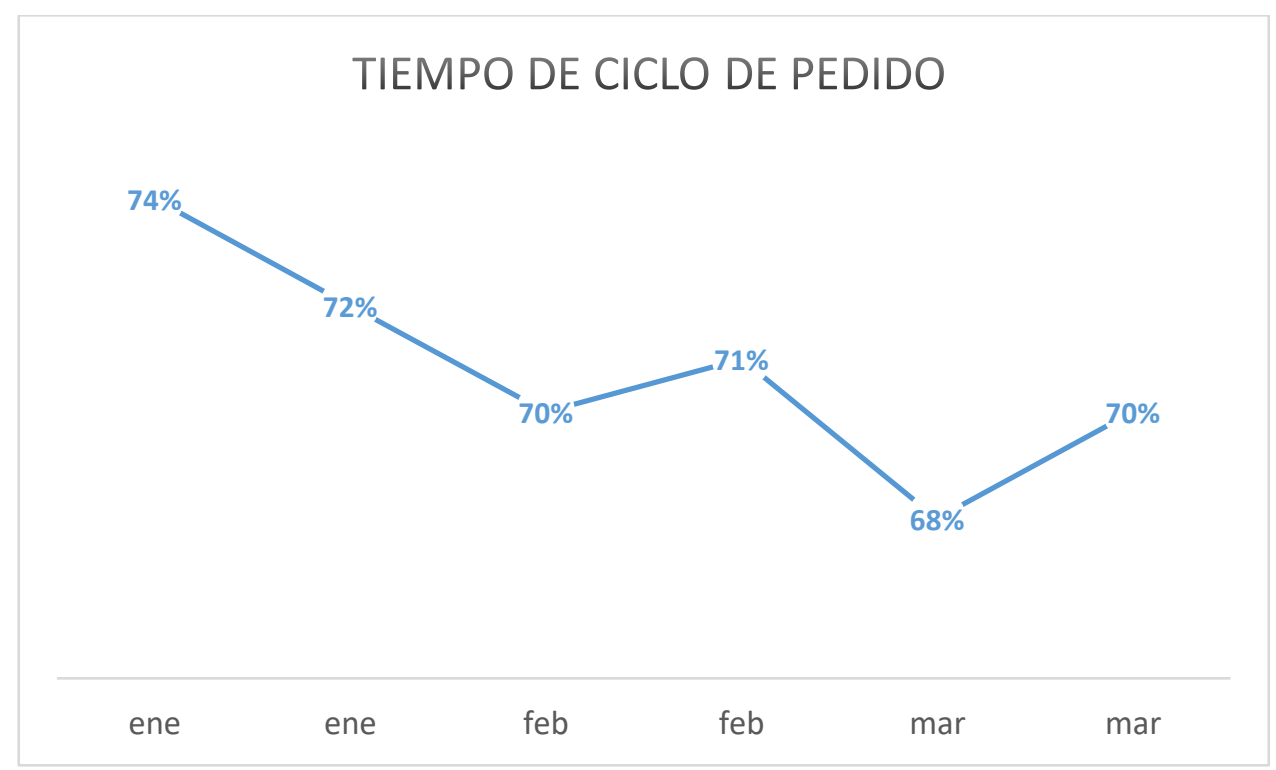

Figura 5. Ciclo de pedido. 


\section{Formulación del problema}

\section{Problema general}

¿Cuál es el impacto de una mejora de la gestión de inventarios en el nivel de servicio de una empresa luminaria?

\section{Problemas especificos}

¿Cuál es el impacto de una mejora de la gestión de inventarios en las entregas perfectas de una empresa luminaria?

¿Cuál es el impacto de una mejora de la gestión de inventarios en las entregas a tiempo de una empresa luminaria?

¿Cuál es el impacto de una mejora de la gestión de inventarios en el porcentaje de devoluciones de una empresa luminaria?

¿Cuál es el impacto de una mejora de la gestión de inventarios en el tiempo de ciclo de pedido de una empresa luminaria?

\section{MARCO REFERENCIAL}

\section{Antecedentes}

\section{Nacionales.}

Calle, D., Matute, F. y Yampasi, E. (2016) en su tesis de maestría "Rediseño del modelo de gestión de inventarios para Sinomaq S.A.: Aumentando el nivel de servicio y optimizando el stock de repuestos" presentada en la Universidad del Pacífico. La problemática principal del almacén gira en base a la falta de espacio, layout inadecuado, sobre stock de repuestos de baja rotación, roturas de stock, retraso en tiempos de atención, baja en indicadores como ROI, baja rotación de inventarios. Asimismo, la tesis tiene como objetivo lograr la eficiencia de los inventarios en el área de almacén central garantizando una entrega oportuna y sin errores de cara al cliente. La investigación es del tipo aplicada, con un diseño pre-experimental, pues la medición es bajo una única muestra. Concluye en la importancia del control de stocks, de esta manera no se incurre en altos costos por mantener o dañar los inventarios y no se arriesga el nivel de servicio deseado por roturas de stock. Se recalca el esfuerzo que debe poner la 
empresa en mejorar constantemente el control y la revisión del inventario en periodos más cortos, actuando pertinentemente a cambios imprevistos de demanda. Así también, se recomienda la optimización del modelo propuesto utilizando un software, ya que este se plantea en una hoja de cálculo.

Adicionalmente, la tesis "Implementación de gestión de inventarios para mejorar el nivel de servicio al cliente en la empresa Lumen Ingeniería S.A.C., Los Olivos, 2017" de Cervantes, R. (2017) tiene como problemática principal la inconformidad de diversos clientes por la entrega de servicios y/o materiales fuera del tiempo estimado, falta de stocks, retraso del trabajo, baja rotación de mercadería y desorden del inventario. De esta manera, busca determinar cómo la implementación de la gestión de inventarios mejorará el nivel de servicio al cliente en la empresa en mención. Utiliza una metodología aplicada con un diseño experimental del tipo cuasi-experimental. Es así que mediante el programa estadístico SPSS obtuvo como resultado un $1.53 \%$ de incremento en el nivel de servicio al cliente. En añadidura, antes de la implementación el ciclo de pedido promedio era de $56,63 \%$, reduciéndose a $7.56 \%$, mejorando óptimamente los tiempos. Finalmente, mejoró en 1.8\% el cumplimiento en el despacho de la mercadería. El autor recomienda un continuo trabajo en el control de existencias, mejorar la comunicación con los stakeholders para estar a la par de sus necesidades y poner mayor ímpetu en optimizar el despacho de pedidos.

Asimismo, Silva, E. (2018) con su tesis de titulación "Aplicación de gestión de inventario en el área de producción de la empresa Consorcio Mosaicos \& Anexos Lima S.A.C., San Juan de Lurigancho, 2018", cuenta como principal problemática el bajo nivel de servicio debido a los ineficientes procesos de recepción y entrega de productos en el área de producción. De esta manera, busca determinar la influencia de la aplicación de gestión de inventarios en la mejora del nivel de servicio dentro del área de producción de la empresa señalada. La metodología empleada es aplicada con un diseño experimental del tipo cuasi-experimental. Concluye en que efectivamente la aplicación de gestión de inventarios, principalmente el orden por clasificación ABC, incrementa el nivel de servicio. Lo cual se aprecia en el incremento de la confiabilidad en $41.45 \%$ y la capacidad de respuesta en $35.07 \%$. Las recomendaciones dadas son realizar un análisis anual del inventario y realizar una medición a largo plazo del beneficio de la gestión de inventarios, pues solo se evaluó para 3 meses. 
Además, Rivera, J. (2018) en su investigación "Implementación de la gestión de inventarios para mejorar el nivel de servicio en la empresa GRELCONPERU E.I.R.L., San Juan de Lurigancho, 2018" tiene como problemática principal un sistema ineficiente de inventarios que no tiene capacidad de gestionar y controlar los mariales, lo que genera compras y gastos innecesarios e incluso compras pasadas de tiempo. Es por ello, que su objetivo es determinar la medida en que la implementación de la gestión de inventario mejora el nivel de servicio en la empresa indicada. Emplea una metodología del tipo aplicada con un diseño de investigación pre-experimental. Por último, la medición del nivel de servicio antes de la implementación fue de $80.5 \%$, al finalizar esta, obtuvieron un resultado de $96 \%$, efectuándose un aumento de 15.5 puntos porcentuales. Las sugerencias propuestas son mantener la línea de la gestión de inventarios implementada dados sus resultados y reproducirla en sus sucursales. En suma, recomienda analizar los indicadores de rotación anualmente, para no perder la eficiencia del capital de trabajo.

En la tesis de Prado, F. (2018), "Aplicación de la gestión de inventarios para mejorar el nivel de servicio del almacén de la empresa productos alimenticios Carter S.A. Ate, 2018", tiene como problemática principal el bajo nivel de servicio en el área de almacén. De esta forma, busca determinar la medida en que la aplicación de gestión de inventarios mejora el nivel de servicio del almacén de la empresa señalada. Cuenta con una metodología aplicada con un diseño experimental, dada la manipulación de la variable independiente únicamente se considera del tipo cuasi-experimental. De esta forma, concluye en que el nivel de servicio tuvo un aumento del $15 \%$, mientras que las entregas perfectas un $9 \%$ y las entregas a tiempo en un $7.6 \%$. Finalmente, el autor sugiere una revisión permanente a la gestión de inventarios. Además de capacitar al personal que realice el picking y el conteo de cantidades para que sea realizado con mayor cuidado y precisión.

Todas las tesis nacionales expuestas anteriormente guardan estrecha relación con la presente tesis pues investigan ambas variables de la misma forma, ya que generan una considerable mejora en la gestión de inventarios de sus respectivas empresas y miden el impacto de ello en el nivel de servicio. Asimismo, utilizan la misma metodología, siendo investigaciones experimentales, de un nivel cuasi-experimental. De esta forma, en el ámbito nacional se encuentran buenas bases de estudio del tema, siendo un precedente de buenos pronósticos para la investigación actual. 


\section{Internacionales.}

Asimismo, Aguilar, P. (2012) en su investigación "Un modelo de clasificación de inventarios para incrementar el nivel de servicio al cliente y la rentabilidad de la empresa" desarrollada en el Centro de Estudios Superiores de Administración, Bogotá, tiene como objetivo proponer un modelo de gestión de inventarios que permita a la empresa mantener una rentabilidad creciente y que asegure el cumplimiento del nivel de servicio propuesto. Cabe señalar que es una investigación del tipo explicativo. De esta forma, utilizando el modelo planteado en la investigación obtuvieron un beneficio doble, pues asegura el alto nivel de servicio y mayor rentabilidad, ya que de esta forma solo se conserva en inventarios los productos con mayor rotación y los principales para la empresa.

Además, se consultó la investigación "Gestión de compras e inventarios a partir de pronósticos Holt-Winters y diferenciación de nivel de servicio por clasificación ABC" de Arango, J., Giraldo, J. y Castrillón, G. (2013) desarrollada en la Universidad Tecnológica de Pereira, Colombia. El objetivo es proponer un modelo de gestión de compras e inventarios. El cual se origina a partir del pronóstico de las ventas mediante el método Holt-Winters, clasificando los volúmenes de productos mediante el modelo $A B C$ asignando un nivel de servicio distinto para cada categoría. Finalmente, muestra como el modelo en mención ha sido aplicado con éxito en distintas empresas. Obteniéndose menores costos de capital de trabajo en inventarios y mejoras importantes en el nivel de servicio, reduciéndose ventas perdidas por roturas de stock. Recomienda la implementación informática de la solución, además que es estrictamente necesario integrarle las bases de datos de la empresa.

Sánchez, P. (2015) “Optimización de inventarios y nivel de servicio” sustentada por ESDAI Universidad Panamericana, México. Tiene como objetivo incrementar los niveles de servicio de Nestlé mediante la optimización de inventarios, para lo que se empleó la metodología CAPDo para instaurar una nueva política de cobertura. Finalmente, obtuvo mejores niveles de servicio y beneficios económicos, como consecuencia, entre estos, reducción de costos, mayores ventas, mejor rotación y frescura en el inventario.

Craig, N., DeHoratius, N. y Raman, A. (2016) en su investigación "The impact of supplier inventory service level on retailer demand" desarrollada en Harvard Business School, Cambridge, se basaron en investigaciones previas, que utilizan modelos analíticos y de laboratorio para estudiar el impacto del nivel de servicio de un proveedor en la demanda de 
los minoristas, hicieron usos del modelo DID (Difference in differences), técnica cuasiexperimental utilizada en econometría que mide el efecto de un tratamiento en un determinado período en el tiempo, probando esta relación en campo realizaron un experimento de campo en el proveedor Hugo Boss para determinar cómo el nivel de servicio de inventario del proveedor afecta la demanda de sus clientes minoristas. Concluyen con sus hallazgos que un aumento en el nivel de servicio puede aumentar sustancialmente los pedidos cuando el nivel de servicio ya es alto, por lo tanto, los gerentes que ignoran la posibilidad de conducir pedidos con aumentos en el nivel de servicio renunciarán a mejoras de la cadena de suministro potencialmente rentables, así como a oportunidades para capturar cuota de mercado. Asimismo, recomiendan en los futuros investigadores podrían basarse en sus descubrimientos empíricos de que los pedidos frecuentes exhiben comportamientos que difieren de los pedidos no frecuentes. Incorporando este efecto diferencial observado en los modelos de inventario estándar podrían conducir a resultados alternativos, por ejemplo, ciclos de pedido más cortos en modelos EOQ (Cantidad Económica de Pedido) con proveedores poco confiables.

Radasanu, A. C. (2016) en su investigación "Inventory management, service level and safety stock. Journal of Public Administration, Finance and Law" desarrollada en Alexandru Ioan Cuza University, laşi, indica que muchas empresas eligen mantener alto nivel de existencias de seguridad como amortiguador contra la variabilidad de la demanda resultando en ineficiencias y altos requisitos de capital de trabajo, por lo que enfatiza en la importancia de la determinación del valor y la combinación de inventario que respalda un servicio elevado para los clientes y maximiza el rendimiento financiero. En su investigación proponen un modelo estadístico con un método más preciso y efectivo para calcular el stock de seguridad; de esta forma, establecer y alcanzar el nivel de servicio objetivo mientras se mantiene un mínimo de niveles de inventario para mantener bajos los costos operativos. Recomienda probar el modelo antes de la implementación final para garantizar que funciona correctamente y para determinar el impacto en niveles de inventario. 


\section{Estado del arte}

A continuación, se presentan diversas teorías relacionadas a la gestión de inventario. Se presentan diversos autores, con diversos enfoques respecto al tema y en distintos momentos a través del tiempo. Sin embargo, todos concuerdan en que la gestión de inventarios es un tema fundamental para las organizaciones, pues de ello depende mucho su competitividad en el mundo actual de los negocios. Asimismo, que es imprescindible encontrar un equilibrio óptimo de los niveles de inventario, obteniendo así un mínimo de costos y un máximo de beneficios.

En primer lugar, Ballou (2004) indica lo siguiente.

El manejo del inventario implica equilibrar la disponibilidad del producto (o servicio al cliente), por una parte, con los costos de suministrar un nivel determinados de disponibilidad del producto, por la otra. Como puede haber más de una manera de cumplir con el objetivo del servicio al cliente, buscaremos minimizar los costos relacionados por el inventario para nivel del servicio al cliente. (pp. 335)

De la misma forma Parada (2009) señala.

La gestión de inventarios se deriva de la importancia que tienen las existencias para la empresa y, por lo tanto, la necesidad de administrarlas y controlarlas. Su objetivo consiste fundamentalmente en mantener un nivel de inventario que permita, a un mínimo de costo, un máximo de servicio a los clientes. (pp. 172)

La formulación de un enfoque multicriterio en la aplicación del método $A B C$ y el matriz costo de adquisición/índice de rotación constituyen dos métodos para clasificar los productos y adoptar estrategias diferenciadas que mejoran la gestión de inventario en las organizaciones. Su elección dependerá de la situación concreta de aplicación. (pp. 184)

Durán (2012) acota lo siguiente.

Al tratarse de grandes inversiones que la empresa de debe realizar, es que las decisiones sobre su nivel óptimo son de gran relevancia. Por ello, se debe manejar una excelente política de administración de inventario que permita a la empresa una mayor liquidez, disminución de los costos y, en consecuencia, aumento de la rentabilidad. Por lo tanto, se debe estudiar la gestión del inventario desde el momento que se proyecta 
la compra, pasando por el proceso de fabricación y hasta la distribución del producto final. (p. 75)

Así también, Molina (2015) señala.

Los motivos básicos para crear Inventarios son: protegerse contra incertidumbres, permitir la producción y compra bajo condiciones económicamente ventajosas, cubrir cambios anticipados en la demanda y la oferta, y mantener el tránsito entre los puntos de producción y almacenamiento. (pp.33)

Una conceptualización en sentido práctico de la Gestión de inventarios como la eficiencia en el manejo de los bienes de cambio, considerando aspectos tales como el análisis de la rotación de productos, el estudio de las cadenas de abastecimiento, los costos asociados al mantenimiento de stock, el resultado negativo de no disponer de bienes para satisfacer al Cliente en tiempo y forma, la necesidad de mantener cubierta la demanda, etc. Es en sí mismo un tema demasiado complejo, porque involucra coordinar los requerimientos de distintos Sectores, en un manejo eficiente para minimizar costos. (pp. 34)

Adicionalmente, Salas-Navarro (2016) indica lo siguiente respecto a la gestión de inventarios.

La mayoría de las empresas en el mundo para lograr ser competitivas en la prestación del servicio al cliente están obligadas a realizar una gestión eficiente de sus inventarios. Básicamente, el objetivo general de la gestión de inventarios es garantizar la disponibilidad oportuna de los elementos que se necesitan (materia prima, materiales en proceso, productos terminados, insumos, repuestos, etc.), en las condiciones deseadas y en el lugar correcto. Teniendo en cuenta que la gestión de inventarios es una actividad transversal a la cadena de suministro, deben implementarse estrategias para lograr un manejo efectivo del mismo con el fin evitar consecuencias no deseadas, como el efecto látigo, un bajo nivel de servicio y el incremento de costos de administración de inventarios. (p. 327)

A continuación, se presentan conclusiones a las que han llegado investigaciones anteriores relacionadas al nivel de servicio.

Jones, Wilkes Murphy, and Smith (2016) exponen lo siguiente. 
Es imposible administrar un servicio correctamente, y mucho menos, sin comprender qué comportamientos realmente importan para ese servicio y cómo medir y evaluar esos comportamientos. Con este fin, nos gustaría definir y ofrecer un nivel de servicio determinado a los usuarios, ya sea que utilicen una interfaz de programación de aplicaciones (del inglés API: Application Programming Interface) o un producto público. Usan la intuición, la experiencia y la comprensión de lo que los usuarios desean definir los indicadores de nivel de servicio (SLI), los objetivos (SLO) y los acuerdos (SLA). Estas mediciones describen las propiedades básicas de las métricas que importan, qué valores quieren que tengan esas métricas y cómo reaccionarán si no pueden proporcionar el servicio esperado.

Por otro lado, Vermorel (2012) señala lo siguiente.

El nivel de servicio representa la probabilidad de no alcanzar a una situación de falta de existencias. Este porcentaje es necesario para calcular las existencias de seguridad. El nivel de servicio también representa una compensación entre el costo de inventario y el costo de la falta de existencias, dado por perdidas en ventas y otros costos intangibles como mala atención al cliente y perdidas de oportunidades.

\section{Marco teórico}

\section{Definición de inventarios.}

En primer lugar, para entender el tema de la presente tesis es necesario partir de lo más básico, como es entender la definición de inventarios Durán (2012) nos brinda un acercamiento a esta de forma clara y concisa.

El inventario es el conjunto de mercancías o artículos que tiene la empresa para comerciar, permitiendo la compra y venta o la fabricación para su posterior venta, en un periodo económico determinado. Su propósito fundamental es proveer a la empresa de materiales necesarios para su continuo y regular desenvolvimiento. Tiene un papel primordial en el funcionamiento del proceso de producción que permite afrontar la demanda. (p. 56)

\section{Definición gestión de inventarios.}

Zapata (2014), señala lo siguiente respecto a la definición de gestión de inventarios. 
En el entorno empresarial se conoce la gestión de inventario como al proceso encargado de asegurar la cantidad de productos adecuados en la organización, de tal manera que se pueda asegurar la operación continua de los procesos de comercialización de productos a los clientes; es decir, asegura que las operaciones de manufactura y distribución no se detengan, cumpliendo con las promesas de entrega de productos a los clientes. (p. 11)

La responsabilidad de servir de colchón para responder a las variaciones de la oferta y la demanda lleva a las empresas a mantener inventarios, de forma que se satisfaga al cliente. Sin embargo, mantener estos inventarios en las organizaciones presenta costos nada depreciables, ya que para esta actividad se requieren hacer inversiones de capital en las mercancías, se requiere espacio para guardarlos, se necesita personal para su administración y cuidado y se requieren recursos tecnológicos y energéticos para su mantenimiento, entre otros. (p. 13)

Mientras que Vidal (2017) afirma lo siguiente.

Debe tenerse en cuenta algunas sugerencias para reducir inventarios, sin compromiso de los niveles de servicio, tales como:

- Concentrarse en ítems clase A y los primeros ítems clase B (los de "mediana importancia") a través de su revisión individual y continua, tamaños de orden más pequeños, pero más frecuentes, y la interacción con los proveedores y clientes para influir en su demanda y reducir sus tiempos de reposición.

- Evitar tamaños excesivos de órdenes, incluso para ítems clase C (los "menos importantes"). En este sentido, un ítem C puede estar desapareciendo del mercado y un tamaño de lote grande podría ocasionar su rápida obsolescencia, generar excesos y problemas de almacenamiento y de saturación de los sistemas de información.

- Depurar periódicamente el inventario, eliminando excesos e ítems obsoletos y de muy bajo movimiento que carezcan de importancia para la organización y para los consumidores.

- Controlar las compras de grandes volúmenes sin los beneficios financieros adecuados. 
- Controlar y rastrear continuamente: el nivel de servicio ofrecido a los consumidores a través de indicadores adecuados; el valor, rotación, cobertura y grado de obsolescencia del inventario; el porcentaje de precisión del inventario físico y la influencia del nivel de inventarios sobre indicadores financieros como el retorno sobre la inversión.

- Racionalizar la compra inicial de ítems nuevos y hacerles un seguimiento exhaustivo. (p. 18-19)

\section{Objetivo de la gestión de inventarios.}

La Universidad Nueva Granada (2011) señala los objetivos de la gestión de inventarios.

El objetivo primordial de la gestión de inventarios es actuar como reguladores entre los ritmos de abastecimiento y las cadencias o consumos de sus salidas. Lo que puede evidenciarse a través de:

- Reducción del riesgo sobre la certeza en la demanda de los productos.

- Disminuir el costo de los suministros de la producción.

- Anticipar las variaciones previstas de la oferta y la demanda.

- Facilitar el transporte y distribución del producto. Igualmente, se debe establecer un equilibrio entre la calidad de servicio y los costos derivados de tener inventario.

Para conseguir este propósito, se deben tener en cuenta dos aspectos complementarios:

- El sistema de reposición.

- El stock de seguridad. (p. 06)

\section{Control de inventarios.}

Zapata (2014), acota lo siguiente respecto al control de inventarios. "El control de inventarios busca mantener disponible los productos que se requieren para la empresa y para los clientes, por lo que implica la coordinación de las áreas de compras, manufactura distribución". (p. 11)

En contraste Wild (2002) señala lo presentado a continuación. 
El propósito del control de inventarios es asegurar el funcionamiento de las actividades de la empresa mediante la optimización conjunta de los siguientes tres objetivos:

- Servicio al cliente

- Costos de inventario

- Costos operativos

La optimización conjunta de estos objetivos significa que no se debe buscar una mejora en alguno de los objetivos descuidando los otros, ya que los tres son igual de importantes.

\section{Rotación de inventarios.}

Zapata (2014) indica lo siguiente respecto a la rotación de inventarios, así mismo se presenta la formula necesaria para encontrar este importante indicador.

Este indicador busca medir las veces en que la mercancía entra y sale de la organización (rotación del inventario) y es expresado como las veces en que el capital invertido en el inventario se recupera a través de las ventas. La ecuación para el cálculo de la rotación del inventario es:

$$
\text { Rotación de inventarios }=\frac{\text { Ventas acumuladas }}{\text { Inventario promedio }}=\text { número de veces }
$$

\section{Inventario de seguridad.}

Así también, Zapata (2014) indica el concepto y la forma de encontrar el inventario de seguridad.

El cálculo del inventario de seguridad se realiza determinando la cantidad de material requerido en stock, de tal manera que la variación en estas variables no sobrepase este valor. La ecuación del stock de seguridad es entonces:

Inventario de seguridad $=\mathrm{SS}=Z_{\propto} \times \sqrt{\sigma_{d}^{2} \times L+d^{2} \times \sigma_{L}^{2}}$

Donde,

Z es la variable aleatoria normal estándar para el nivel de servicio $\alpha$

$\sigma_{d}$ es la desviación estándar diaria de la demanda. 
L es el tiempo de aprovisionamiento

d es la demanda diaria

$\sigma_{L}$ es desviación estándar del tiempo de aprovisionamiento, expresado en días. (p. 46)

Cuanto más alto se establezca el nivel de servicio, más alto será el inventario de seguridad. Si el nivel de servicio definido es cero, entonces no existirá inventario de seguridad y se presentarán agotados del $50 \%$ en los tiempos de entrega. (p. 47)

\section{Gestión de stocks.}

Zapata (2014) menciona lo siguiente respecto a la gestión de stocks.

La gestión de stocks (productos almacenados en la organización) es crítico en el funcionamiento de las organizaciones, pues de estos dependen el correcto funcionamiento de la organización, tanto para actividades de producción como de abastecimiento de los clientes. (p. 27)

La función lógica del manejo de inventarios es entregarle a la compañía un equilibrio entre el suministro y la demanda, de forma que siempre se pueda atender al cliente con el nivel de servicio que él requiera. (p. 29)

\section{Exactitud de registro de inventarios.}

A continuación, se presenta el concepto sobre la exactitud de registro de inventarios según Zapata (2014).

Este indicador busca entregar información sobre la cantidad real de la mercancía en stock en las organizaciones. Su cálculo se realiza determinando la diferencia del inventario en libros y el inventario real (contado manualmente) y dividiendo el valor de esta diferencia por el valor del inventario total, de manera que se pueda determinar el porcentaje faltante de inventario. La fórmula para el cálculo de este indicador es:

$$
\text { Exactitud del inventario }=\frac{\text { Valor diferencia }}{\text { Valor total del inventario }} \times 100 \%
$$

El indicador de exactitud del inventario puede ser calculado con el valor del inventario o las unidades inventariadas, e inclusive puede realizarse por referencia. 


\section{Punto de reorden.}

Zapata (2014) señala lo siguiente respecto al punto de reorden.

El nivel de inventario al momento de que llegue una nueva orden no debe ser cero, sino el correspondiente a el inventario de seguridad. De esta manera la ecuación para el punto de reorden $(\mathrm{ROP})$ en la política de revisión continua es:

$$
R O P(\text { punto de reorden })=d \times L \times S S
$$

Donde,

L es el tiempo de aprovisionamiento

d es la demanda diaria

SS es el inventario de seguridad (p. 47)

\section{Lote económico de pedido.}

Asimismo, Zapata (2014) señala lo siguiente respecto al lote económico de pedido o EOQ, según sus siglas en inglés.

Todo pedido al proveedor implica realizar un proceso de solicitud de abastecimiento y almacenamiento de mercancía, por lo tanto, se generan dos costos asociados a la orden: el costo de pedir y el costo de mantener el inventario, cuya suma es en esencia, el costo total del manejo del inventario. $(p, 35)$

El tamaño económico de lote (EOQ) es sencillamente la cantidad a pedir al proveedor, de un determinado artículo, donde la suma de los costos de ordenar y de mantener inventario es óptimo. Para trabajar el modelo (CEP) es necesario que en el comportamiento del artículo se identifiquen algunas situaciones especiales y aun cuando una o varias de las suposiciones no sean del todo evidenciadas, el modelo es válido como una primera aproximación al cálculo del tamaño de lote a ordenar. (p. 36)

La fórmula para el hallar el EOQ, es la siguiente:

$$
E O Q=\sqrt{\frac{2 D . S}{h . C}}
$$


Donde:

S es el costo de ordenar

D la demanda anual

C costo unitario del producto

h es el costo de mantener un ítem en inventario anualmente

Sin embargo, la interpretación errada de este concepto es pensar que el modelo arroja solo un punto que define la cantidad a pedir al proveedor. Este concepto es mucho más amplio y realmente el valor del modelo radica en identificar un intervalo sobre la zona de optimización. Es decir, no se trata de identificar el tamaño del lote que permite minimizar el total de los costos anuales de hacer pedidos y de manejo de inventario. Sino de identificar el intervalo más adecuado en tamaños del lote que permite minimizar el total de los costos anuales de hacer pedidos y del manejo de inventario. (p. 41)

\section{Clasificación ABC.}

Vidal (2017) menciona lo presentado a continuación con respecto al sistema de clasificación $A B C$ de los inventarios.

Una forma de realizar la clasificación $A B C$ es con base en el producto Di vi, el cual mide el valor anual de las ventas (o la demanda) de cada ítem i, donde:

Di = Demanda anual del ítem i [unidades/año].

$\mathrm{vi}=$ Valor unitario del ítem i [\$/unidad $]$.

Para definir cuáles ítems deben formar parte de cada clase ( $A, B \circ C)$, se escoge un porcentaje de mayor a menor, de acuerdo con el orden secuencial dado por la mayor utilización de los ítems. [...].

Ítems clase $A=10 \%$ del total de ítems, con alrededor del $65 \%$ del total de ventas.

Ítems clase B = 20\% del total de ítems, con alrededor del $25 \%$ del total de ventas.

Ítems clase $\mathrm{C}=70 \%$ del total de ítems, con alrededor del $10 \%$ del total de ventas. (p. 25) 


\section{Nivel de servicio}

Zapata (2014) define el nivel de servicio desde dos enfoques distintos, pero altamente relacionados dentro de la organización.

El nivel de servicio en la gestión de inventarios puede ser definido de dos maneras [...]. Las relaciones de cliente se refieren al hecho de que el cliente se mantenga satisfecho con el servicio prestado, lo cual no solo hace referencia al cumplimiento de las exigencias de compras, sino también a la forma como se relaciona con la empresa y lo que el cliente piensa sobre su proveedor [...]. El aspecto de nivel de servicio relacionado con la disponibilidad de materiales se refiere al hecho de satisfacer el cliente mediante el cumplimiento de su demanda; es decir, asegurando que siempre que éste solicite material, se le abastezca sin ningún inconveniente. [...]. Sin embargo, existe una relación directa entre tener determinadas cantidades de inventario con los costos que esto acarrea, ya que como es obvio, a medida que se aumenta la cantidad de materiales en inventario, los costos logísticos de la empresa se incrementan (p. 16)

Así también, Schalit y Vermonel (2014) indican lo siguiente respecto al nivel de servicio.

Puede definirse como la probabilidad de poder satisfacer la demanda de los clientes sin enfrentarse a pedidos pendientes o a una venta perdida. Si bien un nivel de servicio del $100 \%$-es decir, servir a todos los clientes todo el tiempo- podría parecer deseable, generalmente no es una opción factible. (pp. 01)

En este sentido, el nivel de servicio representa un factor extremadamente importante, sobre todo en el mundo empresarial tan competitivo, pues fideliza al cliente. No obstante, el nivel de servicio debe estar acompañado de una correcta gestión de inventarios, ya que es necesario encontrar el punto óptimo para no generar sobre costo de inventario, ni mucho menos excesivas ventas pérdidas por roturas de stock.

\section{Entregas perfectas}

Según Mora (2007), conceptualiza las entregas perfectas de la siguiente forma.

Cantidad de órdenes que se atienden perfectamente por una compañía y se considera que una orden es atendida de forma perfecta cuando cumple con las siguientes características: 
- La entrega es completa, todos los artículos se entregan a las cantidades solicitadas.

- La fecha de entrega es la estipulada por el cliente.

- La documentación que acompaña la entrega es completa y exacta.

- Los artículos se encuentran en perfectas condiciones físicas.

- La presentación y equipo de transporte utilizado es el adecuado en la entrega al cliente. (p. 86)

Cálculo

$$
\text { Valor }=\frac{\text { pedidos entregados perfectos }}{\text { total de pedidos entregados }}
$$

\section{Entregas a tiempo}

Asimismo, Mora (2007) indica. "Este indicador mide el nivel de cumplimiento de la compañía para realizar la entrega de los pedidos en la fecha o periodo de tiempo pactado con el cliente". (p. 88)

Cálculo

$$
\text { Valor }=\frac{\text { Pedidos entregados a tiempo }}{\text { Total de pedidos entregados }}
$$

\section{Devoluciones}

Rodríguez y Gómez (1991), en su libro mencionan lo siguiente respecto a las devoluciones.

Con este tipo de indicador evaluamos la proporción de productos 0 servicios fuera de especificaciones, es decir aquellos que no cumplen o no están conformes con las características o atributos acordados con el cliente. [...]

El primero de ellos evalúa la proporción del producto fuera de especificaciones que llegan al cliente o usuario y son devueltos, regresados para su reposición o en algunos casos descontados o rebajados de la facturación del servicio Su forma es

$$
\text { Porcentaje devoluciones }=\frac{\begin{array}{c}
\text { Cantidad de productos devueltos } \\
\text { o descontados o rebajados }
\end{array}}{\text { Cantidad de productos despachados }}
$$


Obviamente, el objetivo es que este indicador sea cero "0". Fundamentalmente este indicador nos está evaluando la calidad y capacidad del sistema de control de calidad del producto en la unidad, para detectar los defectuosos y evitar que lleguen al cliente. (p. 30-31)

\section{Tiempo de ciclo de pedido}

Mora (2007) brinda os siguientes conceptos respecto al tiempo de ciclo de pedido.

El ciclo total de pedido del cliente es el indicador por excelencia de velocidad del sistema de logística. Este indicador refleja el tiempo total de repuesta al cliente desde la organización en conjunto. (p. 127)

Controlar el tiempo que consistentemente transcurre desde que los clientes realizan un pedido, hasta que tienen físicamente los productos en sus instalaciones, disponibles para su uso. (p. 137)

Formula

$$
\sum^{\text {Pedidos }} \text { Fecha de recepción - fecha de solicitud }
$$




\section{OBJETIVOS DE LA INVESTIGACIÓN}

\section{Objetivo general}

Determinar el impacto de una mejora de la gestión de inventarios en el nivel de servicio de una empresa luminaria.

\section{Objetivos específicos}

Determinar el impacto de una mejora de la gestión de inventarios en las entregas perfectas de una empresa luminaria.

Determinar el impacto de una mejora de la gestión de inventarios en las entregas a tiempo de una empresa luminaria.

Determinar el impacto de una mejora de la gestión de inventarios en el porcentaje de devoluciones de una empresa luminaria.

Determinar el impacto de una mejora de la gestión de inventarios en el tiempo de ciclo de pedido de una empresa luminaria.

\section{JUSTIFICACIÓN DE LA INVESTIGACIÓN}

\section{Teórica}

La investigación es relevante en la ingeniería industrial pues permite ampliar el conocimiento sobre la gestión de inventarios y su impacto en el nivel de servicio. Lo cual ya ha sido investigado, sin embargo, no desde el enfoque específico del sector mayorista para luminarias.

Asimismo, el estudio sirve como aporte para futuros estudios respecto al tema, siendo partida para resolver problemáticas de distintas empresas y en la determinación de cuál de las dimensiones impacta con mayor fuerza en la variable.

\section{Práctica}

En el mundo actual y el mercado globalizado la competitividad de una empresa representa un elemento clave para su existencia. La presente investigación permite lograr cambios en la empresa reflejados en la rotación de inventarios, roturas y sobre stocks, niveles adecuados de 
inventarios; en consecuencia, mayor rentabilidad. Principalmente, se eleva el nivel de servicio, además de mejorar la imagen organizacional.

\section{Social}

El estudio beneficia ampliamente a los trabajadores de la empresa y, por ende, a sus familias, estas como núcleo de la sociedad. En primer lugar, para el área de almacén, pues el trabajo es más eficiente, en un área laboral más segura y siendo capacitados contribuyendo a su crecimiento personal. También se beneficia el área de ventas, ya que los colaboradores tienen un mejor desempeño al poder contar con el stock suficiente para cumplir con sus clientes en las fechas pactadas.

\section{Económica}

La presente investigación aporta eficiencia a la gestión de inventarios lo cual implica un ahorro en esfuerzos y capital para que los procedimientos se realicen adecuadamente. Asimismo, ello conlleva un mayor porcentaje en el nivel de servicio cumpliendo adecuadamente con los pedidos de los clientes, lo cual aumente su satisfacción y fidelidad a la empresa, ello transformándose en resultados monetarios positivos. 


\section{HIPOTESIS}

\section{Hipótesis general}

Una mejora de la gestión de inventarios impacta positivamente en el nivel de servicio de una empresa luminaria.

\section{Hipótesis especificas}

Una mejora de la gestión de inventarios impacta positivamente en las entregas perfectas de una empresa luminaria.

Una mejora de la gestión de inventarios impacta positivamente en las entregas a tiempo de una empresa luminaria.

Una mejora de la gestión de inventarios impacta positivamente en el porcentaje de devoluciones de una empresa luminaria.

Una mejora de la gestión de inventarios impacta positivamente en el tiempo de ciclo de pedido de una empresa luminaria. 


\section{MATRIZ DE CONSISTENCIA}

Tabla 4

Matriz de consistencia.

\begin{tabular}{|c|c|c|c|c|c|}
\hline \multicolumn{5}{|c|}{ IMPACTO DE UNA MEJORA DE LA GESTIÓN DE INVENTARIOS EN EL NIVEL DE SERVICIO DE UNA EMPRESA LUMINARIA } & \multirow[b]{2}{*}{ METODOLOGÍA } \\
\hline PROBLEMA GENERAL & OBJETIVO GENERAL & HIPOTESIS GENERAL & VARIABLES & DIMENSIONES & \\
\hline $\begin{array}{c}\text { ¿Cuál es el impacto de una } \\
\text { mejora de la gestión de } \\
\text { inventarios en el nivel de } \\
\text { servicio de una empresa } \\
\text { luminaria? }\end{array}$ & $\begin{array}{l}\text { Determinar el impacto de una } \\
\text { mejora de la gestión de } \\
\text { inventarios en el nivel de } \\
\text { servicio de una empresa } \\
\text { luminaria. }\end{array}$ & $\begin{array}{c}\text { Una mejora de la gestión de } \\
\text { inventarios impacta positivamente } \\
\text { en el nivel de servicio de una } \\
\text { empresa luminaria. }\end{array}$ & & $\begin{array}{c}0=\text { Sin mejora } \\
1=\text { Con mejora }\end{array}$ & \\
\hline PROBLEMAS ESPECÍFICOS & OBJETIVOS ESPECÍFICOS & HIPÓTESIS ESPECIFICAS & & DIMENSIONES & \\
\hline $\begin{array}{c}\text { ¿Cuál es el impacto de una } \\
\text { mejora de la gestión de } \\
\text { inventarios en las entregas } \\
\text { perfectas de una empresa } \\
\text { luminaria? }\end{array}$ & $\begin{array}{c}\text { Determinar el impacto de una } \\
\text { mejora de la gestión de } \\
\text { inventarios en las entregas } \\
\text { perfectas de una empresa } \\
\text { luminaria. }\end{array}$ & $\begin{array}{c}\text { Una mejora de la gestión de } \\
\text { inventarios impacta positivamente } \\
\text { en las entregas perfectas de una } \\
\text { empresa luminaria. }\end{array}$ & $\begin{array}{l}\text { V. independiente } \\
\text { MEJORA EN LA } \\
\text { GESTIÓN DE } \\
\text { INVENTARIOS }\end{array}$ & $\begin{array}{l}\text { Entregas } \\
\text { perfectas }\end{array}$ & $\begin{array}{l}\text { Investigación cuasi- } \\
\text { experimental de tipo }\end{array}$ \\
\hline $\begin{array}{c}\text { ¿Cuál es el impacto de una } \\
\text { mejora de la gestión de } \\
\text { inventarios en las entregas a } \\
\text { tiempo de una empresa } \\
\text { luminaria? }\end{array}$ & $\begin{array}{c}\text { Determinar el impacto de una } \\
\text { mejora de la gestión de } \\
\text { inventarios en las entregas } \\
\text { perfectas de una empresa } \\
\text { luminaria. }\end{array}$ & $\begin{array}{c}\text { Una mejora de la gestión de } \\
\text { inventarios impacta positivamente } \\
\text { en las entregas a tiempo de una } \\
\text { empresa luminaria. }\end{array}$ & & $\begin{array}{c}\text { Entregas a } \\
\text { tiempo }\end{array}$ & $\begin{array}{c}\text { post-experimental } \\
\text { de enfoque } \\
\text { cuantitativo y } \\
\text { paradigma } \\
\text { positivista. }\end{array}$ \\
\hline $\begin{array}{c}\text { ¿Cuál es el impacto de una } \\
\text { mejora de la gestión de } \\
\text { inventarios en el porcentaje de } \\
\text { devoluciones de una empresa } \\
\text { luminaria? }\end{array}$ & $\begin{array}{c}\text { Determinar el impacto de una } \\
\text { mejora de la gestión de } \\
\text { inventarios en el porcentaje de } \\
\text { devoluciones de una empresa } \\
\text { luminaria. }\end{array}$ & $\begin{array}{c}\text { Una mejora de la gestión de } \\
\text { inventarios impacta positivamente } \\
\text { en el porcentaje de devoluciones de } \\
\text { una empresa luminaria. }\end{array}$ & $\begin{array}{l}\text { V. dependiente } \\
\text { NIVEL DE } \\
\text { SERVICIO }\end{array}$ & $\begin{array}{l}\text { Porcentaje de } \\
\text { devoluciones }\end{array}$ & \\
\hline $\begin{array}{c}\text { ¿Cuál es el impacto de una } \\
\text { mejora de la gestión de } \\
\text { inventarios en el tiempo de ciclo } \\
\text { de pedido de una empresa } \\
\text { luminaria? }\end{array}$ & $\begin{array}{l}\text { Determinar el impacto de una } \\
\text { mejora de la gestión de } \\
\text { inventarios en el tiempo de } \\
\text { ciclo de pedido de una } \\
\text { empresa luminaria. }\end{array}$ & $\begin{array}{c}\text { Una mejora de la gestión de } \\
\text { inventarios impacta positivamente } \\
\text { en el tiempo de ciclo de pedido de } \\
\text { una empresa luminaria. }\end{array}$ & & $\begin{array}{l}\text { Tiempo de ciclo } \\
\text { de pedido }\end{array}$ & \\
\hline
\end{tabular}




\section{MARCO METODOLÓGICO}

\section{Metodología}

La presente tesis es una investigación cuantitativa, bivariada, experimental y de paradigma positivista. Por consiguiente, utilizando los conocimientos de la ingeniería en el campo de gestión de inventarios, se plantea realizar una mejora sustancial en la actual gestión de la empresa luminaria. De esta manera, ese cambio se ve reflejado en el nivel de servicio, realizándose una medición tanto previa y posterior a la implementación de la mejora.

\section{Paradigma}

El paradigma que se utiliza en este estudio es positivista. De modo que, se establecen objetivos, hipótesis, técnicas estadísticas para analizar la información y ver la correlación entre las variables de estudio.

\section{Enfoque}

El enfoque es cuantitativo, en este sentido, los problemas serán analizados con mayor precisión. Hernández (2014) define el mencionado enfoque del siguiente modo. "Usa la recolección de datos para probar hipótesis, con base en la medición numérica y el análisis estadístico, para establecer patrones de comportamiento y probar teorías" (p.04). De ahí la razón de que la investigación se realiza de forma metódica y secuencial. Recopilando datos numéricos respecto a la mejora en la gestión de inventarios y el nivel de servicio, con el objeto de probar la hipótesis mediante métodos estadístico, y así, sacar las conclusiones correspondientes.

\section{Método}

El método de la investigación es del tipo cuasi-experimental que según Hernández (2014) es conceptualizados de la siguiente forma.

Los diseños cuasiexperimentales también manipulan deliberadamente, al menos, una variable independiente para observar su efecto y relación con una o más variables dependientes [...]. En los diseños cuasi experimentales los sujetos no se asignan al azar a los grupos ni se emparejan, sino que dichos grupos ya están formados antes del experimento: son grupos intactos [...] (p. 148). 
De esta forma, se realiza una pre-prueba de un mes escogido aleatoriamente respecto al nivel de servicio, variable dependiente, lo cual representa el diagnóstico previo de la empresa luminaria. Luego de realizar un diagnóstico de la situación actual para así plantear y aplicar una mejora en la gestión de inventarios, variable dependiente, se aplica una post-prueba a la variable dependiente de también un mes escogido aleatoriamente. Es así que se determina las diferencias de las mediciones y el impacto de una variable sobre otra.

Se emplea como instrumento de recolección de datos el análisis documental y base de datos del sistema ERP. De esta forma, se analiza los datos mediante pruebas de normalidad y constatación de hipótesis, para visualizar estadísticamente la forma en que fue afectado el nivel de servicio por los cambios en la gestión de inventarios.

\section{VARIABLE}

\section{Independiente}

\section{Mejora de la gestión de inventarios}

Zapata (2014) define la gestión de inventarios de la siguiente manera.

En el entorno empresarial se conoce la gestión de inventario como al proceso encargado de asegurar la cantidad de productos adecuados en la organización, de tal manera que se pueda asegurar la operación continua de los procesos de comercialización de productos a los clientes; es decir, asegura que las operaciones de manufactura y distribución no se detengan, cumpliendo con las promesas de entrega de productos a los clientes. (p. 11)

La gestión de inventarios en la empresa objeto de estudio es el proceso que se encarga de garantizar que cuenten con las existencias necesarias para cumplir con el proceso de distribución de las luces LED en todas sus variedades a los clientes. La mejora de la gestión de inventarios se realiza mediante los siguientes indicadores: rotación de inventarios, clasificación $A B C$, registro de exactitud de inventarios, punto de reorden y lote óptimo de pedido, incidiendo en cada aspecto para mejorarlos en eficiencia y productividad. 


\section{Dependiente}

\section{Nivel de servicio.}

El nivel de servicio según Zapata (2014) es conceptualizado del siguiente modo.

El aspecto de nivel de servicio relacionado con la disponibilidad de materiales se refiere al hecho de satisfacer el cliente mediante el cumplimiento de su demanda; es decir, asegurando que siempre que éste solicite material, se le abastezca sin ningún inconveniente. (p. 16)

Para la empresa el nivel de servicio es una ratio muy relevante, pues demuestra su capacidad para responder a las necesidades de sus clientes en el momento y de la forma en que lo soliciten. El nivel de servicio en la empresa luminaria se mide mediante cuatro (04) indicadores que son las entregas perfectas, entregas a tiempo, porcentaje de devoluciones y tiempo de ciclo de pedido.

Dimensiones de nivel de servicio

Entregas perfectas: representan los pedidos entregados con cada uno de los artículos solicitados, en la fecha establecida, con la documentación correcta y bajo todas las especificaciones que cada cliente puede solicitar.

Entregas a tiempo: porcentaje en que se cumple la entrega de las ordenes en el periodo establecido con el comprador.

Devoluciones: porcentaje en que las ordenes son retornadas a la empresa porque el cliente se encuentra descontento con la misma. Dentro de la empresa el ratio es muy bajo, pues brindan garantía de un año, en caso el producto este dañado o defectuoso, se procede a aplicar la garantía. Si no cuentan con stock en almacén para el cambio, recién emiten la nota de crédito correspondiente al producto y se considera como devolución.

Tiempo de ciclo de pedido: tiempo en que una orden es emitida hasta que es recepcionada por el cliente. 
Tabla 5

Matriz de operacionalización de la variable nivel de servicio

\begin{tabular}{|c|c|c|c|c|c|}
\hline VARIABLES & INDICADORES & TÉCNICA & $\begin{array}{l}\text { INSTRU } \\
\text { MENTO }\end{array}$ & $\begin{array}{l}\text { UNIDAD } \\
\text { DE } \\
\text { MEDIDA }\end{array}$ & FÓRMULA \\
\hline $\begin{array}{l}\text { ENTREGAS } \\
\text { PERFECTAS }\end{array}$ & $\begin{array}{l}\text { \% de pedidos } \\
\text { entregados } \\
\text { según lo } \\
\text { solicitado }\end{array}$ & $\begin{array}{c}\text { Análisis } \\
\text { documental }\end{array}$ & $\begin{array}{l}\text { Paquete } \\
\text { de } \\
\text { reportes }\end{array}$ & Porcentaje & $\begin{array}{l}\text { Pedidos entregados } \\
\frac{\text { perfectos }}{\text { Total de pedidos }} \times 100 \\
\text { entregados }\end{array}$ \\
\hline $\begin{array}{c}\text { ENTREGAS A } \\
\text { TIEMPO }\end{array}$ & $\begin{array}{l}\text { \% de pedidos } \\
\text { entregados en la } \\
\text { fecha acordada }\end{array}$ & $\begin{array}{l}\text { Análisis } \\
\text { documental }\end{array}$ & $\begin{array}{l}\text { Paquete } \\
\text { de } \\
\text { reportes }\end{array}$ & Porcentaje & $\begin{array}{l}\text { Pedidos entregados } \\
\frac{\text { a tiempo }}{\text { Total de pedidos }} \times 100 \\
\text { entregados }\end{array}$ \\
\hline DEVOLUCIONES & $\begin{array}{l}\% \text { de pedidos } \\
\text { regresados a la } \\
\text { empresa }\end{array}$ & $\begin{array}{l}\text { Análisis } \\
\text { documental }\end{array}$ & $\begin{array}{l}\text { Paquete } \\
\text { de } \\
\text { reportes }\end{array}$ & Porcentaje & $\begin{array}{l}\text { Devolución de } \\
\text { pedidos en soles } \\
\text { Total de pedidos } \\
\text { entregados en soles }\end{array}$ \\
\hline $\begin{array}{l}\text { TIEMPO DE } \\
\text { CICLO DE } \\
\text { PEDIDO }\end{array}$ & $\begin{array}{l}\text { Promedio de } \\
\text { días entre la } \\
\text { solicitud de la } \\
\text { orden de } \\
\text { compra y la } \\
\text { entrega física al } \\
\text { cliente. }\end{array}$ & $\begin{array}{l}\text { Análisis } \\
\text { documental }\end{array}$ & $\begin{array}{l}\text { Paquete } \\
\text { de } \\
\text { reportes }\end{array}$ & Días & $\sum_{- \text {fecha de solicitud }}^{\text {Pedidos }}$ Fecha de entrega fisica \\
\hline
\end{tabular}

Elaboración propia

\section{POBLACIÓN Y MUESTRA}

\section{Población}

Hernández (2014) define población de la siguiente forma. "Conjunto de todos los casos que concuerdan con determinadas especificaciones" (p. 174).

En este sentido, la población de la presente investigación son todas las transacciones de salida del almacén de la empresa luminaria durante los meses de abril, marzo y junio del 2019, en lo que respecta al pre-test. Mientras que, la población para el post-test son las transacciones de salida de almacén de los meses de agosto, setiembre y octubre del 2019. Loa población en mención es seleccionada debido a cláusulas de confidencialidad con la empresa en estudio. 


\section{Muestra}

La definición de muestra es dada por Hernández (2014) de la siguiente manera. "[...] la muestra es un subgrupo de la población de interés sobre el cual se recolectarán datos, y que tiene que definirse y delimitarse de antemano con precisión, además de que debe ser representativo de la población" (p. 173)

En el presente estudio la muestra será del tipo probabilístico del tipo aleatorio simple, ya que se realizan mediciones de pre-test y post-test de un mes cada una. Lo cual es conceptualizado de la siguiente forma. Hernández (2014), señala.

[...] todos los elementos de la población tienen la misma posibilidad de ser escogidos para la muestra y se obtiene definiendo las características de la población y el tamaño de la muestra, y por medio de una selección aleatoria o mecánica de las unidades de muestreo/análisis. (p. 175)

Asimismo, para determinar el tamaño de la muestra y que la aleatoriedad sea la correcta se ha utilizado el software estadístico SPSS, el cual es ampliamente recomendado por la universidad y su plana docente.

\section{UNIDAD DE ANÁLISIS}

Hernández (2014) las define de la siguiente forma. "Se les denomina también casos o elementos" (p. 172). Para el caso de la presente investigación son las transacciones de salida del almacén de la empresa luminaria antes y después de aplicar la mejora en la gestión de inventarios.

\section{INSTRUMENTOS Y TÉCNICAS}

Hernández (2014) indica lo siguiente respecto a los instrumentos de recolección de datos. "Recurso que utiliza el investigador para registrar información o datos sobre las variables que tiene en mente." (p. 199)

En este sentido, un instrumento es la forma de traducir las variables en datos cuantificables que puedan comprobar la hipótesis de investigación. "Como citó Hernández (2014) Un instrumento de medición adecuado es aquel que registra datos observables que representan 
verdaderamente los conceptos o las variables que el investigador tiene en mente." (Grinnell, Williams y Unrau, 2009) (p. 199)

En la presente investigación se utiliza el análisis documental como instrumento de medición. Ello debido a que cada dimensión de la variable dependiente se encuentra registrada en el sistema ERP de la empresa. De esta manera, se obtiene las bases de datos ya consolidadas.

De esta manera, se procede a extraer los datos del sistema ERP y convertirlos en base de datos específicas para la medición de cada dimensión, que procederá a ser analizada por el software SPSS versión 22.0.

\section{PROCEDIMIENTO Y MÉTODO DE ANÁLISIS}

\section{Procedimiento}

En primer lugar, mencionar que se comunicó a todo el personal el inicio de la mejora en la gestión de inventarios, de esta manera, se obtuvo soporte no solo del área de almacén, sino también de las demás áreas de la organización. Se tuvo apoyo directo de gerencia, lo cual facilitó el trabajo en gran medida.

Mediante el proceso de identificación del problema el cual resulta la deficiente gestión de inventarios, se ha encontrado problemas colaterales y oportunidades de mejora para el desempeño de almacén. En este sentido, al encontrar que el almacén se encuentra congestionado, con falta de señalización y distribución, entre otras situaciones, se decide instalar un programa con la filosofía y metodología 5 S. 


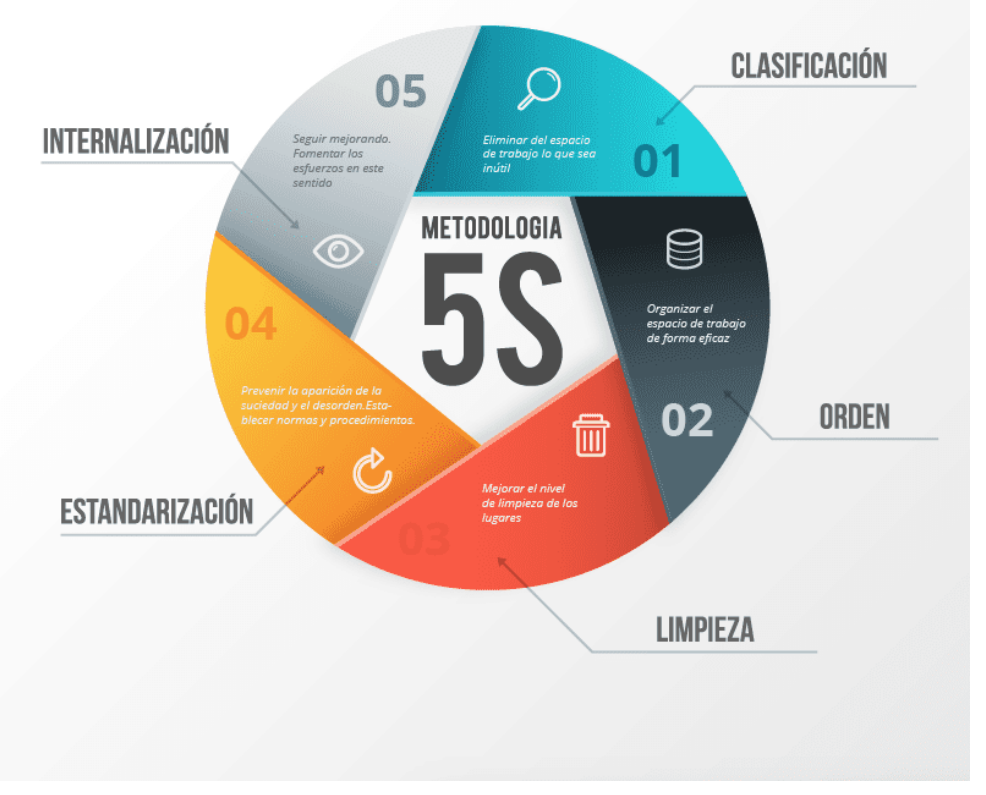

Figura 6. Metodología 5S

Tabla 6

Aplicación de las 5S: Iniciativa mejora de desempeño de almacén

\begin{tabular}{|c|c|c|}
\hline $5 S$ & Oportunidad de mejora & Recomendación \\
\hline Clasificar & $\begin{array}{l}\text { Clasificar y agrupar productos según características, } \\
\text { marcas y familias. }\end{array}$ & $\begin{array}{l}\text { Realizar clasificación ABC } \\
\text { Estandarizar criterios de } \\
\text { clasificación. }\end{array}$ \\
\hline Ordenar & $\begin{array}{c}\text { Ordenar los productos en almacén teniendo en cuenta } \\
\text { la rotación de cada uno para garantizar un mayor nivel } \\
\text { de servicio. }\end{array}$ & Actualizar layout \\
\hline Limpiar & $\begin{array}{c}\text { Mantener pasadizos libres y señalizados para no } \\
\text { obstaculizar el tránsito. }\end{array}$ & Señalización y normas \\
\hline Estandarizar & $\begin{array}{l}\text { Supervisar y desarrollar controles periódicos para el } \\
\text { correcto desempeño de almacén }\end{array}$ & Generar procedimientos y fichas. \\
\hline Internalizar & $\begin{array}{l}\text { Crear compromiso, capacitaciones y sensibilización a } \\
\qquad \text { los trabajadores }\end{array}$ & $\begin{array}{l}\text { Motivar buena actitud y prácticas } \\
\text { a los trabajadores }\end{array}$ \\
\hline
\end{tabular}

Elaboración propia

Por otro lado, se determinó el nivel de rotación que tenía cada SKU en almacén. De esta forma, se pudo determinar el estado de cada uno y tomar las medidas necesarias. A 
continuación, se presenta el cuadro resumen de la rotación de inventarios por familia y subfamilias. El desagregado por SKU se puede encontrar en el Anexo 2.

Tabla 7

Rotación de inventario por sub-familias

\begin{tabular}{|c|c|c|c|c|}
\hline Artículos & $\begin{array}{l}\text { Unidades } \\
\text { vendidas }\end{array}$ & $\begin{array}{l}\text { Inventario } \\
\text { promedio }\end{array}$ & Rotación & Días \\
\hline ESENCIALES & 238672 & 69216 & 3.45 & 106 \\
\hline Bulbos alta potencia & 1485 & 1178 & 1.26 & 289 \\
\hline Bulbos filament & 1507 & 396 & 3.80 & 96 \\
\hline Bulbos led & 45877 & 12933 & 3.55 & 103 \\
\hline Dicroicos led & 84411 & 17393 & 4.85 & 75 \\
\hline Eclipse & 33885 & 3059 & 11.08 & 33 \\
\hline Globos led & 6914 & 6602 & 1.05 & 349 \\
\hline Octogonales clásicos & 0 & 243 & 0.00 & 0 \\
\hline Octogonales press \& fit & 20973 & 11908 & 1.76 & 207 \\
\hline Panel clásico & 36582 & 12134 & 3.01 & 121 \\
\hline Panel clásico nickel & 2131 & 3062 & 0.70 & 524 \\
\hline Panel hielo & 2627 & 4918 & 0.53 & 683 \\
\hline Prisma & 2280 & 2548 & 0.89 & 408 \\
\hline $\begin{array}{l}\text { INTERRUPTORES Y } \\
\text { TOMACORRIENTES }\end{array}$ & 59487 & 128463 & 0.46 & 788 \\
\hline Int \& tom blanco & 47450 & 52211 & 0.91 & 402 \\
\hline Int \& tom gris & 234 & 5555 & 0.04 & 8665 \\
\hline Int \& tom marfil & 7595 & 40163 & 0.19 & 1930 \\
\hline Int \& tom placas de colores & 4208 & 30534 & 0.14 & 2649 \\
\hline LLAVES TERMICAS & 7934 & 10298 & 0.77 & 474 \\
\hline Llaves térmicas & 7934 & 10298 & 0.77 & 474 \\
\hline PREMIUM & 74527 & 24454 & 3.05 & 120 \\
\hline Octogonales Premium & 54983 & 19779 & 2.78 & 131 \\
\hline Panel Slim 4 & 16430 & 4674 & 3.52 & 104 \\
\hline Panel Slim 4 pro & 3114 & 3122 & 1.00 & 366 \\
\hline PROFESIONAL & 28584 & 22527 & 1.27 & 288 \\
\hline Down light & 3259 & 4908 & 0.66 & 550 \\
\hline Fixtures led & 3502 & 1383 & 2.53 & 144 \\
\hline Luces de emergencia & 979 & 1455 & 0.67 & 542 \\
\hline Par led & 2638 & 1484 & 1.78 & 205 \\
\hline Propanel & 1183 & 508 & 2.33 & 157 \\
\hline Reflectores led slim ip65 & 9914 & 6959 & 1.42 & 256 \\
\hline Tubos led t5 & 7109 & 7887 & 0.90 & 405 \\
\hline ULTIMO STOCK & 2230 & 30161 & 0.07 & 4937 \\
\hline Último stock & 2230 & 30161 & 0.07 & 4937 \\
\hline
\end{tabular}

Elaboración propia 


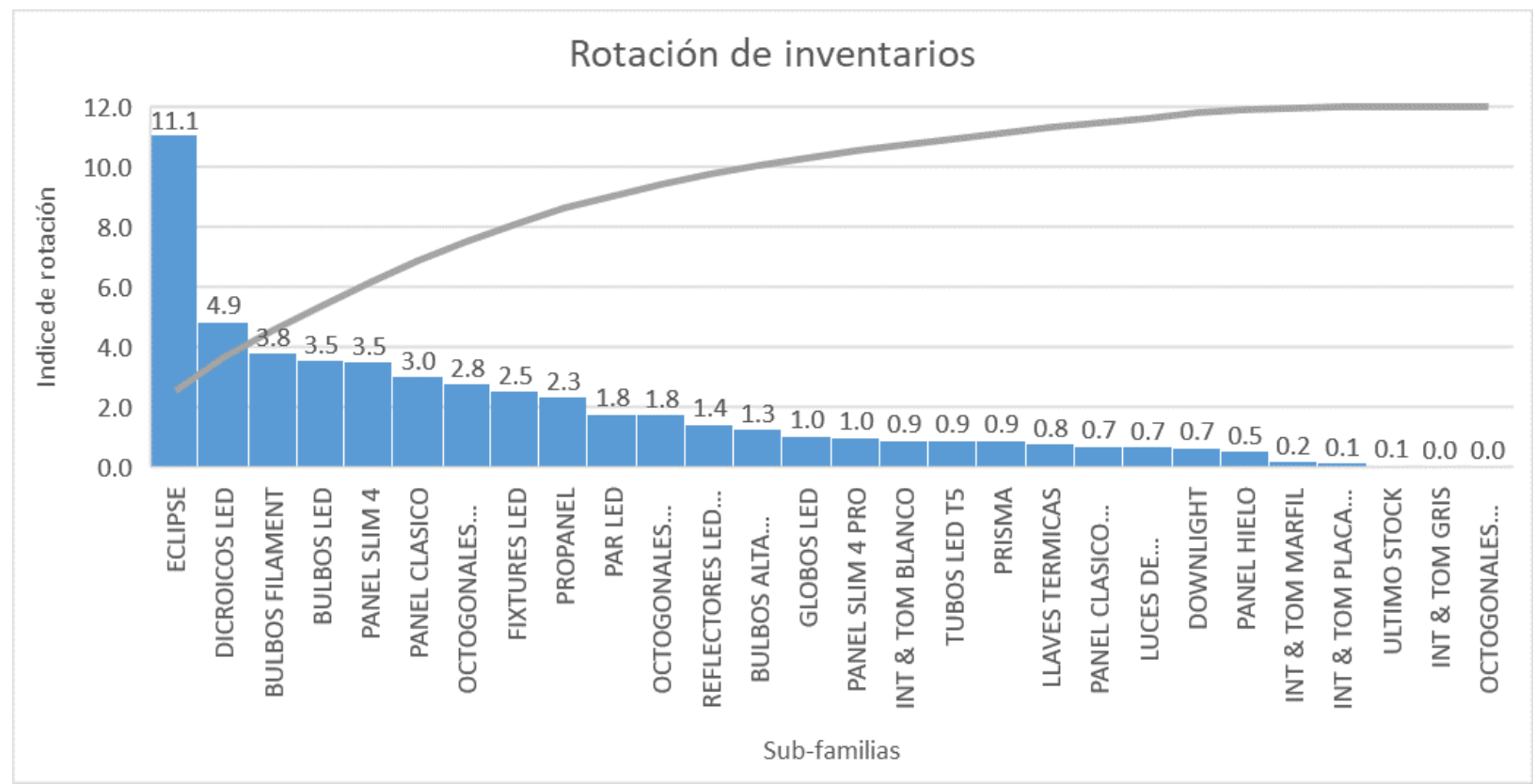

Figura 7. Rotación de inventarios por sub-familia

En este sentido, se puede detectar dos problemas extremos en el almacén de la empresa. En primer lugar, para el caso de Eclipse con una rotación de 11.1, se encuentra la problemática de ordenes deficientes, por lo que la rotación es de un amplio espectro, lo que significa mayores costos logísticos para la empresa y posibles bajas en el nivel de servicio por la falta de stock. Es necesario que se realice un pronóstico exhaustivo.

Por otro lado, se encuentran las sub-familias de Globos LED, Panel Slim Pro 4, Int y Tom blanco, Tubos LED T5, Prisma, Llaves térmicas, Panel clásico, Luces de emergencia, Dowligth, Panel hielo, Int y Tom marfli, Int y Tom placa de colores, Último stock, Int y Tom gris y Octogonales clásicos, lo cuales tienen una rotación menor a 1. De esta manera, es necesario determinar individualmente las acciones a tomar con cada artículo.

En principio, los artículos de la sub-familias Globos LED, Panel Slim Pro 4, Tubos LED T5, Prisma, Llaves térmicas, Panel clásico, Luces de emergencia, Dowligth y Panel hielo deben mantenerse en inventarios, pues de estos depende la venta de otros artículos; sin embargo, es necesario evaluar la cantidad que se está ordenando periódicamente. Mientras que, los artículos de la familia Interruptores y Toma Corrientes se pudo detectar que hubo un error en la solicitud al proveedor, obteniéndose un sobre stock de estos artículos. Asimismo, en la familia de Ultimo stock se puede encontrar artículos descontinuados. Es por ello, que, para 
ambos casos, se proyecta realizar remates en los artículos de mencionadas familias, ya que al mantenerse en almacén se están generando gastos operativos y de almacenamiento.

Asimismo, se determina la medición de indicador Rotación de inventario cada 6 meses, de esta forma se puede controlar de un mejor modo los artículos en almacén, pues en el rubro de la empresa la obsolescencia de productos es alta.

El siguiente paso de la mejora fue determinar la clasificación ABC para los artículos, lo cual permite crear políticas adecuadas para cada caso. 
Tabla 8

Clasificación ABC

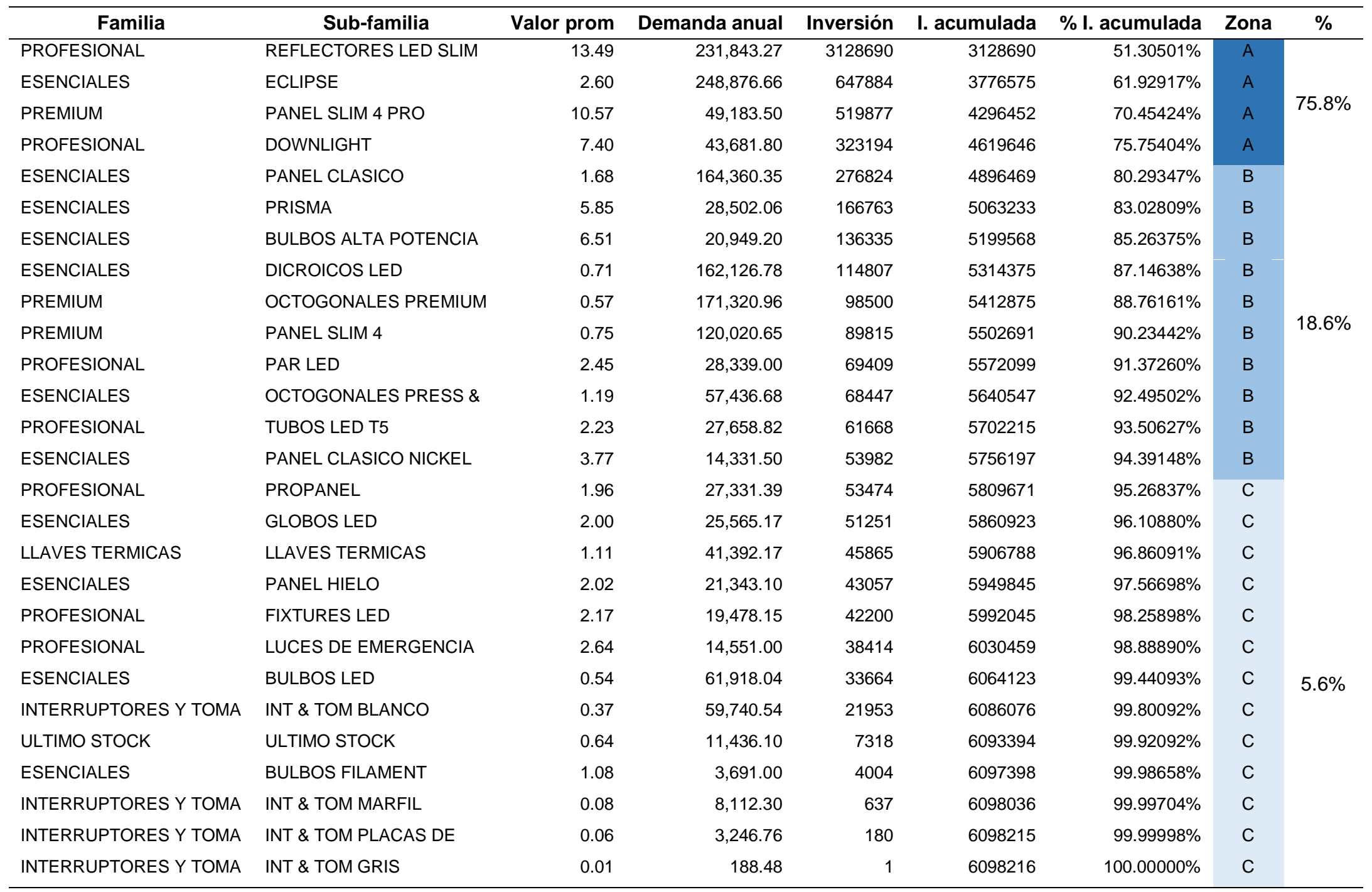

Elaboración propia 
Tabla 9

Cuadro resumen de clasificación $A B C$

\begin{tabular}{cccccc}
\hline Zona & $\mathbf{N}^{\circ}$ elementos & \% artículos & \% acumu. & \% inversión & $\%$ inv. A. \\
\hline A & 4 & $15 \%$ & $15 \%$ & $75.8 \%$ & $75.8 \%$ \\
B & 10 & $37 \%$ & $52 \%$ & $18.6 \%$ & $94.4 \%$ \\
C & 13 & $48 \%$ & $100 \%$ & $5.6 \%$ & $100.0 \%$ \\
Total & 27 & $100 \%$ & & $100.0 \%$ & \\
\hline
\end{tabular}

Elaboración propia

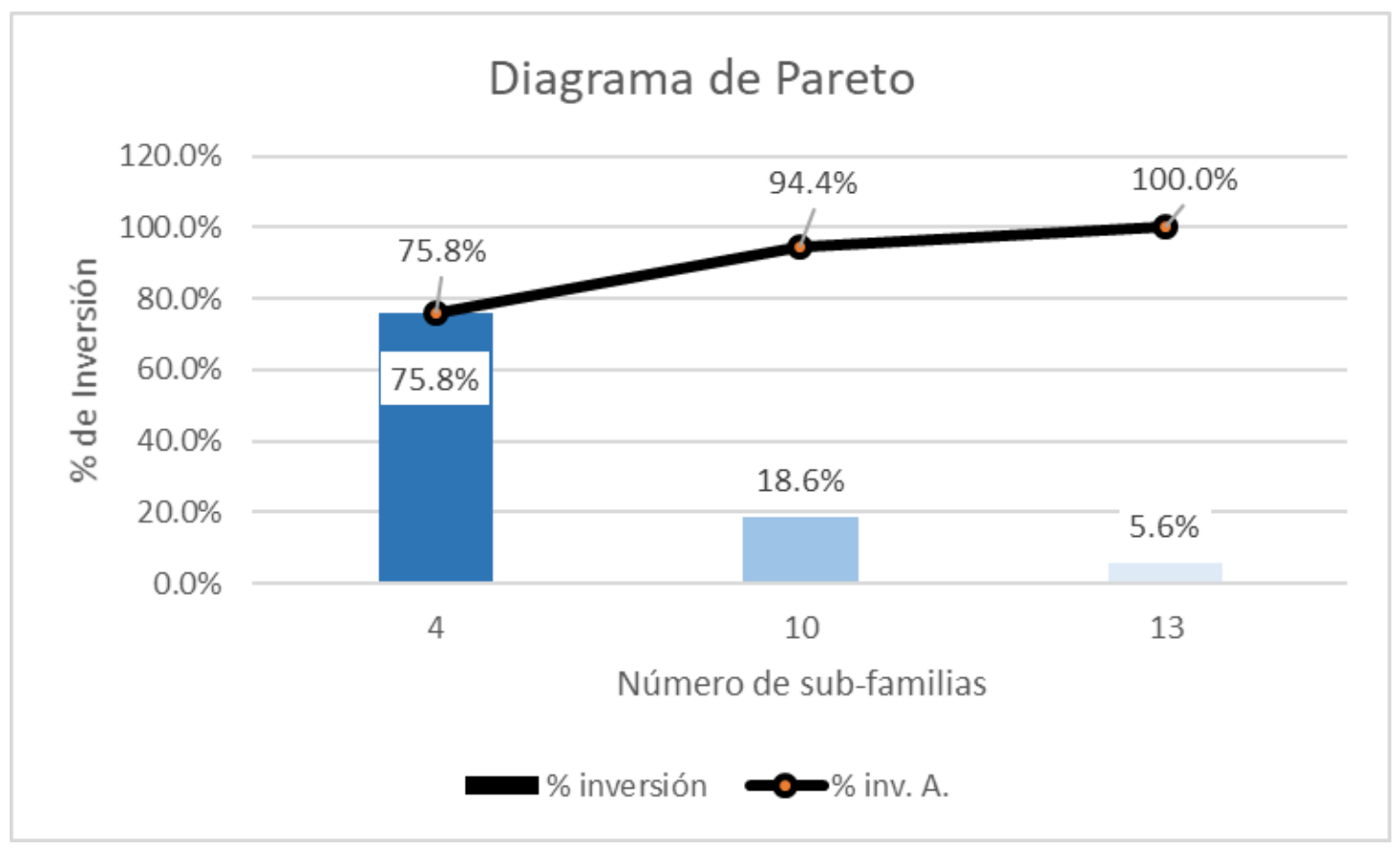

Figura 8. Clasificación ABC

En este sentido, el $15 \%$ de los artículos son el $75.8 \%$ de la inversión en inventario, por lo que son de la clasificación A. Mientras que, el $37 \%$ de los artículos representan el $18.6 \%$ de la inversión, siendo los de clase B. Finalmente, el $48 \%$ de los artículos son el $5.6 \%$ de la inversión, formando la clasificación C. De esta forma, se pueden crear políticas específicas para cada clasificación que permita una mejor de los inventarios.

Para los artículos de clasificación A se establecen las políticas de:

- Mayor rigurosidad en elección de proveedores y creación de alianzas con los mismos. 
- Elaboración de check-list detallada para el control en el inventario fijo.

- Indicador de exactitud de inventario quincenal.

- El pronóstico debe ser minuciosamente formulado y evaluado por gerencia.

En lo que respecta a la clasificación $B$.

- Las órdenes de pedido, en la medida de lo posible, deben desarrollarse en grupo. Buscando precios competitivos.

- Elaboración de check-list para el control de inventario.

- Indicador de exactitud de inventarios mensual.

- El pronóstico debe ser minuciosamente formulado.

En lo correspondientes a los artículos de clase C.

- Para artículos baratos y con nivel de demanda moderado se deben realizar pedidos en lotes grandes y combinados para minimizar la frecuencia.

- Mientras que, para artículos caros y con poca demanda, se debe mantener un inventario mínimo.

- Indicador de exactitud de inventarios trimestral.

- Deben seguir la misma línea de formulación de pronóstico.

Por otro lado, siguiendo la línea de la política de revisión continua que posee la empresa y que su sistema ERP soporta, se procedió a realizar una revisión exhaustiva y recalculo de los indicadores de punto de re-orden, inventario de seguridad y lote económico de pedido, los cuales se encuentran contenidos en el Anexo 3.

Como parte de la mejora en la gestión de inventario, se procedió a evaluar el proceso de recepción de mercadería. Encontrándose diversos re-procesos, es por ello que modifico, evaluó y documento la formulación del nuevo procedimiento. Tal como se muestra en el siguiente DOP. 


\section{EVOLITE PERU}

DIAGRAMA DE FLUJO DE PROCESO (OPERATIVO)

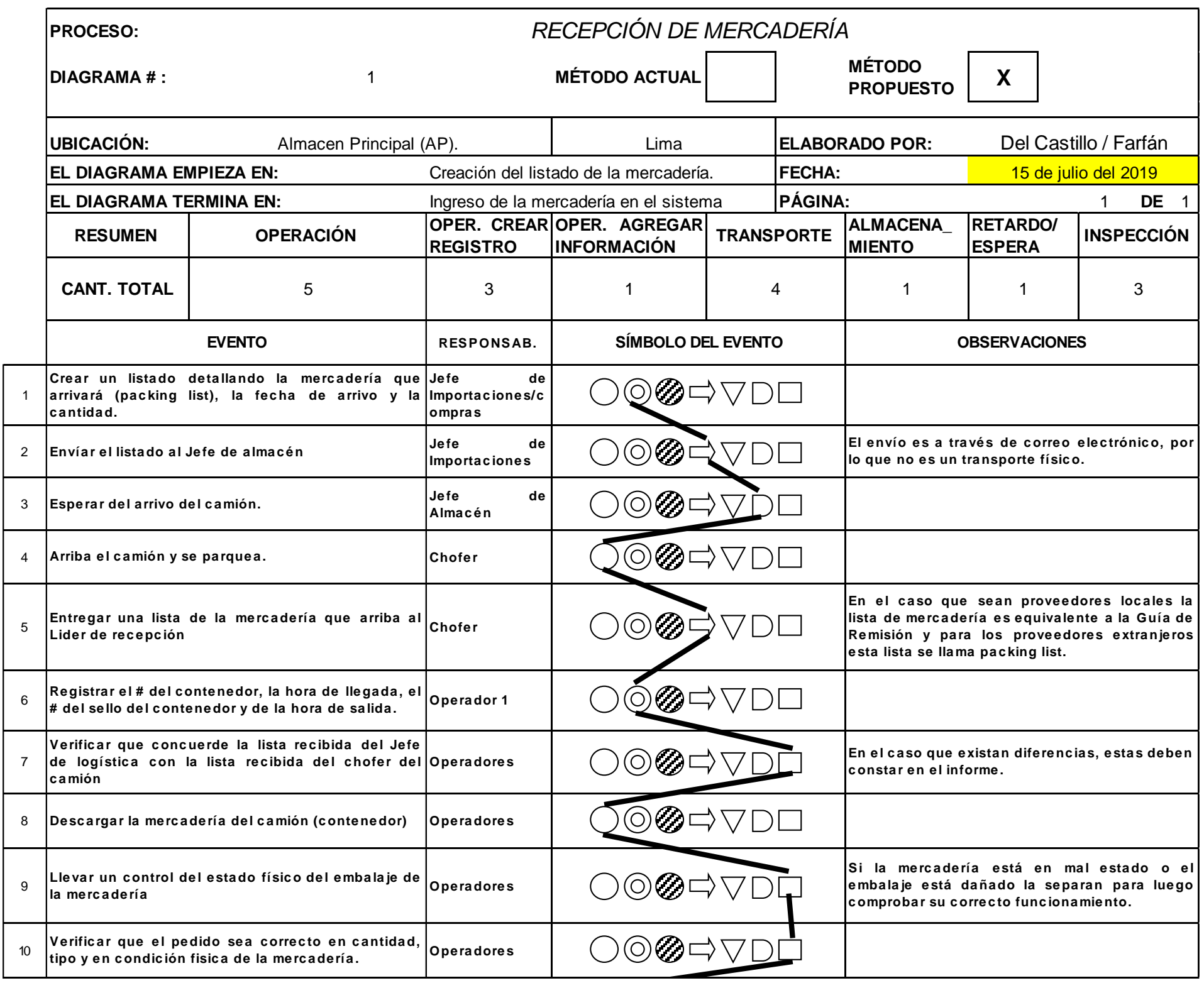




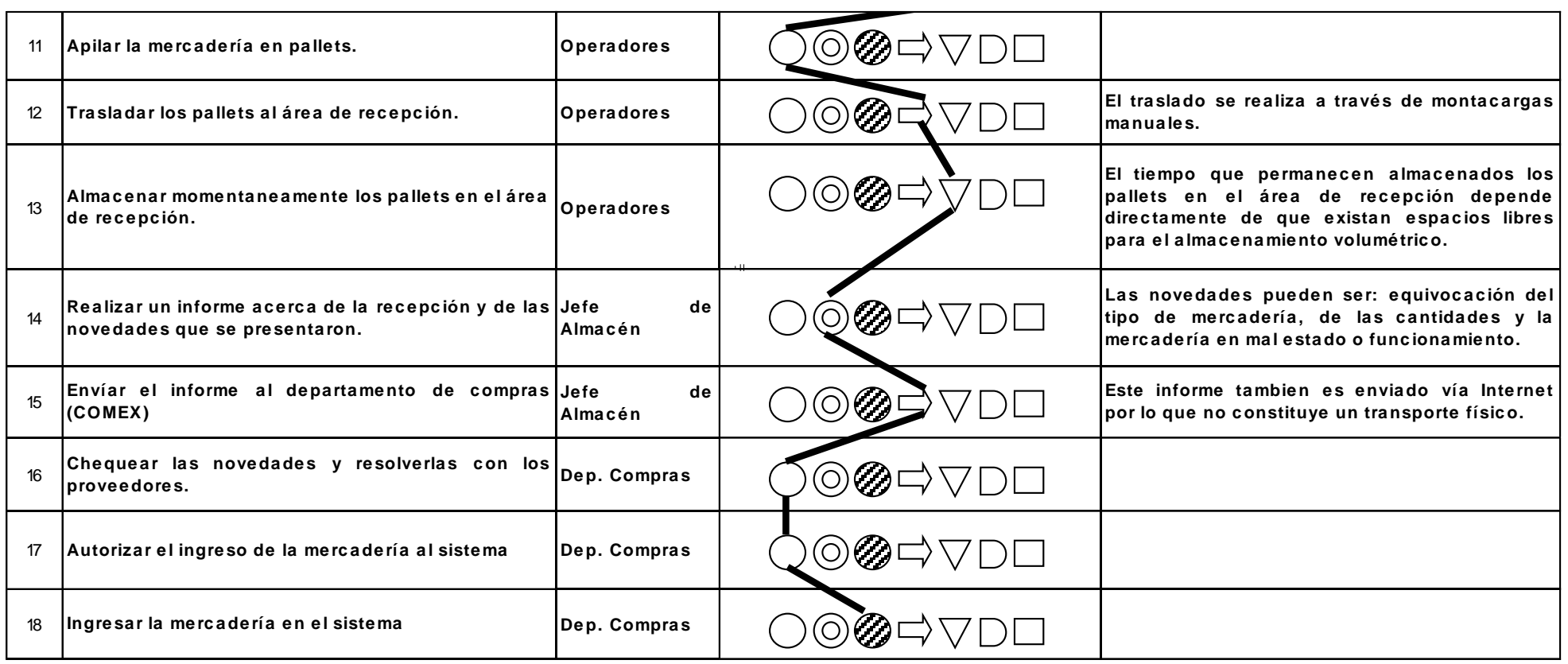

SIMBOLOGÍA:

\begin{tabular}{|l|l|c|l|}
\hline & Operación & Almacenamiento. \\
\hline & $\begin{array}{l}\text { Operación de trá mite para crear un resgistro, un } \\
\text { conjunto de informes o conjunto de documentos }\end{array}$ & Demora, Retraso o Espera. \\
\hline & $\begin{array}{l}\text { Operación de trá mite para agregar información a } \\
\text { un registro. }\end{array}$ & Inspección \\
\hline & Transporte o Traslado. & & \\
\hline
\end{tabular}

Figura 9. DOP recepción de mercadería.

Elaboración propia. 
Por otra parte, en el diagnóstico situacional de la empresa se detectó que muchos de los errores en el área de almacén se debía al capital humano. Es por ello, que en conjunto con el área de Recursos Humanos se programó diversas capacitaciones y entrenamientos necesarios para mejorar el desempeño de los colaboradores. De esta manera, la empresa no solo, de alguna manera, asegura que los procedimientos se cumplan de manera adecuada, sino que apoya al desarrollo profesional de su personal, lo cual genera una motivación intrínseca en este. Asimismo, cabe señalar que estas capacitaciones se dieron de forma progresiva en el mes de julio del 2019.

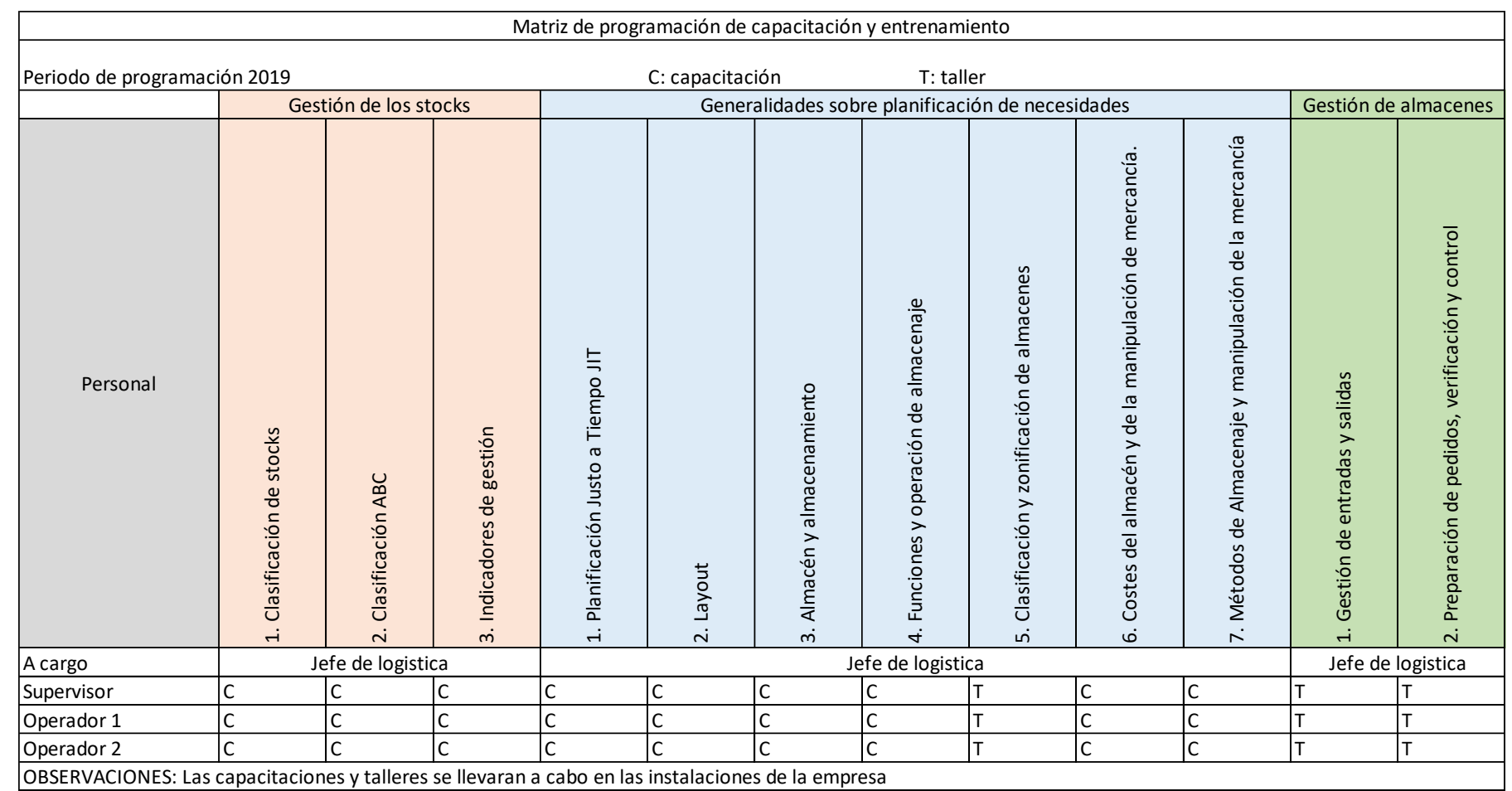

Figura 10. Matriz de programación de capacitación. 
Finalmente, dadas las mejoras en la gestión de inventarios en la empresa se procedió a realizar las respectivas mediciones de las dimensiones de la variable dependiente Nivel de Servicio, las cuales son entregas perfectas, entregas a tiempo, porcentaje de devoluciones y tiempo de ciclo de pedido. Se procedió a realizar la medición de tres meses - abril, mayo, junio - como pre-test del histórico de la empresa. La implementación de la mejora en la gestión de inventarios se dio en el mes de julio. Por lo tanto, se esperó tres meses más - agosto, septiembre y octubre - para poder realizar las mediciones respectivas del post-test. Como se muestra en el siguiente gráfico.

- Toma de datos antes de la mejora de la gestión de inventario

-Meses: Abril, mayo y junio del 2019

\section{Grupo de pre-} prueba

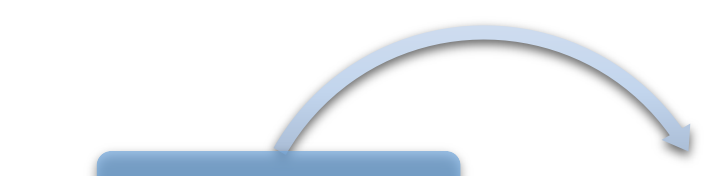

- Toma de datos después de la mejora de gestión de inventario

-Mejora de la gestión de -Meses: Agosto, septiembre y octubre del 2019

Grupo de

post-prueba

Figura 11. Diseño de la investigación

\section{Método de análisis}

Dado que los datos recolectados son de variable cuantitativa, es necesaria la aplicación de los siguientes análisis.

\section{Análisis descriptivo}

En lo que corresponde a medidas de variabilidad se mide rango, desviación, varianza, media, límites y asimetría. 
Respecto a la prueba de normalidad, para mostrar el tipo de distribución de datos, se emplea Kolmogorov-Smirnov y Shapiro-Wilk.

\section{Análisis inferencial}

Para la comprobación de hipótesis de investigación se empleó la prueba U de MannWhitney.

Dado que la empresa facilitó información de tres meses - abril, mayo y junio - para el pretest y tres meses - agosto, septiembre y octubre - para post-test, se procede a determinar de forma aleatoria dentro de la población antes mencionada, el mes de muestra que se empleará para el análisis de datos.

En este sentido, se seleccionó el mes de mayo, para el pre-test, como se aprecia en la tabla 10.

Tabla 10

Muestreo Aleatorio Pre-test

\begin{tabular}{cc}
\hline Mes & $\begin{array}{c}\text { Selección } \\
\text { aleatoria de } \\
\text { muestra }\end{array}$ \\
\hline abr-19 & 0 \\
may-19 & 1 \\
jun-19 & 0 \\
jul-19 & \\
\cline { 2 - 2 } Dato de la empresa - Elaboración propia
\end{tabular}

Para la muestra post-test, también se seleccionó el mes de octubre, en forma aleatorio, como se precia en la tabla 11.

Tabla 11

Muestreo Aleatorio Pre-test

Mes $\begin{gathered}\text { Selección } \\ \text { aleatoria de } \\ \text { muestra }\end{gathered}$

jul-19

ago-19 0

sep-19 $\quad 0$

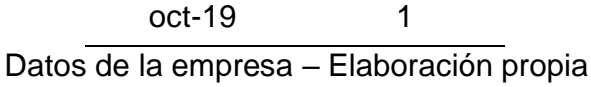




\section{RESULTADOS}

La lectura de los resultados de la investigación, se han obtenido en dos tiempos diferentes, antes de la mejora de la gestión de inventarios y después de la implementación de la mejora de la gestión de inventarios. Llamaremos pre-test a la lectura de los resultados anterior a la implementación de la mejora de la gestión de inventarios y post-test a la lectura de los resultados, después de la implementación de la mejora de gestión, para cada dimensión de la gestión de inventarios.

\section{Entregas Perfectas}

La data pre-test se muestra en la Tabla 12. El pre-test corresponde al mes de mayo del 2019. Para determinar el Ratio, de las entregas perfectas, se ha calculado las órdenes de compras del día y los faltantes por cada una de ella.

Tabla 12

Entregas Perfectas Pre-test - Mayo 2019

\begin{tabular}{ccccc}
\hline Día & Órdenes de Compra & Faltante & Entrega Perfecta & Ratio Entrega Perfecta \\
\hline 1-May & 2 & 0 & 2 & 1.00 \\
2-May & 1 & 0 & 1 & 1.00 \\
6-May & 4 & 1 & 3 & 0.75 \\
7-May & 6 & 1 & 5 & 0.83 \\
8-May & 6 & 0 & 6 & 1.00 \\
9-May & 5 & 3 & 2 & 0.40 \\
10-May & 2 & 0 & 2 & 1.00 \\
13-May & 10 & 2 & 8 & 0.80 \\
14-May & 7 & 0 & 7 & 1.00 \\
15-May & 7 & 0 & 7 & 1.00 \\
16-May & 5 & 0 & 5 & 1.00 \\
17-May & 5 & 4 & 1 & 0.20 \\
20-May & 10 & 4 & 6 & 0.60 \\
21-May & 6 & 0 & 6 & 1.00 \\
22-May & 4 & 1 & 3 & 0.75 \\
23-May & 4 & 0 & 4 & 1.00 \\
24-May & 9 & 4 & 5 & 0.56 \\
27-May & 10 & 1 & 9 & 0.90 \\
28-May & 5 & 2 & 3 & 0.60 \\
29-May & 13 & 3 & 10 & 0.77 \\
30-May & 8 & 1 & 7 & 0.88 \\
31-May & 14 & 2 & 12 & 0.86 \\
Total & 143 & 29 & & \\
\hline & Datos de la empresa - Elaboración propia &
\end{tabular}


En la Tabla 13, se muestra la estadística descriptiva de las Entregas Perfectas Pre-Test, en la cual se puede observar que la media del ratio es 0.81 con una desviación estándar de 0.22 .

Tabla 13

Estadística Descriptiva de Entregas Perfectas Pre-test - Mayo 2019.

\begin{tabular}{|c|c|c|c|c|}
\hline \multicolumn{5}{|c|}{ Descriptivos } \\
\hline & & & Estadístico & Desv. Error \\
\hline \multirow[t]{13}{*}{ Ratio Entrega Perfecta } & Media & & .813636 & .0474526 \\
\hline & $95 \%$ de intervalo de & Límite inferior & .714953 & \\
\hline & confianza para la media & Límite superior & .912319 & \\
\hline & Media recortada al $5 \%$ & & .836364 & \\
\hline & Mediana & & .870000 & \\
\hline & Varianza & & ,050 & \\
\hline & Desv. Desviación & & .2225725 & \\
\hline & Mínimo & & .2000 & \\
\hline & Máximo & & 1.0000 & \\
\hline & Rango & & .8000 & \\
\hline & Rango intercuartil & & .2875 & \\
\hline & Asimetría & & $-1,325$ & ,491 \\
\hline & Curtosis & & 1,436 & ,953 \\
\hline
\end{tabular}

Datos de la empresa - Elaboración SPSS

En la Tabla 14, se muestra la Prueba de Normalidad, que se realiza a la muestra Pre-Test de Entregas Perfectas. Como se puede ver esta prueba demuestra que los datos no siguen una distribución normal, por lo tanto, se debe realizar una prueba no paramétrica para comprobar la hipótesis específica en la cual participa las Entregas Perfectas. El p-valor es 0,001.

Tabla 14

Prueba de Normalidad de Entregas Perfectas Pre-test - Mayo 2019

\begin{tabular}{|c|c|c|c|c|c|c|}
\hline \multicolumn{7}{|c|}{ Pruebas de normalidad } \\
\hline & \multicolumn{3}{|c|}{ Kolmogorov-Smirnova } & \multicolumn{3}{|c|}{ Shapiro-Wilk } \\
\hline & Estadístico & Gl & Sig. & Estadístico & Gl & Sig. \\
\hline Ratio Entrega Perfecta & 208, & 22 & ,014 & ,824 & 22 & ,001 \\
\hline
\end{tabular}


La data post-test se muestra en la Tabla 15. El post-test corresponde al mes de octubre del 2019. Para determinar el Ratio, de las entregas perfectas, se ha calculado las órdenes de compras del día y los faltantes por cada una de ella.

Tabla 15

Entregas Perfectas Post-test - Octubre 2019

\begin{tabular}{|c|c|c|c|c|}
\hline Día & $\begin{array}{l}\text { Órdenes de } \\
\text { Compra }\end{array}$ & Faltante & $\begin{array}{l}\text { Entrega } \\
\text { Perfecta }\end{array}$ & $\begin{array}{l}\text { Ratio Entrega } \\
\text { Perfecta }\end{array}$ \\
\hline 2-Oct & 2 & 1 & 1 & 0.50 \\
\hline 3-Oct & 1 & 0 & 1 & 1.00 \\
\hline 4-Oct & 21 & 0 & 21 & 1.00 \\
\hline 7-Oct & 12 & 1 & 11 & 0.92 \\
\hline 9-Oct & 13 & 0 & 13 & 1.00 \\
\hline 10-Oct & 6 & 0 & 6 & 1.00 \\
\hline 11-Oct & 7 & 0 & 7 & 1.00 \\
\hline 12-Oct & 1 & 0 & 1 & 1.00 \\
\hline 14-Oct & 8 & 1 & 7 & 0.88 \\
\hline $15-$ Oct & 16 & 2 & 14 & 0.88 \\
\hline $16-$ Oct & 2 & 0 & 2 & 1.00 \\
\hline 17-Oct & 2 & 0 & 2 & 1.00 \\
\hline 18-Oct & 7 & 0 & 7 & 1.00 \\
\hline 21-Oct & 2 & 0 & 2 & 1.00 \\
\hline 22-Oct & 14 & 1 & 13 & 0.93 \\
\hline 23-Oct & 9 & 1 & 8 & 0.89 \\
\hline 24-Oct & 10 & 0 & 10 & 1.00 \\
\hline 25-Oct & 8 & 0 & 8 & 1.00 \\
\hline 28-Oct & 8 & 1 & 7 & 0.88 \\
\hline 29-Oct & 4 & 0 & 4 & 1.00 \\
\hline 30-Oct & 7 & 0 & 7 & 1.00 \\
\hline 31-Oct & 15 & 1 & 14 & 0.93 \\
\hline Total & 175 & 9 & & \\
\hline
\end{tabular}

En la Tabla 16, se muestra la estadística descriptiva de las Entregas Perfectas Post.Test. Como se puede ver, la media del ratio de las Entregas Perfectas post-test es 0.94, con una desviación estándar de 0.11 
Tabla 16

Estadística Descriptiva de Entregas Perfectas Post-test - Octubre 2019

\begin{tabular}{|c|c|c|c|c|}
\hline \multicolumn{5}{|c|}{ Descriptivos } \\
\hline & & & Estadístico & Desv. Error \\
\hline \multirow[t]{13}{*}{ Ratio Entrega Perfecta } & Media & & .945909 & .0235916 \\
\hline & $95 \%$ de intervalo de & Límite inferior & .896848 & \\
\hline & confianza para la media & Límite superior & .994970 & \\
\hline & Media recortada al $5 \%$ & & .965758 & \\
\hline & Mediana & & 1.000000 & \\
\hline & Varianza & &, 012 & \\
\hline & Desv. Desviación & & .1106543 & \\
\hline & Mínimo & & .5000 & \\
\hline & Máximo & & 1.0000 & \\
\hline & Rango & & .5000 & \\
\hline & Rango intercuartil & & .0875 & \\
\hline & Asimetría & & $-3,383$ & ,491 \\
\hline & Curtosis & & 13,318 &, 953 \\
\hline
\end{tabular}

En la Tabla 17 se muestra la Prueba de Normalidad, realizada al ratio de la Entregas Perfectas post-test, para comprobar que la muestra sigue una distribución normal. El p-valor es 0.00 lo cual indica que la muestra no sigue una distribución normal, por lo tanto, se debe realizar una prueba no paramétrica para comprobar la hipótesis específica.

Tabla 17

Prueba de Normalidad de Entregas Perfectas Post-test - Octubre 2019

\begin{tabular}{|c|c|c|c|c|c|c|}
\hline \multicolumn{7}{|c|}{ Pruebas de normalidad } \\
\hline & \multicolumn{3}{|c|}{ Kolmogorov-Smirnova } & \multicolumn{3}{|c|}{ Shapiro-Wilk } \\
\hline & Estadístico & Gl & Sig. & Estadístico & Gl & Sig. \\
\hline Ratio Entrega Perfecta & ,324 & 22 &, 000 &, 530 & 22 &, 000 \\
\hline a. Corrección de signific & Sn de Lilliefors & & & & & \\
\hline
\end{tabular}

En la Tabla 18, se muestra un comparativo entre la muestra pre-test y post test, del ratio Entregas Perfectas. Como se puede apreciar, el incremento en el ratio es del 0.14. Para comprobar la hipótesis específica, realizaremos una prueba No Paramétrica. 
Tabla 18.

Comparativo Pre-test Post-test de Entregas Perfectas.

\begin{tabular}{|c|c|}
\hline $\begin{array}{l}\text { Entregas } \\
\text { Perfectas Pre- } \\
\text { test - Mayo } \\
2019\end{array}$ & 0.81 \\
\hline $\begin{array}{c}\text { Entregas } \\
\text { Perfectas Post- } \\
\text { test - Octubre } \\
2019\end{array}$ & 0.95 \\
\hline Incremento & 0.14 \\
\hline
\end{tabular}

Mediante una prueba U de Mann-Whitney, comprobaremos la siguiente hipótesis.

\section{“Una mejora de la gestión de inventarios impacta positivamente en las entregas perfectas de una empresa luminaria."}

Ya se ha comprobado que el ratio de Entregas Perfectas son impactadas positivamente por que el ratio se incrementa en 0.14. La prueba $U$ de Mann-Whitney, comprueban si las dos muestras son dependientes, es decir pertenecen a la misma población y como se puede ver en la Figura 12, el p-valor de la prueba es 0.022 , rechazando la hipótesis nula, por lo tanto, ambas muestras pertenecen a poblaciones diferentes, lo cual demuestra que este incremento en el ratio se debe a la mejora en la gestión de inventarios.

\section{Resumen de prueba de hipótesis}

\begin{tabular}{|c|c|c|c|c|}
\hline & Hipótesis nula & Prueba & Sig. & Decisión \\
\hline 1 & $\begin{array}{l}\text { La distribución de Ratio Entrega } \\
\text { Perfecta es la misma entre las } \\
\text { categorías de Test. }\end{array}$ & $\begin{array}{l}\text { Prueba U de } \\
\text { Mann-Whitney } \\
\text { para muestras } \\
\text { independientes }\end{array}$ &, 022 & $\begin{array}{l}\text { Rechazar la } \\
\text { hipótesis } \\
\text { nula. }\end{array}$ \\
\hline
\end{tabular}

Se muestran significaciones asintóticas. El nivel de significación es de ,05.

Figura 12. Prueba U de Mann - Whitney de Entregas Perfectas

Datos de la empresa - Elaboración SPSS 


\section{Entregas a Tiempo}

La data pre-test se muestra en la Tabla 19. El pre-test corresponde al mes de mayo del 2019. Para determinar el Ratio, de las entregas a tiempo, se ha calculado las órdenes de compras del día y de ellas, cuáles se entregaron a tiempo.

Tabla 19

Entregas a Tiempo Pre-test - Mayo 2019

\begin{tabular}{cccc}
\hline Día & $\begin{array}{c}\text { Órdenes de } \\
\text { Compra }\end{array}$ & $\begin{array}{c}\text { Entrega a } \\
\text { Tiempo }\end{array}$ & $\begin{array}{c}\text { Ratio Entregas a } \\
\text { Tiempo }\end{array}$ \\
\hline 1-May & 2 & 2 & 1.00 \\
2-May & 1 & 1 & 1.00 \\
6-May & 4 & 2 & 0.50 \\
7-May & 6 & 0 & 0.00 \\
8-May & 6 & 3 & 0.50 \\
9-May & 5 & 5 & 1.00 \\
10-May & 2 & 0 & 0.00 \\
13-May & 10 & 6 & 0.60 \\
14-May & 7 & 4 & 0.57 \\
15-May & 7 & 4 & 0.57 \\
16-May & 5 & 4 & 0.80 \\
17-May & 5 & 4 & 0.80 \\
20-May & 10 & 9 & 0.90 \\
21-May & 6 & 1 & 0.17 \\
22-May & 4 & 2 & 0.50 \\
23-May & 4 & 3 & 0.75 \\
24-May & 9 & 8 & 0.89 \\
27-May & 10 & 9 & 0.90 \\
28-May & 5 & 3 & 0.60 \\
29-May & 13 & 13 & 1.00 \\
30-May & 8 & 8 & 1.00 \\
31-May & 14 & 14 & 1.00 \\
Total & 143 & 105 & \\
\hline & Datos de la empresa - Elaboración propia \\
20 & 5 & \\
\hline
\end{tabular}

En la Tabla 20, se muestra la estadística descriptiva del ratio de la Entregas a Tiempo Pretest, obtenido mediante el SPSS. Como se puede ver, la media es 0.68 y la desviación estándar es 0.31. A continuación se comprobará si los datos siguen una distribución normal. 
Tabla 20

Estadística Descriptiva de Entregas a Tiempo Pre-test - Mayo 2019

\begin{tabular}{|c|c|c|c|c|}
\hline \multicolumn{5}{|c|}{ Descriptivos } \\
\hline & & & Estadístico & Desv. Error \\
\hline \multirow[t]{13}{*}{ Ratio Entrega a Tiempo } & Media & & .684091 & .0675440 \\
\hline & $95 \%$ de intervalo de & Límite inferior & .543626 & \\
\hline & confianza para la media & Límite superior & .824556 & \\
\hline & Media recortada al $5 \%$ & & .704545 & \\
\hline & Mediana & & .775000 & \\
\hline & Varianza & & ,100 & \\
\hline & Desv. Desviación & & .3168094 & \\
\hline & Mínimo & & .0000 & \\
\hline & Máximo & & 1.0000 & \\
\hline & Rango & & 1.0000 & \\
\hline & Rango intercuartil & & .5000 & \\
\hline & Asimetría & &,- 951 & ,491 \\
\hline & Curtosis & & ,157 & ,953 \\
\hline
\end{tabular}

En la Tabla 21, se muestra la Prueba de Normalidad, de la muestra pre-test de la Entregas a Tiempo, en esta prueba se puede ver que los datos no siguen una distribución normal, ya que el p-valor es 0.005 . De esta forma se deberá tomar una prueba no paramétrica para comprobar la hipótesis específica, en la cual participa esta muestra.

Tabla 21

Prueba de Normalidad de Entregas a Tiempo Pre-test - Mayo 2019

\begin{tabular}{|c|c|c|c|c|c|c|}
\hline \multicolumn{7}{|c|}{ Pruebas de normalidad } \\
\hline & \multicolumn{3}{|c|}{ Kolmogorov-Smirnova } & \multicolumn{3}{|c|}{ Shapiro-Wilk } \\
\hline & Estadístico & gl & Sig. & Estadístico & $\mathrm{Gl}$ & Sig. \\
\hline Ratio Entrega a Tiempo & 159 & 22 & 152 & 861 & 22 & 005 \\
\hline a. Corrección de significe & de Lilliefors & & & & & \\
\hline
\end{tabular}

La data post-test se muestra en la Tabla 22. El post-test corresponde al mes de octubre del 2019. Para determinar el Ratio, de las entregas a tiempo, se ha calculado las órdenes de compras del día y de ellas, cuáles se entregaron a tiempo. 
Tabla 22

Entregas a Tiempo Post-test - Octubre 2019

\begin{tabular}{cccc}
\hline Día & $\begin{array}{c}\text { Órdenes de } \\
\text { Compra }\end{array}$ & $\begin{array}{c}\text { Entrega a } \\
\text { Tiempo }\end{array}$ & $\begin{array}{c}\text { Ratio Entregas a } \\
\text { Tiempo }\end{array}$ \\
\hline 2-Oct & 2 & 2 & 1.00 \\
3-Oct & 1 & 1 & 1.00 \\
4-Oct & 21 & 21 & 1.00 \\
7-Oct & 12 & 12 & 1.00 \\
9-Oct & 13 & 12 & 0.92 \\
10-Oct & 6 & 6 & 1.00 \\
11-Oct & 7 & 7 & 1.00 \\
12-Oct & 1 & 1 & 1.00 \\
14-Oct & 8 & 8 & 1.00 \\
15-Oct & 16 & 15 & 0.94 \\
16-Oct & 2 & 1 & 0.50 \\
17-Oct & 2 & 1 & 0.50 \\
18-Oct & 7 & 7 & 1.00 \\
21-Oct & 2 & 2 & 1.00 \\
22-Oct & 14 & 11 & 0.79 \\
23-Oct & 9 & 7 & 0.78 \\
24-Oct & 10 & 10 & 1.00 \\
25-Oct & 8 & 6 & 0.75 \\
28-Oct & 8 & 7 & 0.88 \\
29-Oct & 4 & 4 & 1.00 \\
30-Oct & 7 & 6 & 0.86 \\
31-Oct & 15 & 14 & 0.93 \\
Total & 175 & 161 & \\
\hline & Datos de la empresa - Elaboración propia \\
\hline & & & \\
\hline
\end{tabular}

En la Tabla 23, se muestra la estadística descriptiva del ratio de las Entregas a Tiempo del Post-test. Como se puede ver, la media del ratio es 0.90 con una desviación estándar de 0.15. A continuación se realiza una prueba de Kolmogorov - Smirnov, para comprobar que los datos siguen una distribución normal. 
Tabla 23

Estadística Descriptiva de Entregas a Tiempo Post-test - Octubre 2019

\begin{tabular}{|c|c|c|c|c|}
\hline \multicolumn{5}{|c|}{ Descriptivos } \\
\hline & & & Estadístico & Desv. Error \\
\hline \multirow[t]{13}{*}{ Ratio Entrega a Tiempo } & Media & & .902273 & .0326925 \\
\hline & $95 \%$ de intervalo de & Límite inferior & .834285 & \\
\hline & confianza para la media & Límite superior & .970261 & \\
\hline & Media recortada al $5 \%$ & & .919192 & \\
\hline & Mediana & & 1.000000 & \\
\hline & Varianza & &, 024 & \\
\hline & Desv. Desviación & & .1533416 & \\
\hline & Mínimo & & .5000 & \\
\hline & Máximo & & 1.0000 & \\
\hline & Rango & & .5000 & \\
\hline & Rango intercuartil & & .1575 & \\
\hline & Asimetría & & $-1,827$ & ,491 \\
\hline & Curtosis & & 2,757 & ,953 \\
\hline
\end{tabular}

En la Tabla 24 se muestra el resultado de la prueba de Kolmogorov - Smirnov, como se puede apreciar el p-valor es 0.00 lo cual indica que los datos no siguen una distribución normal, por lo tanto, se debe correr una prueba no paramétrica para comprobar las hipótesis específicas, en las cuales se menciona a las Entregas a Tiempo.

Tabla 24

Prueba de Normalidad de Entregas a Tiempo Post-test - Octubre 2019

\begin{tabular}{|c|c|c|c|c|c|c|}
\hline \multicolumn{7}{|c|}{ Pruebas de normalidad } \\
\hline & \multicolumn{3}{|c|}{ Kolmogorov-Smirnova } & \multicolumn{3}{|c|}{ Shapiro-Wilk } \\
\hline & Estadístico & $\mathrm{gl}$ & Sig. & Estadístico & $\mathrm{Gl}$ & Sig. \\
\hline Ratio Entrega a Tiempo & 283 & 22 & 000 & 689 & 22 & 000 \\
\hline a. Corrección de significa & de Lilliefors & & & & & \\
\hline
\end{tabular}

La hipótesis específica es la siguiente.
"Una mejora de la gestión de inventarios impacta positivamente en las entregas a tiempo de una empresa luminaria."


Para comprobar el impacto de la gestión de inventarios en las entregas a tiempo, comparamos ambas muestras. En la Tabla 25 se muestra esta comparación, y se puede observar que la gestión de inventarios impacta positivamente en las entregas a tiempo, con 0.27 , lo cual es significativo.

Tabla 25

Comparativo entre Pre-test y Post-test de Entregas a Tiempo

\begin{tabular}{|c|c|}
\hline $\begin{array}{c}\text { Entregas a } \\
\text { Tiempo Pre-test - } \\
\text { Mayo } 2019\end{array}$ & 0.68 \\
\hline $\begin{array}{c}\text { Entregas a } \\
\text { Tiempo Post-test } \\
\text { - Octubre } 2019\end{array}$ & 0.95 \\
\hline Incremento & 0.27 \\
\hline
\end{tabular}

Como ya se explicó en el punto anterior, se debe realizar una prueba de U Mann - Whitney, para comprobar si las dos muestras son independientes. En este caso el p-valor es 0.013 lo cual indica que se rechaza la hipótesis nula, por lo tanto, ambas muestras son independientes, por que pertenecen a poblaciones diferentes, lo cual indica que efectivamente la gestión de inventarios impacta positivamente en las entregas a tiempo. En la Figura 13 se muestra la prueba de U Mann - Whitney.

Resumen de prueba de hipótesis

\begin{tabular}{|clrl|}
\hline \multicolumn{1}{|c}{ Hipótesis nula } & Prueba & Sig. & Decisión \\
\hline 1 La distribución de Ratio Entrega a & $\begin{array}{l}\text { Prueba U de } \\
\text { Mann-Whitney } \\
\text { catego es la misma entre las } \\
\text { cara muestras } \\
\text { independientes }\end{array}$ & 013 le Test. & $\begin{array}{l}\text { Rechazar la } \\
\text { hipótesis } \\
\text { nula. }\end{array}$ \\
\hline
\end{tabular}

Se muestran significaciones asintóticas. El nivel de significación es de ,05.

Figura 13. Prueba de U Mann - Whitney para Entregas a Tiempo

Datos de la empresa - Elaboración SPSS 


\section{Devoluciones}

La data pre-test se muestra en la Tabla 26. El pre-test corresponde al mes de mayo del 2019. Para determinar el Ratio, de las devoluciones, se ha calculado el monto de las ventas del día y el monto de las devoluciones realizadas día por día.

Tabla 26

Devoluciones Pre-test - Mayo 2019

\begin{tabular}{|c|c|c|c|c|c|}
\hline Día & $\begin{array}{l}\text { Monto } \\
\text { Facturado }\end{array}$ & $\begin{array}{c}\text { Monto } \\
\text { Devoluciones }\end{array}$ & $\begin{array}{l}\text { Órdenes de } \\
\text { Compra }\end{array}$ & Devoluciones & $\begin{array}{c}\text { Ratio de } \\
\text { Devoluciones }\end{array}$ \\
\hline 1-May & 3655.26 & & 2 & & 0.0000 \\
\hline 2-May & 3172.88 & & 1 & & 0.0000 \\
\hline 6-May & 864.24 & & 4 & & 0.0000 \\
\hline 7-May & 4413.26 & & 6 & & 0.0000 \\
\hline 8-May & 4368.12 & 3039.84 & 6 & 4 & 0.6667 \\
\hline 9-May & 12852.98 & 36.44 & 5 & 1 & 0.2000 \\
\hline 10-May & 2966.1 & 19.75 & 2 & 1 & 0.5000 \\
\hline 13-May & 11676.6 & 61.4 & 10 & 1 & 0.1000 \\
\hline 14-May & 5904.82 & & 7 & & 0.0000 \\
\hline 15-May & 4097.22 & & 7 & & 0.0000 \\
\hline 16-May & 13053.4 & & 5 & & 0.0000 \\
\hline 17-May & 19967.64 & & 5 & & 0.0000 \\
\hline 20-May & 30837.28 & 5898.48 & 10 & 2 & 0.2000 \\
\hline 21-May & 8737.78 & 50.85 & 6 & 1 & 0.1667 \\
\hline 22-May & 5997.62 & & 4 & & 0.0000 \\
\hline 23-May & 11848.12 & 3414.06 & 4 & 3 & 0.7500 \\
\hline 24-May & 18403.28 & & 9 & & 0.0000 \\
\hline 27-May & 9260.84 & & 10 & & 0.0000 \\
\hline 28-May & 13510.18 & 51.69 & 5 & 1 & 0.2000 \\
\hline 29-May & 27792.1 & 7.63 & 13 & 1 & 0.0769 \\
\hline 30-May & 11254.32 & 12.71 & 8 & 1 & 0.1250 \\
\hline 31-May & 26972.92 & 1155.51 & 14 & 4 & 0.2857 \\
\hline Total & 251606.96 & 13748.36 & 143 & 20 & \\
\hline
\end{tabular}

Datos de la empresa - Elaboración propia

En la Tabla 27, se muestra la estadística descriptiva del ratio de las Devoluciones Pre-Test, en la cual se puede observar que la media del ratio es 0.1486 con una desviación estándar de 0.2216. 
Tabla 27

Estadística Descriptiva de Devoluciones Pre-test - Mayo 2019

\begin{tabular}{|c|c|c|c|c|}
\hline \multicolumn{5}{|c|}{ Descriptivos } \\
\hline & & & Estadístico & Desv. Error \\
\hline \multirow[t]{13}{*}{ Ratio Devoluciones } & Media & & .148682 & .0472536 \\
\hline & $95 \%$ de intervalo de & Límite inferior & .050413 & \\
\hline & confianza para la media & Límite superior & .246951 & \\
\hline & Media recortada al 5\% & & .123956 & \\
\hline & Mediana & & .038450 & \\
\hline & Varianza & & ,049 & \\
\hline & Desv. Desviación & & .2216392 & \\
\hline & Mínimo & & .0000 & \\
\hline & Máximo & & .7500 & \\
\hline & Rango & & .7500 & \\
\hline & Rango intercuartil & & .2000 & \\
\hline & Asimetría & & 1,761 & ,491 \\
\hline & Curtosis & & 2,398 & ,953 \\
\hline
\end{tabular}

En la Tabla 28, se muestra la Prueba de Normalidad, que se realiza a la muestra Pre-Test de Devoluciones. Como se puede ver, en esta prueba se demuestra que los datos no siguen una distribución normal, por lo tanto, se debe realizar una prueba no paramétrica para comprobar la hipótesis específica en la cual participa las Devoluciones. El p-valor es 0,00.

Tabla 28

Prueba de Normalidad de Devoluciones Pre-test - Mayo 2019

\begin{tabular}{|c|c|c|c|c|c|c|}
\hline \multicolumn{7}{|c|}{ Pruebas de normalidad } \\
\hline & \multicolumn{3}{|c|}{ Kolmogorov-Smirnova } & \multicolumn{3}{|c|}{ Shapiro-Wilk } \\
\hline & Estadístico & $\mathrm{Gl}$ & Sig. & Estadístico & $g l$ & Sig. \\
\hline Ratio Devoluciones & ,251 & 22 &, 001 &, 714 & 22 &, 000 \\
\hline a. Corrección de sigr & ación de Lillie & & & & & \\
\hline
\end{tabular}

La data post-test se muestra en la Tabla 29. El post-test corresponde al mes de octubre del 2019. Para determinar el Ratio, de las devoluciones, se ha calculado el monto de las ventas del día y el monto de las devoluciones realizadas día por día. 
Tabla 29

Devoluciones Post-test - Octubre 2019

\begin{tabular}{|c|c|c|c|c|c|}
\hline Día & $\begin{array}{l}\text { Monto } \\
\text { Facturado }\end{array}$ & $\begin{array}{c}\text { Monto } \\
\text { Devoluciones }\end{array}$ & $\begin{array}{l}\text { Órdenes de } \\
\text { Compra }\end{array}$ & Devoluciones & $\begin{array}{c}\text { Ratio de } \\
\text { Devoluciones }\end{array}$ \\
\hline 2-Oct & 349.3 & & 2 & & 0.0000 \\
\hline 3-Oct & 284.74 & & 1 & & 0.0000 \\
\hline 4-Oct & 48757.56 & 67.8 & 21 & 1 & 0.0476 \\
\hline 7-Oct & 8445.08 & 286.44 & 12 & 1 & 0.0833 \\
\hline 9-Oct & 19519.68 & 16.95 & 13 & 1 & 0.0769 \\
\hline $10-$ Oct & 14685.58 & & 6 & & 0.0000 \\
\hline $11-$ Oct & 9127.46 & & 7 & & 0.0000 \\
\hline $12-O c t$ & 2545.76 & & 1 & & 0.0000 \\
\hline $14-O c t$ & 17878.62 & & 8 & & 0.0000 \\
\hline $15-$ Oct & 18735.76 & 847.46 & 16 & 1 & 0.0625 \\
\hline $16-$ Oct & 4732.54 & & 2 & & 0.0000 \\
\hline 17-Oct & 410.18 & & 2 & & 0.0000 \\
\hline 18-Oct & 8173.86 & & 7 & & 0.0000 \\
\hline 21-Oct & 6930.5 & & 2 & & 0.0000 \\
\hline 22-Oct & 11408 & 946.96 & 14 & 1 & 0.0714 \\
\hline 23-Oct & 21019.46 & & 9 & & 0.0000 \\
\hline 24-Oct & 18047.28 & & 10 & & 0.0000 \\
\hline 25-Oct & 7767.48 & & 8 & & 0.0000 \\
\hline 28-Oct & 9105.14 & & 8 & & 0.0000 \\
\hline 29-Oct & 9961.02 & & 4 & & 0.0000 \\
\hline 30-Oct & 18024.58 & & 7 & & 0.0000 \\
\hline 31-Oct & 21725.84 & 24.92 & 15 & 1 & 0.0667 \\
\hline Total & 277635.42 & 2190.53 & 175 & 6 & \\
\hline
\end{tabular}

En la Tabla 30, se muestra la estadística descriptiva del ratio de las Devoluciones Post.Test. Como se puede ver, la media del ratio de las Devoluciones post-test es 0.0185 , con una desviación estándar de 0.0316 
Tabla 30

Estadística Descriptiva de Devoluciones Post-test - Octubre 2019

\begin{tabular}{|c|c|c|c|c|}
\hline \multicolumn{5}{|c|}{ Descriptivos } \\
\hline & & & Estadístico & Desv. Error \\
\hline \multirow[t]{13}{*}{ Ratio Devoluciones } & Media & & .018564 & .0067404 \\
\hline & $95 \%$ de intervalo de & Límite inferior & .004546 & \\
\hline & confianza para la media & Límite superior & .032581 & \\
\hline & Media recortada al 5\% & & .016031 & \\
\hline & Mediana & & .000000 & \\
\hline & Varianza & &, 001 & \\
\hline & Desv. Desviación & & .0316152 & \\
\hline & Mínimo & & .0000 & \\
\hline & Máximo & & .0833 & \\
\hline & Rango & & .0833 & \\
\hline & Rango intercuartil & & .0513 & \\
\hline & Asimetría & & 1,220 & ,491 \\
\hline & Curtosis & &,- 394 & ,953 \\
\hline
\end{tabular}

En la Tabla 31 se muestra la Prueba de Normalidad, realizada al ratio de las Devoluciones post-test, para comprobar que la muestra sigue una distribución normal. El p-valor es 0.00 lo cual indica que la muestra no sigue una distribución normal, por lo tanto, se debe realizar una prueba no paramétrica para comprobar la hipótesis específica.

Tabla 31

Prueba de Normalidad de Devoluciones Post-test - Octubre 2019

\section{Pruebas de normalidad}

Kolmogorov-Smirnova

Shapiro-Wilk

\begin{tabular}{lrrrrrr} 
& Estadístico & Gl & \multicolumn{1}{c}{ Sig. } & Estadístico & Gl & \multicolumn{1}{c}{ Sig. } \\
\hline Ratio Devoluciones &, 449 & 22 &, 000 &, 607 & 22 &, 000
\end{tabular}

a. Corrección de significación de Lilliefors

Datos de la empresa - Elaboración SPSS

En la Tabla 32, se muestra un comparativo entre la muestra pre-test y post test, del ratio Devoluciones. Como se puede apreciar, la disminución en el ratio es del 0.13. Para comprobar la hipótesis específica, realizaremos una prueba No Paramétrica. 
Tabla 32

Comparativo Pre-test Post-test de Devoluciones

\begin{tabular}{|c|c|}
\hline $\begin{array}{l}\text { Devoluciones Pre- } \\
\text { test - Mayo } 2019\end{array}$ & 0.1486 \\
\hline $\begin{array}{l}\text { Devoluciones Post- } \\
\text { test - Octubre } 2019\end{array}$ & 0.0185 \\
\hline Disminución & 0.1301 \\
\hline
\end{tabular}

Mediante una prueba U de Mann-Whitney, comprobaremos la siguiente hipótesis.

\section{"Una mejora de la gestión de inventarios impacta positivamente en el porcentaje de devoluciones de una empresa luminaria."}

Ya se ha comprobado que el ratio de Devoluciones son impactadas positivamente por que el ratio disminuye en 0.13 . La prueba $U$ de Mann-Whitney, comprueban si las dos muestras son dependientes, es decir pertenecen a la misma población y como se puede ver en la Figura 14, el p-valor de la prueba es 0.021 , rechazando la hipótesis nula, por lo tanto, ambas muestras pertenecen a poblaciones diferentes, lo cual demuestra que la disminución en el ratio de la devoluciones se debe a la mejora en la gestión de inventarios.

\section{Resumen de prueba de hipótesis}

\begin{tabular}{|c|c|c|c|c|}
\hline & Hipótesis nula & Prueba & Sig. & Decisión \\
\hline 1 & $\begin{array}{l}\text { La distribución de Ratio } \\
\text { Devoluciones es la misma entre las } \\
\text { categorías de Test. }\end{array}$ & $\begin{array}{l}\text { Prueba U de } \\
\text { Mann-Whitney } \\
\text { para muestras } \\
\text { independientes }\end{array}$ &, 021 & $\begin{array}{l}\text { Rechazar la } \\
\text { hipótesis } \\
\text { nula. }\end{array}$ \\
\hline
\end{tabular}

Se muestran significaciones asintóticas. El nivel de significación es de ,05.

Figura 14. Prueba U de Mann - Whitney de Devoluciones

Datos de la empresa - Elaboración SPSS 


\section{Tiempo de Ciclo}

La data pre-test se muestra en la Tabla 33. El pre-test corresponde al mes de mayo del 2019. Para determinar el Tiempo de Ciclo, se ha calculado el tiempo desde que se registran las órdenes de compras hasta su entrega al cliente del pedido. La muestra fue seleccionada aleatoriamente.

Tabla 33

Tiempo de Ciclo Pre-test - Mayo 2019

\begin{tabular}{rc}
\hline Documento & Tiempo de ciclo \\
\hline FF01000304 & 1 \\
FF01000344 & 4 \\
FF01000291 & 1 \\
FF01000292 & 1 \\
FF01000275 & 3 \\
FF01000295 & 1 \\
FF01000279 & 8 \\
FF01000297 & 3 \\
FF01000327 & 1 \\
FF01000339 & 1 \\
FF01000288 & 1 \\
FF01000281 & 3 \\
FF01000296 & 3 \\
FF01000307 & 4 \\
FF01000277 & 1 \\
FF01000286 & 3 \\
FF01000289 & 3 \\
FF01000276 & 5 \\
FF01000285 & 1 \\
FF01000311 & 3 \\
FF01000260 & 1 \\
FF01000290 & 4 \\
FF01000306 & 6 \\
FF01000294 & 1 \\
FF01000261 & 1 \\
FF01000278 & 1 \\
FF01000253 & 1 \\
FF01000301 & 1 \\
FF01000280 & 4 \\
FF01000303 & 3 \\
Total & 30 \\
\hline
\end{tabular}

Datos de la empresa - Elaboración propia 
En la Tabla 34, se muestra la estadística descriptiva del Tiempo de Ciclo Pre-test, obtenido mediante el SPSS. Como se puede ver, la media es 2.46 y la desviación estándar es 1.79. A continuación se comprobará si los datos siguen una distribución normal.

Tabla 34

Estadística Descriptiva de Tiempo de Ciclo Pre-test - Mayo 2019

\begin{tabular}{|c|c|c|c|c|}
\hline \multicolumn{5}{|c|}{ Descriptivos } \\
\hline & & & Estadístico & Desv. Error \\
\hline \multirow[t]{13}{*}{ Tiempo de Ciclo } & Media & & 2.466667 & .3277697 \\
\hline & $95 \%$ de intervalo de & Límite inferior & 1.796302 & \\
\hline & confianza para la media & Límite superior & 3.137031 & \\
\hline & Media recortada al 5\% & & 2.277778 & \\
\hline & Mediana & & 2.000000 & \\
\hline & Varianza & & 3,223 & \\
\hline & Desv. Desviación & & 1.7952684 & \\
\hline & Mínimo & & 1.0000 & \\
\hline & Máximo & & 8.0000 & \\
\hline & Rango & & 7.0000 & \\
\hline & Rango intercuartil & & 2.2500 & \\
\hline & Asimetría & & 1,265 & ,427 \\
\hline & Curtosis & & 1,672 & ,833 \\
\hline
\end{tabular}

En la Tabla 35, se muestra la Prueba de Normalidad, de la muestra pre-test del Tiempo de Ciclo, en esta prueba se puede ver que los datos no siguen una distribución normal, ya que el p-valor es 0.000. De esta forma se deberá tomar una prueba no paramétrica para comprobar la hipótesis específica, en la cual participa esta muestra.

Tabla 35

Prueba de Normalidad de Tiempo de Ciclo Pre-test - Mayo 2019

\begin{tabular}{lcccccc}
\hline & \multicolumn{3}{c}{ Pruebas de normalidad } & & \\
& Kolmogorov-Smirnova & & Shapiro-Wilk \\
& Estadístico & gl & Sig. & Estadístico & Gl & Sig. \\
\hline Tiempo de Ciclo & 293 & 30 &, 000 &, 786 & 30 &, 000 \\
a. Corrección de significación de Lilliefors & & & & \\
\hline
\end{tabular}

Datos de la empresa - Elaboración SPSS 
La data post-test se muestra en la Tabla 36. El post-test corresponde al mes de octubre del 2019. Para determinar el Tiempo de Ciclo, se ha calculado el tiempo desde que se registran las órdenes de compras hasta su entrega al cliente del pedido. La selección de los documentos que componen la muestra fue aleatoria.

Tabla 36

Tiempo de Ciclo Post-test - Octubre 2019

\begin{tabular}{rr}
\hline Documento & Tiempo de ciclo \\
\hline FF01000970 & 2 \\
FF01000973 & 2 \\
FF01000978 & 1 \\
BB01000013 & 1 \\
FF01000994 & 1 \\
FF01001009 & 1 \\
FF01001003 & 2 \\
FF01000966 & 2 \\
FF01000977 & 2 \\
FF01001142 & 1 \\
FF01001017 & 1 \\
FF01001004 & 1 \\
FF01000989 & 1 \\
FF01000971 & 1 \\
FF01000998 & 1 \\
FF01001041 & 1 \\
FF01001005 & 2 \\
FF01000969 & 1 \\
FF01000968 & 1 \\
FF01000999 & 1 \\
FF01000996 & 1 \\
FF01001074 & 1 \\
FF01000975 & 1 \\
FF01001057 & 1 \\
FF01001031 & 1 \\
FF01000981 & 1 \\
FF01001028 & 1 \\
BB01000012 & 1 \\
FF01000974 & 1 \\
FF01000972 & 1 \\
Total & 1 \\
\hline de la empresa - Elaboración propia \\
\end{tabular}


En la Tabla 37, se muestra la estadística descriptiva del Tiempo de Ciclo del Post-test. Como se puede ver, la media es 1.3 con una desviación estándar de 0.46 . A continuación se realiza una prueba de Kolmogorov - Smirnov, para comprobar que los datos siguen una distribución normal.

\section{Tabla 37}

Estadística Descriptiva de Tiempo de Ciclo Post-test - Octubre 2019

\begin{tabular}{|c|c|c|c|c|}
\hline \multicolumn{5}{|c|}{ Descriptivos } \\
\hline & & & Estadístico & Desv. Error \\
\hline \multirow[t]{13}{*}{ Tiempo de Ciclo } & Media & & 1.300000 & .0850963 \\
\hline & $95 \%$ de intervalo de & Límite inferior & 1.125959 & \\
\hline & confianza para la media & Límite superior & 1.474041 & \\
\hline & Media recortada al $5 \%$ & & 1.277778 & \\
\hline & Mediana & & 1.000000 & \\
\hline & Varianza & & ,217 & \\
\hline & Desv. Desviación & & .4660916 & \\
\hline & Mínimo & & 1.0000 & \\
\hline & Máximo & & 2.0000 & \\
\hline & Rango & & 1.0000 & \\
\hline & Rango intercuartil & & 1.0000 & \\
\hline & Asimetría & & ,920 & , 427 \\
\hline & Curtosis & & $-1,242$ & ,833 \\
\hline
\end{tabular}

En la Tabla 38 se muestra el resultado de la prueba de Kolmogorov - Smirnov, como se puede apreciar el p-valor es 0.00 lo cual indica que los datos no siguen una distribución normal, por lo tanto, se debe correr una prueba no paramétrica para comprobar las hipótesis específicas, en las cuales se menciona el Tiempo de Ciclo.

Tabla 38

Prueba de Normalidad de Tiempo de Ciclo Post-test - Octubre 2019

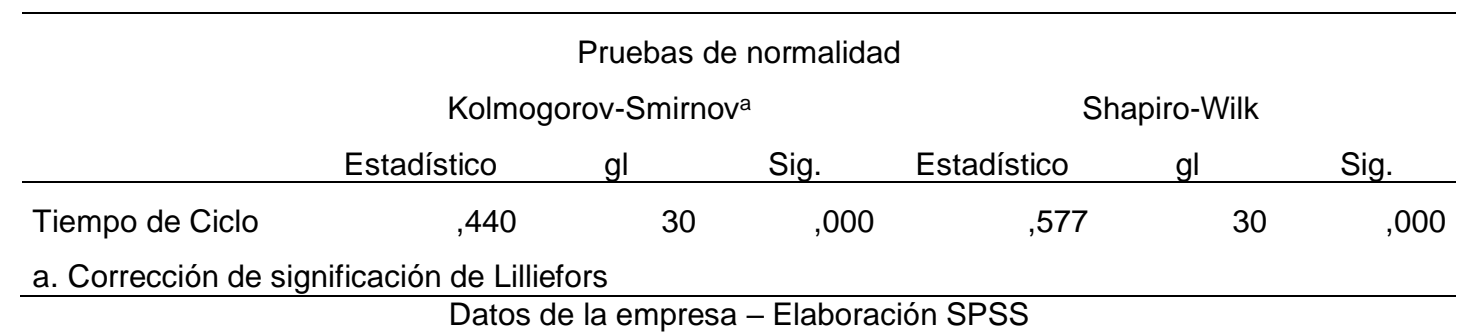


La hipótesis específica es la siguiente.

\section{"Una mejora de la gestión de inventarios impacta positivamente en el tiempo de ciclo de pedido de una empresa luminaria."}

Para comprobar el impacto de la gestión de inventarios en el Tiempo de Ciclo, comparamos ambas muestras. En la Tabla 39 se muestra esta comparación, y se puede observar que la gestión de inventarios impacta positivamente en el Tiempo de Ciclo, con una disminución en el tiempo de 1.16.

Tabla 39

Comparativo entre Pre-test y Post-test de Tiempo de Ciclo

\begin{tabular}{cc}
\hline $\begin{array}{c}\text { Tiempo de Ciclo } \\
\text { Pre-test - Mayo } \\
2019\end{array}$ & 2.46 \\
\hline $\begin{array}{c}\text { Tiempo de Ciclo } \\
\text { Post-test - } \\
\text { Octubre } 2019\end{array}$ & 1.3 \\
\hline Datos de la empresa - Elaboración propia & Disminución 1.16
\end{tabular}

Como ya se explicó en el punto anterior, se debe realizar una prueba de U Mann - Whitney, para comprobar si las dos muestras son independientes. En este caso el p-valor es 0.008 lo cual indica que se rechaza la hipótesis nula, por lo tanto, ambas muestras son independientes, por que pertenecen a poblaciones diferentes, lo cual indica que efectivamente la gestión de inventarios impacta positivamente en el Tiempo de Ciclo. En la Figura 15 se muestra la prueba de U Mann - Whitney.

Resumen de prueba de hipótesis

\begin{tabular}{|llll|}
\hline \multicolumn{1}{|c|}{ Hipótesis nula } & Prueba & Sig. & Decisión \\
\hline $\begin{array}{l}\text { La distribución de Tiempo de Ciclo } \\
\text { es la misma entre las categorías de } \\
\text { Test. }\end{array}$ & $\begin{array}{l}\text { Prueba U de } \\
\text { Mann-Whitney } \\
\text { para muestras } \\
\text { independientes }\end{array}$ & $008 \begin{array}{l}\text { Rechazar la } \\
\text { hipótesis } \\
\text { nula. }\end{array}$ \\
\hline
\end{tabular}

Se muestran significaciones asintóticas. El nivel de significación es de ,05.

Figura 15. Prueba de U Mann - Whitney para Tiempo de Ciclo

Datos de la empresa - Elaboración SPSS 
Para comprobar la Hipótesis General, que dice.

\section{"Una mejora de la gestión de inventarios impacta positivamente en el nivel de servicio de una empresa luminaria."}

El nivel de servicio se analizó en función de 4 dimensiones, en la Tabla 40 , se muestra un resumen de las dimensiones analizadas y estudiadas y los resultados obtenidos. Como se puede ver, la mejora en la gestión de inventarios impacta positivamente en el nivel de servicio de una empresa luminaria.

Tabla 40

Dimensiones del Nivel de Servicio de una empresa luminaria.

\begin{tabular}{cccc}
\hline $\begin{array}{c}\text { Entregas } \\
\text { Perfectas }\end{array}$ & $\begin{array}{c}\text { Entregas a } \\
\text { Tiempo }\end{array}$ & Devoluciones & $\begin{array}{c}\text { Tiempo de } \\
\text { Ciclo }\end{array}$ \\
\hline+0.14 & +0.27 & -0.13 & -1.16 \\
\hline \multicolumn{3}{c}{ Datos de la empresa - Elaboración propia }
\end{tabular}




\section{DISCUSIÓN}

Existe diversas investigaciones respecto al tema, en la de Prado (2018): "APLICACIÓN DE LA GESTIÓN DE INVENTARIOS PARA MEJORAR EL NIVEL DE SERVICIO DEL ALMACÉN DE LA EMPRESA DE PRODUCTOS ALIMENTICIOS CARTER S.A., ATE, 2018" el objetivo es determinar la medida en que la aplicación de gestión de inventarios mejora el nivel de servicio de Carter. Concluyendo que con la aplicación el nivel de servicio mejoró en 15\%, las entregas perfectas en $9 \%$ y entregas a tiempo en $7.6 \%$. Del mismo modo, en la presente investigación hubo una mejora en el nivel de servicio, las entregas perfectas mejoraron en 14\% y las entregas a tiempo en $27 \%$. Ambas investigaciones aplican la misma metodología aplicada con un diseño cuasi-experimental.

Asimismo, la tesis "IMPLEMENTACIÓN DE GESTIÓN DE INVENTARIOS PARA MEJORAR EL NIVEL DE SERVICIO AL CLIENTE EN LA EMPRESA LUMEN INGENIERÍA S.A.C., LOS OLIVOS, 2017" de Cervantes (2017), la cual busca determinar el modo la implementación de gestión de inventarios mejora el nivel de servicio de su empresa. De esta manera, precisan que hubo un incremento de $1.53 \%$ en el nivel de servicio, así también una mejora en el tiempo de ciclo de pedido, el cual se redujo en $7.56 \%$. En esta misma línea, la presente tesis obtuvo una reducción de 1.16 días en el tiempo de ciclo de pedido.

Calle, Matute y Yampasi (2016) en su tesis "REDISEÑO DEL MODELO DE GESTIÓN DE INVENTARIOS PARA SINOMAQ S.A.: AUMENTANDO EL NIVEL DE SERVICIO Y OPTIMIZANDO EL STOCK DE REPUESTOS" el objetivo es lograr la eficiencia de inventarios garantizando una entrega oportuna y sin errores. Finalmente, concluyen en la importancia del control de stock en tiempos más cortos, lo que conlleva a menores mermas, a dar curso de acción inmediata por cambios de demanda, además de menores roturas de stock; todo lo anterior impactando positivamente en el nivel de servicio. Así también, se comprobó en la tesis la importancia de controlar los inventarios mediante el cálculo constante de los indicadores, como es el caso de rotación, exactitud de inventarios, y realizar el chequeo constante del inventario físico, lo cual termina impactando en el nivel de servicio.

En la investigación "INVENTORY MANAGEMENT SERVICE LEVEL AND SAFETY STOCK" de Radasanu (2016) proponen un modelo estadístico para el cálculo del stock de seguridad mientras se alcanza el nivel de servicio. Concluye que el modelo efectivamente funciona para determinar los niveles de inventario adecuado, que no generen costos 
operativos excesivos y que al mismo tiempo cumplan con el nivel de servicio propuesto. En contraste, en la presente tesis se pudo encontrar que con un cálculo correcto del inventario de seguridad se reducen los costos de almacenamiento, mermas por manipuleo y stock obsoleto, sin la necesidad de sacrificar el nivel de servicio de cara al cliente. Es por ello, muy relevante comprender los métodos y sus aplicaciones, los cuales aplicados correctamente generan un win-win para cualquier organización. 


\section{CONCLUSIONES}

En conclusión, una mejora en la gestión de inventarios impacta positivamente en el nivel de servicio de una empresa luminaria. Ello debido a que el nivel de servicio fue medido en sus cuatro dimensiones, y en todas ellas el impacto fue positivo.

En primer lugar, las entregas perfectas de la empresa luminaria mejoraron en un $14 \%$, las cuales antes de la mejora eran de $81 \%$, aumentando a $95 \%$. Siguiendo la misma línea, las entregas a tiempo tuvieron un impacto positivo, incrementando su ratio en $27 \%$, desde un $68 \%$ a un $95 \%$. Respecto a las devoluciones el porcentaje se redujo en $13 \%$. Finalmente, el tiempo de ciclo de pedido tuvo una reducción de 1.16 días, lo cual es significativo, pues antes de la mejora el tiempo de ciclo era de 2.46 días, lo cual mejoró a 1.3 días.

Lo que permite deducir que la mejora en la gestión de inventarios y las diversas herramientas que se utilizó para realizarla como es la clasificación $A B C$, los indicadores de rotación para tomar decisiones acertadas sobre lo que ya se mantiene en stock, la evaluación y cálculo del stock de seguridad, lote económico de pedido, punto de re-orden. Además, de la importancia del control de inventarios de forma periódica que permita llevar el modelo de gestión de forma constante. Asimismo, el principal soporte para la mejora que son los colaboradores, por ello la importancia de poseer un plan de capacitación adecuado y mantenerlos comprometidos y motivados. Todo lo anterior impactando directamente en el cliente, lo cual fue medido mediante el indicador de nivel de servicio y sus dimensiones. 


\section{RECOMENDACIONES}

- Se recomienda instaurar un manual de políticas y procedimientos de almacén, creando políticas específicas para cada sub-proceso a detalle, que respete todas las leyes y normativas legal peruana actual existente en operaciones logísticas, se sugiere que se cuente con el apoyo de una consultora especializada para su creación y redacción.

- Además, es importante delimitar el alcance de las operaciones en el manual de políticas y procedimientos de almacén, especificando las limitaciones de las misma, alineándose a las directrices propuestas en el plan estratégico de la empresa, y que sea acorde con la visión y misión de la organización, una vez aprobadas por gerencia, estas deben ser publicadas, comunicadas de manera dinámica y de fácil entendimiento a todo el personal del área. De esta forma, se está incentiva a la creación y establecimiento de compromiso de los operarios de la cadena logística hacia los objetivos de la empresa.

- Para el sub-proceso de transporte se recomienda que se realice una planificación de rutas, de manera tal que se reduzca la distancia de movimiento de mercancías, reduciendo el tiempo y el costo del transporte ya sea externo o interno. De la misma forma, se recomienda considerar que las operaciones logísticas no solo contemplan el apoyo o soporte al producto ofrecido al cliente externo, sino también a las necesidades de transporte interno que tenga la empresa. Se recomienda también que se tenga como objetivo consolidar los despachos y organizarlo por días de la semana, de tal manera que se pueda reducir el uso y costo del transporte.

- De igual forma, coordinar elaborar protocolos de salud y seguridad ocupacional en las operaciones logísticas, no únicamente que se cuente con equipos de protección personal, sino que también con estandarización de procedimientos de carga de materiales livianos o pesados de manera que no se perjudique ergonómicamente a los operarios de almacén y despacho. Así se podrá garantizar su salud, promover el desarrollo sostenible y mantener el compromiso de trabajadores y la empresa con las operaciones logísticas. 
- Se propone también que se establezcan políticas estrictas en recepción de mercaderías y el despacho de las mismas, brindándole el soporte al jefe de área en realización de inspecciones y guardar registro de estas. De esta manera, se podrá realizar cotejo entre antes y después, e identificas si existió una mal manipuleo o mala práctica en el proceso distribución o transporte de productos, ya sea por parte de trabajadores o incluso recepción de mercadería de clientes.

- Se aconseja también coordinar con el área de Recursos Humanos, de manera que las inducciones y capacitaciones se den de manera eficiente y oportunamente, reduciendo así el tiempo de adaptación a cambios en las políticas y estrategias logísticas, ya que se percibió una leve resistencia al cambio en los trabajadores del área.

- Realizar protocolos para posibles situaciones en el área de almacén como proveedores sin factura, indicadores fuera de los rangos, puntos críticos de control, entre otros. Asimismo, realizar un guía con las preguntas frecuentes en el área de almacén. De esta manera, los colaboradores podrán identificar la situación y tomar decisiones acertadas en el momento adecuado y bajo un estándar de acción. Esto ayudaría también a crear un proceso de introducción al puesto de trabajo más amigable.

- Por otro lado, se recomienda brindar a los vendedores herramientas más ágiles como aplicaciones móviles o toma pedidos que actualmente existen en el mercado, de forma que puedan gestionar sus pedidos en tiempo real y con acceso a stock y líneas de crédito actualizadas. Aquello impactando en la motivación de la fuerza de ventas, calidad del servicio prestado y evitando ordenes no atendidas.

- Realizar un nuevo análisis para determinar si se puede continuar aumentando los volúmenes de ventas manteniendo el proceso o requiere nuevas implementaciones o recursos para ello.

- Es recomendable ampliar su gama de proveedores, quienes podrían brindarle los productos con menores costos y menores tiempos de producción, reduciendo los tiempos de aprovisionamiento, lo cual podría reducir los puntos de re-orden y el 
inventario de seguridad, ello teniendo un impacto positivo desde la perspectiva financiera.

- Finalmente, ante la actual coyuntura pandémica se recomienda realizar la investigación respectiva de proveedores considerando localización y facilidad de transporte hacía los puertos principales de China. 


\section{SUGERENCIAS}

- Para futuras investigaciones, se sugiere realizar una exhaustiva revisión a los procesos del área de compras, ya que posee diversas oportunidades de mejora.

- Realizar un análisis semestral de tal manera que se puedan identificar nuevos puntos críticos del proceso de almacenamiento y distribución de productos

- Se sugiere igualmente, identificar nuevos riesgos de seguridad y salud ocupacional, así como impactos ambientales que no fueron contemplados en la propuesta original, así se podrá tener una cultura de seguridad más amplia entre colaboradores y usuarios transportistas.

- Realiza un análisis Costo - Beneficio cada semestre de la propuesta de optimización del proceso de almacenamiento y distribución para identificar y sea reportado a gerencia.

- La presente investigación tiene como primordial objetivo mejorar la gestión logística, se podría estudiar la interacción existente con las demás áreas, de esta manera se podría optimizar las operaciones de la empresa de forma global. 


\section{REFERENCIAS}

Acevedo, J., Maiguel, H. y Salas, K. (2017). Metodología de gestión de inventarios para determinar los niveles de integración y colaboración en una cadena de suministro. Ingeniare. Revista chilena de ingeniería, 25(2), 326-337. Recuperado de: https://dx.doi.org/10.4067/S0718-33052017000200326.

Aguilar, P. (2012). Un modelo de clasificación de inventarios para incrementar el nivel de servicio al cliente y la rentabilidad de la empresa. Centro de Estudios Superiores de Administración, Bogotá. Recuperado de: http://www.scielo.org.co/scielo.php?pid=S1657$\underline{62762012000100007 \& \text { script }=s c i \text { abstract\&tlng }=e s}$

Alonso, A. et al. (2016). Métodos de investigación de enfoque experimental. Recuperado de: http://www.postgradoune.edu.pe/pdf/documentos-academicos/ciencias-de-laeducacion/10.pdf

Arango, J., Castrillón, O. y Giraldo, J. (diciembre de 2013). Gestión de compras e inventarios a partir de pronósticos Holt-Winters y diferenciación de nivel de servicio por clasificación ABC. Scientia et Technica. Año XVIII, 18(4), 743-747.

Ballou, R. (2004). Logística. Administración de la cadena de suministros. Quinta edición, México DC, México: Pearson. Recuperado de: https://ulisesmv1.files.wordpress.com/2015/08/logistica administracion de la cadena de suministro 5ta edicion - ronald h- ballou.pdf

Calle, D., Matute, F. y Yampasi, E. (2016). Rediseño del modelo de gestión de inventario para SINOMAQ S.A.: aumentando el nivel de servicio y optimizando e stock de repuestos (tesis de maestría). Universidad Pacífico, Lima, Perú. Recuperado de: http://repositorio.up.edu.pe/handle/11354/1679

Castillo, L. (2005). Análisis documental. Recuperado de: https://www.uv.es/macas/T5.pdf

Cervantes, R. (2017). Implementación de gestión de inventarios para mejorar el nivel del servicio al cliente en la empresa Lumen Ingeniería S.A.C., Los Olivos 2017 (tesis de 
pregrado). Universidad César Vallejo. Recuperado de: https://pubsonline.informs.org/doi/abs/10.1287/msom.2016.0582

Craig, N., DeHoratius, N., \& Raman, A. (2016). The impact of supplier inventory service level on retailer demand. Harvard Business School. Recuperado de: http://repositorio.ucv.edu.pe/handle/UCV/10078

Creando futuro. (2014). Implementación de las 5 S con enfoque práctico [Imagen]. Recuperado de: https://creandofuturo.org/wp-content/uploads/2014/03/Captura-de-pantalla-201612-29-a-las-18.57.08.png

Durán, Y. (enero - junio 2012). Administración del inventario: elemento clave para la optimización de las utilidades en las empresas. Visión Gerencial. Volumen (1), 55-78.

Goméz, M. (2008). Introducción a la metodología de la investigación científica. Primera edición, Córdoba, Argentina: Editorial Brujas.

Guell, L. (30 de mayo del 2011). Nivel de servicio e inventario. Grupo de Diarios de América. Recuperado de: https://search.proquest.com/docview/868994001\%20?accountid=43847

Hernández, R. Baptista, P. y Fernández, C. (2014). Metodología de la investigación. Sexta edición, México DC, México: Mc Grill.

Hinostroza, M. (2018). Implementación de gestión de inventario para mejorar el nivel de servicio en la empresa GRELCONPERU E.I.R.L., San Juan de Lurigancho, 2018 (tesis de pregrado). Universidad César Vellejo, Lima, Perú. Recuperado de: http://repositorio.ucv.edu.pe/handle/UCV/29354

Mejía, K., Reyes, C. y Sánchez, H. (2018). Manual de términos en investigación científica, tecnológica y humanística, Lima, Perú: Universidad Ricardo Palma.

Mora, L. (2007). Indicadores de la gestión logística. Recuperado de: https://www.fesc.edu.co/portal/archivos/e libros/logistica/ind logistica.pdf

Molina, D. (2015). Gestión de inventarios: una herramienta útil para mejorar la rentabilidad. Universidad FASTA. Recuperado de: 
http://redi.ufasta.edu.ar:8080/xmlui/bitstream/handle/123456789/839/dolores\%20moli na.pdf?sequence $=1$

Orduz, A. (2019). Gestión de inventarios como proceso vital en la rentabilidad, Bogota, Colombia, Universidad Militar Nueva Granada. Recuperado de: https://repository.unimilitar.edu.co/bitstream/handle/10654/20833/OrduzHernandezAn dres2019.pdf.pdf? sequence $=1$ \&isAllowed $=y$

Parada, O. (2009). Un enfoque multicriterio para la toma de decisiones en la gestión de inventarios. Cuadernos de administración. Volumen 22 (38), 169-187. Recuperado de: https://www.redalyc.org/pdf/205/20511730009.pdf

Prado, F. (2018). Aplicación de la gestión de inventarios para mejorar el nivel de servicio del almacén de la empresa productos alimenticios Carter S.A. Ate, 2018 (tesis de pregrado). Universidad César Vallejo, Lima, Perú. Recuperado de: http://repositorio.ucv.edu.pe/handle/UCV/20727

Porto, J. y Merino, M. (2014). Definición de devolución. Recuperado de: https://definicion.de/devolucion/

Radasanu, A. C. (2016). Inventory management, service level and safety stock. Journal of Public Administration, Finance and Law, (2018), 145-153.

Rodriguez, F. y Gomez, L. (1991). Indicadores de calidad y productividad en la empresa. Corporación andina de fomento. Recuperado de: https://scioteca.caf.com/bitstream/handle/123456789/863/Indicadores\%20de\%20calid ad\%20y\%20productividad\%20en\%20la\%20empresa.PDF

Salas-Navarro, K., Maiguel-Mejía, H. y Acevedo-Chedid, J. (2016). Metodología de gestión de inventarios para determinar los niveles de integración y colaboración en una cadena de suministros. Ingeniare - Revista chilena de ingeniería. Volumen 25 (2), pp 326-337.

Sánchez, P. (2015). Optimización de inventarios y nivel de servicio. ESDAI Universidad Panamericana, México. Recuperado de: http://eds.b.ebscohost.com/eds/pdfviewer/pdfviewer?vid=0\&sid=63cba95d-34a84c85-b515-5b9faf906962\%40sessionmgr101 
Schalit, S. y Vermonel, J. (2014). Nivel de servicio (Cadena de suministros). LOKAD. Recuperado de: https://www.lokad.com/es/definicion-nivel-de-servicio

Silva, J. (2018). Aplicación de gestión de inventario en el área logística para mejorar el nivel de servicio al área de producción de la empresa Consorcio Mosaicos \& Anexos Lima S.A.C., San Juan de Lurigancho, 2018 (tesis de pregrado). Universidad César Vallejo, Lima, Perú. Recuperado de: http://repositorio.ucv.edu.pe/handle/UCV/30587

Universidad Militar de Nueva Granada. (s/f.). Gestión de inventarios. Recuperado de: http://virtual.umng.edu.co/distancia/ecosistema/ovas/administracion empresas/logistic a/unidad 3/DM.pdf

Universidad Simón Bolivar. (s/f.). Gestión de inventarios. Recuperado de: http://prof.usb.ve/nbaquero/USB\%20Gestion\%20Inventarios.pdf

Vidal, J. (2010). Fundamentos de control y gestión de inventarios, Santiago de Cali, Colombia: Programa Editorial universidad del Valle.

Zapata, J. (2014). Fundamentos de la gestión de inventarios, Medellín, Colombia: Centro Editorial Esumer. 
Anexo I. Matriz de operacionalización.

\begin{tabular}{|c|c|c|c|c|c|c|c|}
\hline VARIABLES & DEFINICIÓN CONCEPTUAL & $\begin{array}{c}\text { DEFINICIÓN } \\
\text { OPERACIONAL }\end{array}$ & $\begin{array}{l}\text { INDICA } \\
\text { DORES }\end{array}$ & TÉCNICA & $\begin{array}{l}\text { INSTRU } \\
\text { MENTO }\end{array}$ & $\begin{array}{l}\text { UNIDAD } \\
\text { DE } \\
\text { MEDIDA }\end{array}$ & FÓRMULA \\
\hline $\begin{array}{l}\text { V.I.: MEJORA EN } \\
\text { LA GESTIÓN DE } \\
\text { INVENTARIOS }\end{array}$ & $\begin{array}{l}\text { En el entorno empresarial se } \\
\text { conoce la gestión de } \\
\text { inventario como al proceso } \\
\text { encargado de asegurar la } \\
\text { cantidad de productos } \\
\text { adecuados la } \\
\text { organización, de tal manera } \\
\text { que se pueda asegurar la } \\
\text { operación continua de los } \\
\text { procesos de comercialización } \\
\text { de productos a los clientes; es } \\
\text { decir, asegura que las } \\
\text { operaciones de manufacturay } \\
\text { distribución no se detengan, } \\
\text { cumpliendo con las promesas } \\
\text { de entrega de productos a los } \\
\text { clientes. (Zapata, 2014) }\end{array}$ & $\begin{array}{l}\text { La gestión de } \\
\text { inventarios en la } \\
\text { empresa objeto de } \\
\text { estudio es }\end{array}$ & $\begin{array}{c}0=\text { No se } \\
\text { mejora } \\
1=\mathrm{Se} \\
\text { mejora }\end{array}$ & $\begin{array}{l}\text { Observación } \\
\text { y búsqueda } \\
\text { documental }\end{array}$ & $\begin{array}{l}\text { Observación } \\
\text { Reportes }\end{array}$ & & \\
\hline
\end{tabular}


El aspecto de nivel de servicio

relacionado

con

la

se refiere al hecho de

satisfacer el cliente mediante

V.D.:NIVEL DE

SERVICIO

el cumplimiento de su

demanda; es decir,

asegurando que siempre que

éste solicite material, se le

abastezca sin ningún

inconveniente. (Zapata, 2014) disponibilidad de materiales

Para la empresa el nivel de servicio es un ratio muy relevante pues demuestra su capacidad para responder a las necesidades de sus clientes en $\mathrm{el}$ momento y de la forma en que lo soliciten.

\section{DIMENSIONES}

Cantidad de órdenes que se atienden perfectamente por una compañía y se considera que una orden es atendida de forma perfecta cuando cumple

con las siguientes características
Las

para la

en cuestión

representan los

pedidos entregados

con cada uno de los artículos solicitados, empresa luminaria

Para encontrar el nivel de servicio óptimo se debe maximizar la contribución a las utilidades netas

$$
\operatorname{Max} U N
$$

Lo que equivale a

$$
\Delta U B=\Delta C L
$$

(cuando los $\Delta x$ son iguales)

\section{Análisis \\ documental}

Solver

\section{Porcentaje}

$\Delta U B=$ Cambio en la utilidad

bruta por incrementar el nivel de

servicio en $\Delta x$

$\Delta C L=$ Cambio en los costos

logisticos por incrementar el

nivel de servicio en $\Delta x$

$\Delta x=$ Porcentaje a incrementar

\section{$\%$ de \\ pedidos \\ entregados \\ Análisis Paquete de \\ documental reportes \\ Porcentaje}

según lo
Pedidos entregados

$$
\begin{aligned}
& \text { perfectos } \\
& \text { Total de pedidos } \times 100 \\
& \text { entregados }
\end{aligned}
$$


- La entrega es en la fecha completa, todos los establecida, con la artículos se entregan documentación a las cantidades correcta y bajo todas solicitadas. las especificaciones

Este indicador mide el nivel de ENTREGAS A TIEMPO cumplimento de la compañía para realizas la entrega de los $\%$ de
pedidos
entregados Análisis documental
- La fecha de la entrega es la estipulada por el cliente.

- La documentación que acompaña la entrega es completa y exacta.

- Los artículos se encuentran en perfectas

condiciones físicas.

- La presentación y equipo de transporte utilizado es el adecuado en la entrega al cliente. (Mora, 2007) La empresa en investigación indicador como e que cada cliente puede solicitar.

pedidos en la fecha o periodo
Pedidos entregados

$$
\begin{gathered}
\text { a tiempo } \\
\text { entre de pedidos }
\end{gathered} \times 100
$$


de tiempo pactado con el porcentaje en que se cliente. (Mora, 2007)

En el ámbito del comercio, la cuando un comprador no

DEVOLUCIONES mercadería recibida y decide

\section{TIEMPO DE} CICLO DE PEDIDO idea de devolución se aplica queda conforme con la regresarla al vendedor. (Porto, 2014)

El presente indicador representa para la empresa el porcentaje en que las ordenes son devueltas porque el cliente se encuentra descontento con la misma.$$
\text { La }
$$$$
\text { empresa }
$$

Número medio de días calendario desde que el cliente realiza el pedido, hasta que se entrega el mismo. (Mora, 2007)

este indicador como

el tiempo en que una

orden es emitida

hasta que es

recepcionada por el cumple la entrega de las ordenes en el periodo establecido con el comprador.

en la fecha

acordada

\section{$\%$ de \\ pedidos}

regresados

a la

Análisis Paquete de

documental reportes

empresa

Promedio

de días

luminaria considera entre la

cliente. solicitud de

la orden de

compra y

la entrega

física al

cliente.
Devolución de $\frac{\text { pedidos en soles }}{\text { Total de pedidos }} \times 100$ entregados en soles 
Anexo II: Rotación de inventario por SKU

\begin{tabular}{|c|c|c|c|c|}
\hline Artículos & Unidades vendidas & Inventario promedio & Rotación & Días \\
\hline ESENCIALES & 238672 & 69216 & 3.45 & 106 \\
\hline BULBOS ALTA POTENCIA & 1485 & 1178 & 1.26 & 289 \\
\hline T15060W-D & 590 & 606 & 0.97 & 375 \\
\hline T15080W-D & 895 & 572 & 1.56 & 233 \\
\hline BULBOS FILAMENT & 1507 & 396 & 3.80 & 96 \\
\hline G1258WF-C & 1507 & 857 & 1.76 & 208 \\
\hline BULBOS LED & 45877 & 12933 & 3.55 & 103 \\
\hline A6012W-C & 3406 & 771 & 4.42 & 83 \\
\hline A6012W-D & 15146 & 1791 & 8.46 & 43 \\
\hline A606W-C & 2797 & 1321 & 2.12 & 172 \\
\hline A606W-D & 19769 & 9995 & 1.98 & 185 \\
\hline A6518W-C & 0 & 2813 & 0.00 & 0 \\
\hline A6518W-D & 4759 & 1283 & 3.71 & 98 \\
\hline DICROICOS LED & 84411 & 17393 & 4.85 & 75 \\
\hline L39MR16B-C & 8221 & 1705 & 4.82 & 76 \\
\hline L39MR16B-D & 14132 & 2548 & 5.55 & 66 \\
\hline L7G1B-C & 4807 & 774 & 6.21 & 59 \\
\hline L7G1B-D & 3676 & 1832 & 2.01 & 182 \\
\hline L7MR16B-C & 7332 & 764 & 9.60 & 38 \\
\hline L7MR16B-D & 10245 & 2294 & 4.47 & 82 \\
\hline LD10G1C-C & 10012 & 1520 & 6.59 & 55 \\
\hline LD10G1C-D & 5176 & 1984 & 2.61 & 140 \\
\hline LD10MR16C-C & 8675 & 1589 & 5.46 & 67 \\
\hline LD10MR16C-D & 12135 & 5703 & 2.13 & 172 \\
\hline ECLIPSE & 33885 & 3059 & 11.08 & 33 \\
\hline ECL18W-C & 2596 & 555 & 4.68 & 78 \\
\hline ECL18W-D & 11760 & 945 & 12.44 & 29 \\
\hline ECL36W-C & 1784 & 433 & 4.12 & 89 \\
\hline ECL36W-D & 8309 & 843 & 9.86 & 37 \\
\hline ECL48W-C & 1604 & 512 & 3.13 & 117 \\
\hline ECL48W-D & 7832 & 836 & 9.37 & 39 \\
\hline GLOBOS LED & 6914 & 6602 & 1.05 & 349 \\
\hline FG19W-D & 4617 & 1998 & 2.31 & 158 \\
\hline FG26W-C & 10 & 1 & 10.00 & 37 \\
\hline FG26W-D & 2287 & 2919 & 0.78 & 466 \\
\hline FGN26W-D & 0 & 1992 & 0.00 & 0 \\
\hline OCTOGONALES CLASICOS & 0 & 243 & 0.00 & 0 \\
\hline PR8WEO-C & 0 & 26 & 0.00 & 0 \\
\hline PR8WEO-D & 0 & 217 & 0.00 & 0 \\
\hline OCTOGONALES PRESS \& FIT & 20973 & 11908 & 1.76 & 207 \\
\hline APFDOR & 735 & 2279 & 0.32 & 1132 \\
\hline
\end{tabular}




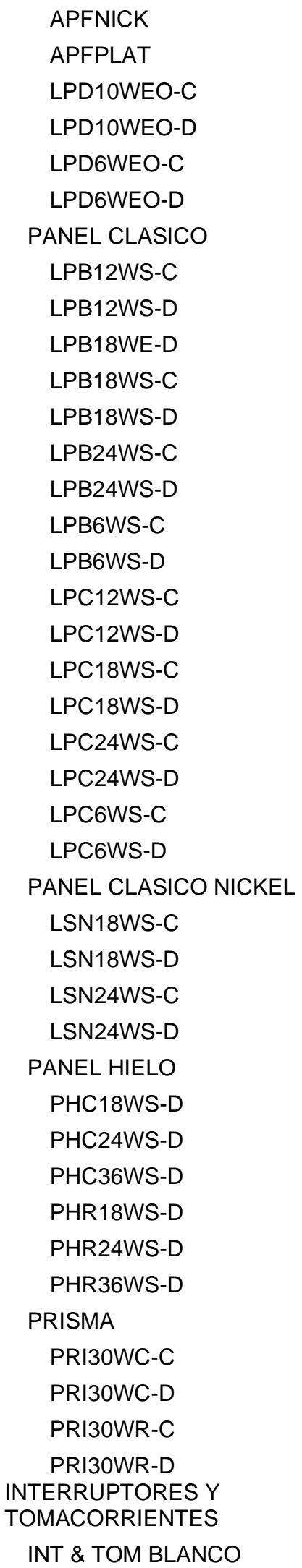

\begin{tabular}{|c|c|c|c|}
\hline 1429 & 2673 & 0.53 & 683 \\
\hline 100 & 879 & 0.11 & 3208 \\
\hline 2604 & 1633 & 1.59 & 229 \\
\hline 5067 & 1923 & 2.64 & 138 \\
\hline 3418 & 968 & 3.53 & 103 \\
\hline 7620 & 1837 & 4.15 & 88 \\
\hline 36582 & 12134 & 3.01 & 121 \\
\hline 590 & 617 & 0.96 & 382 \\
\hline 5576 & 1143 & 4.88 & 75 \\
\hline 1159 & 170 & 6.80 & 54 \\
\hline 700 & 1285 & 0.54 & 670 \\
\hline 12606 & 3325 & 3.79 & 96 \\
\hline 540 & 746 & 0.72 & 504 \\
\hline 7754 & 2023 & 3.83 & 95 \\
\hline 0 & 686 & 0.00 & 0 \\
\hline 2890 & 666 & 4.34 & 84 \\
\hline 0 & 282 & 0.00 & 0 \\
\hline 255 & 1542 & 0.17 & 2207 \\
\hline 418 & 207 & 2.02 & 181 \\
\hline 2264 & 1216 & 1.86 & 196 \\
\hline 30 & 412 & 0.07 & 5009 \\
\hline 1605 & 1157 & 1.39 & 263 \\
\hline 81 & 493 & 0.16 & 2223 \\
\hline 114 & 579 & 0.20 & 1854 \\
\hline 2131 & 3062 & 0.70 & 524 \\
\hline 125 & 374 & 0.33 & 1092 \\
\hline 966 & 1235 & 0.78 & 467 \\
\hline 165 & 212 & 0.78 & 468 \\
\hline 875 & 1429 & 0.61 & 596 \\
\hline 2627 & 4918 & 0.53 & 683 \\
\hline 305 & 694 & 0.44 & 831 \\
\hline 235 & 764 & 0.31 & 1187 \\
\hline 183 & 816 & 0.22 & 1628 \\
\hline 711 & 1787 & 0.40 & 917 \\
\hline 716 & 2282 & 0.31 & 1163 \\
\hline 477 & 1747 & 0.27 & 1336 \\
\hline 2280 & 2548 & 0.89 & 408 \\
\hline 250 & 370 & 0.68 & 540 \\
\hline 743 & 936 & 0.79 & 460 \\
\hline 360 & 312 & 1.16 & 316 \\
\hline 927 & 931 & 1.00 & 366 \\
\hline 59487 & 128463 & 0.46 & 788 \\
\hline 47450 & 52211 & 0.91 & 402 \\
\hline
\end{tabular}




\begin{tabular}{|c|c|c|c|c|}
\hline PCW-30301 & 9290 & 4825 & 1.93 & 190 \\
\hline PCW-30302 & 3289 & 2861 & 1.15 & 318 \\
\hline PCW-30303 & 776 & 1367 & 0.57 & 643 \\
\hline PCW-30401 & 2967 & 223 & 13.32 & 27 \\
\hline PCW-30402 & 1604 & 571 & 2.81 & 130 \\
\hline PCW-30501 & 235 & 93 & 2.53 & 144 \\
\hline PCW-30502 & 681 & 834 & 0.82 & 447 \\
\hline PCW-40301 & 3085 & 4192 & 0.74 & 496 \\
\hline PCW-40303 & 20374 & 7660 & 2.66 & 137 \\
\hline PCW-40401 & 1100 & 518 & 2.12 & 172 \\
\hline PCW-40402 & 246 & 752 & 0.33 & 1116 \\
\hline PCW-40403 & 880 & 356 & 2.47 & 148 \\
\hline PCW-50301 & 1750 & 3621 & 0.48 & 755 \\
\hline PCW-60600 & 553 & 580 & 0.95 & 383 \\
\hline PCW-60601 & 380 & 23866 & 0.02 & 22924 \\
\hline INT \& TOM GRIS & 234 & 5555 & 0.04 & 8665 \\
\hline PCG-30303 & 0 & 17 & 0.00 & 0 \\
\hline PCG-30401 & 0 & 400 & 0.00 & 0 \\
\hline PCG-30402 & 0 & 129 & 0.00 & 0 \\
\hline PCG-30403 & 10 & 248 & 0.04 & 9041 \\
\hline PCG-30501 & 4 & 494 & 0.01 & 45063 \\
\hline PCG-30502 & 0 & 11 & 0.00 & 0 \\
\hline PCG-40301 & 10 & 727 & 0.01 & 26527 \\
\hline PCG-40401 & 50 & 47 & 1.06 & 343 \\
\hline PCG-40402 & 0 & 449 & 0.00 & 0 \\
\hline PCG-40403 & 0 & 150 & 0.00 & 0 \\
\hline PCG-50301 & 0 & 734 & 0.00 & 0 \\
\hline PCG-60600 & 60 & 1642 & 0.04 & 9990 \\
\hline PCG-60601 & 0 & 723 & 0.00 & 0 \\
\hline INT \& TOM MARFIL & 7595 & 40163 & 0.19 & 1930 \\
\hline PC-30301 & 1410 & 3667 & 0.38 & 949 \\
\hline PC-30302 & 630 & 1536 & 0.41 & 890 \\
\hline PC-30303 & 190 & 2128 & 0.09 & 4088 \\
\hline PC-30401 & 320 & 738 & 0.43 & 842 \\
\hline PC-30402 & 220 & 1584 & 0.14 & 2627 \\
\hline PC-30403 & 20 & 71 & 0.28 & 1300 \\
\hline PC-30501 & 230 & 466 & 0.49 & 739 \\
\hline PC-30502 & 80 & 162 & 0.49 & 739 \\
\hline PC-40301 & 625 & 3758 & 0.17 & 2195 \\
\hline PC-40303 & 3160 & 3092 & 1.02 & 357 \\
\hline PC-40401 & 290 & 622 & 0.47 & 783 \\
\hline PC-40402 & 20 & 2140 & 0.01 & 39058 \\
\hline PC-40403 & 70 & 1002 & 0.07 & 5224 \\
\hline PC-50301 & 180 & 5815 & 0.03 & 11791 \\
\hline
\end{tabular}




\begin{tabular}{|c|c|c|c|c|}
\hline PC-60600 & 50 & 5561 & 0.01 & 40592 \\
\hline PC-60601 & 100 & 7820 & 0.01 & 28545 \\
\hline INT \& TOM PLACAS DE COLORES & 4208 & 30534 & 0.14 & 2649 \\
\hline PC-70701 & 598 & 3908 & 0.15 & 2385 \\
\hline PC-70702 & 344 & 1169 & 0.29 & 1241 \\
\hline PC-70703 & 646 & 4037 & 0.16 & 2281 \\
\hline PC-70704 & 769 & 429 & 1.79 & 203 \\
\hline PC-70705 & 751 & 5165 & 0.15 & 2510 \\
\hline PC-70706 & 193 & 2688 & 0.07 & 5083 \\
\hline PC-70707 & 258 & 3186 & 0.08 & 4507 \\
\hline PC-70708 & 198 & 5903 & 0.03 & 10883 \\
\hline PC-70709 & 243 & 2040 & 0.12 & 3065 \\
\hline PC-70710 & 208 & 2240 & 0.09 & 3931 \\
\hline LAVES TERMICAS & 7934 & 10298 & 0.77 & 474 \\
\hline LLAVES TERMICAS & 7934 & 10298 & 0.77 & 474 \\
\hline R103100 & 87 & 57 & 1.52 & 241 \\
\hline $\mathrm{R} 103125$ & 38 & 155 & 0.25 & 1487 \\
\hline R10380 & 52 & 69 & 0.75 & 484 \\
\hline $\mathrm{R} 6 \mathrm{C} 102$ & 48 & 184 & 0.26 & 1396 \\
\hline $\mathrm{R} 6 \mathrm{C} 110$ & 12 & 18 & 0.67 & 548 \\
\hline $\mathrm{R} 6 \mathrm{C} 120$ & 0 & 178 & 0.00 & 0 \\
\hline $\mathrm{R} 6 \mathrm{C} 132$ & 24 & 180 & 0.13 & 2743 \\
\hline $\mathrm{R} 6 \mathrm{C} 150$ & 0 & 110 & 0.00 & 0 \\
\hline $\mathrm{R} 6 \mathrm{C} 163$ & 0 & 19 & 0.00 & 0 \\
\hline $\mathrm{R} 6 \mathrm{C} 210$ & 115 & 45 & 2.53 & 144 \\
\hline $\mathrm{R} 6 \mathrm{C} 216$ & 979 & 398 & 2.46 & 148 \\
\hline $\mathrm{R} 6 \mathrm{C} 220$ & 1458 & 707 & 2.06 & 177 \\
\hline $\mathrm{R} 6 \mathrm{C} 225$ & 518 & 115 & 4.51 & 81 \\
\hline $\mathrm{R} 6 \mathrm{C} 232$ & 1431 & 1019 & 1.40 & 260 \\
\hline $\mathrm{R} 6 \mathrm{C} 240$ & 273 & 699 & 0.39 & 935 \\
\hline $\mathrm{R} 6 \mathrm{C} 250$ & 54 & 417 & 0.13 & 2815 \\
\hline $\mathrm{R} 6 \mathrm{C} 263$ & 182 & 990 & 0.18 & 1985 \\
\hline $\mathrm{R} 6 \mathrm{C} 310$ & 10 & 145 & 0.07 & 5284 \\
\hline R6C316 & 14 & 668 & 0.02 & 17422 \\
\hline R6C320 & 54 & 400 & 0.14 & 2704 \\
\hline $\mathrm{R} 6 \mathrm{C} 325$ & 42 & 307 & 0.14 & 2672 \\
\hline R6C332 & 184 & 862 & 0.21 & 1710 \\
\hline $\mathrm{R} 6 \mathrm{C} 340$ & 154 & 279 & 0.55 & 661 \\
\hline $\mathrm{R} 6 \mathrm{C} 350$ & 22 & 280 & 0.08 & 4648 \\
\hline R6C363 & 191 & 598 & 0.32 & 1144 \\
\hline RC6K216 & 0 & 38 & 0.00 & 0 \\
\hline RC6K220 & 21 & 75 & 0.28 & 1312 \\
\hline RC6K232 & 9 & 103 & 0.09 & 4171 \\
\hline RD30216 & 59 & 32 & 1.82 & 200 \\
\hline
\end{tabular}




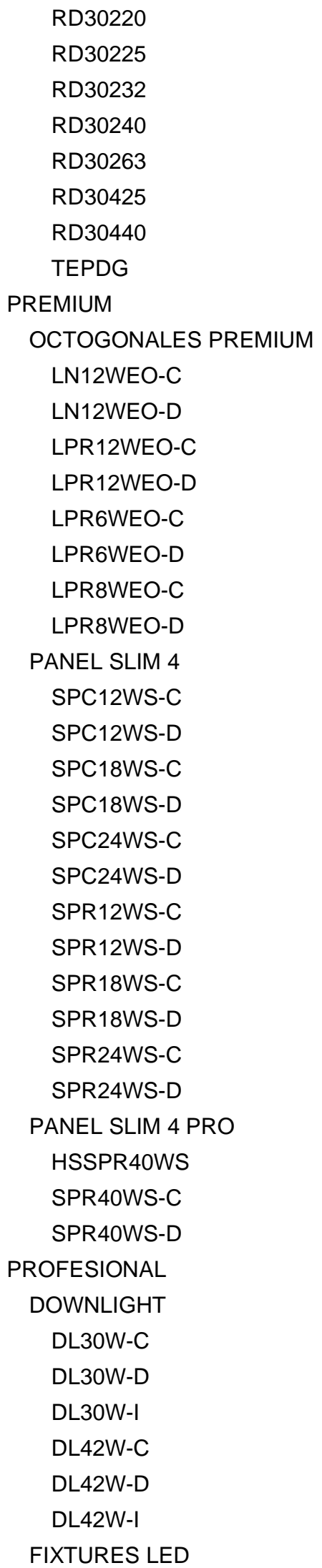

\begin{tabular}{|c|c|c|c|}
\hline 70 & 142 & 0.49 & 741 \\
\hline 1287 & 665 & 1.94 & 189 \\
\hline 60 & 24 & 2.50 & 146 \\
\hline 282 & 158 & 1.78 & 205 \\
\hline 28 & 165 & 0.17 & 2153 \\
\hline 15 & 65 & 0.23 & 1572 \\
\hline 1 & 1 & 1.00 & 365 \\
\hline 160 & 237 & 0.68 & 540 \\
\hline 74527 & 24454 & 3.05 & 120 \\
\hline 54983 & 19779 & 2.78 & 131 \\
\hline 0 & 3447 & 0.00 & 0 \\
\hline 0 & 5321 & 0.00 & 0 \\
\hline 5633 & 2787 & 2.02 & 181 \\
\hline 12433 & 4709 & 2.64 & 138 \\
\hline 0 & 90 & 0.00 & 0 \\
\hline 0 & 1276 & 0.00 & 0 \\
\hline 16901 & 3776 & 4.48 & 82 \\
\hline 20016 & 9759 & 2.05 & 178 \\
\hline 16430 & 4674 & 3.52 & 104 \\
\hline 218 & 214 & 1.02 & 358 \\
\hline 350 & 458 & 0.76 & 478 \\
\hline 916 & 231 & 3.97 & 92 \\
\hline 2141 & 899 & 2.38 & 153 \\
\hline 988 & 247 & 4.00 & 91 \\
\hline 2042 & 728 & 2.80 & 130 \\
\hline 290 & 104 & 2.79 & 131 \\
\hline 564 & 231 & 2.44 & 149 \\
\hline 1353 & 428 & 3.16 & 115 \\
\hline 3680 & 839 & 4.39 & 83 \\
\hline 1105 & 356 & 3.11 & 118 \\
\hline 2783 & 1551 & 1.79 & 203 \\
\hline 3114 & 3122 & 1.00 & 366 \\
\hline 498 & 321 & 1.55 & 235 \\
\hline 764 & 1115 & 0.68 & 533 \\
\hline 1852 & 1686 & 1.10 & 332 \\
\hline 28584 & 22527 & 1.27 & 288 \\
\hline 3259 & 4908 & 0.66 & 550 \\
\hline 255 & 26 & 9.77 & 37 \\
\hline 783 & 959 & 0.82 & 447 \\
\hline 383 & 406 & 0.94 & 387 \\
\hline 294 & 50 & 5.87 & 62 \\
\hline 1239 & 2226 & 0.56 & 656 \\
\hline 305 & 1327 & 0.23 & 1588 \\
\hline 3502 & 1383 & 2.53 & 144 \\
\hline
\end{tabular}




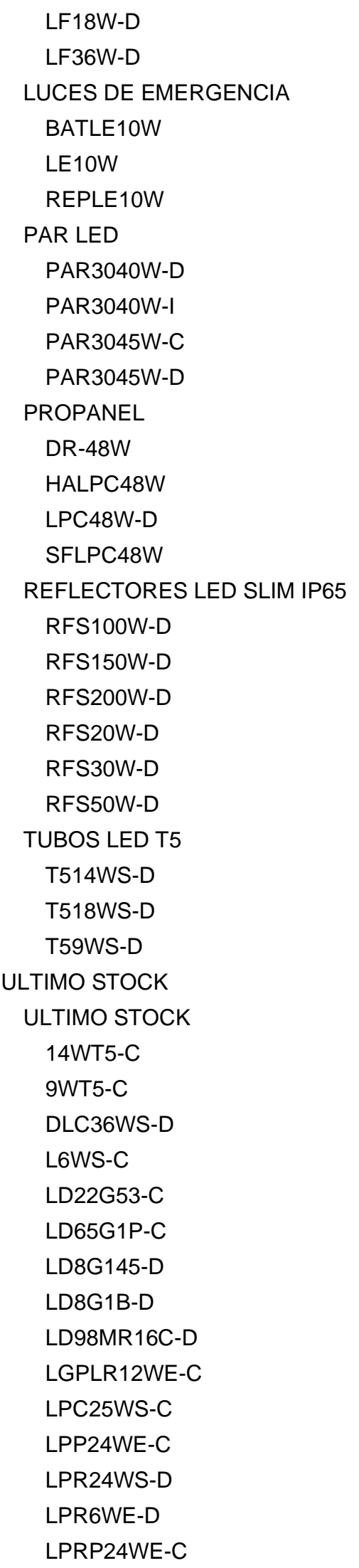

\begin{tabular}{|c|c|c|c|}
\hline 1495 & 760 & 1.97 & 186 \\
\hline 2007 & 813 & 2.47 & 148 \\
\hline 979 & 1455 & 0.67 & 542 \\
\hline 0 & 106 & 0.00 & 0 \\
\hline 979 & 1400 & 0.70 & 522 \\
\hline 0 & 5 & 0.00 & 0 \\
\hline 2638 & 1484 & 1.78 & 205 \\
\hline 1972 & 474 & 4.16 & 88 \\
\hline 666 & 581 & 1.15 & 318 \\
\hline 0 & 1668 & 0.00 & 0 \\
\hline 0 & 2628 & 0.00 & 0 \\
\hline 1183 & 508 & 2.33 & 157 \\
\hline 0 & 15 & 0.00 & 0 \\
\hline 0 & 399 & 0.00 & 0 \\
\hline 1183 & 482 & 2.46 & 149 \\
\hline 0 & 244 & 0.00 & 0 \\
\hline 9914 & 6959 & 1.42 & 256 \\
\hline 2313 & 915 & 2.53 & 144 \\
\hline 612 & 267 & 2.29 & 159 \\
\hline 1485 & 682 & 2.18 & 168 \\
\hline 1165 & 407 & 2.87 & 127 \\
\hline 1004 & 1065 & 0.94 & 387 \\
\hline 3335 & 3623 & 0.92 & 397 \\
\hline 7109 & 7887 & 0.90 & 405 \\
\hline 2548 & 2481 & 1.03 & 355 \\
\hline 2351 & 2052 & 1.15 & 319 \\
\hline 2210 & 3355 & 0.66 & 554 \\
\hline 2230 & 30161 & 0.07 & 4937 \\
\hline 2230 & 30161 & 0.07 & 4937 \\
\hline 0 & 5 & 0.00 & 0 \\
\hline 25 & 55 & 0.45 & 803 \\
\hline 0 & 13 & 0.00 & 0 \\
\hline 0 & 288 & 0.00 & 0 \\
\hline 0 & 1 & 0.00 & 0 \\
\hline 0 & 2 & 0.00 & 0 \\
\hline 10 & 20 & 0.50 & 730 \\
\hline 0 & 1 & 0.00 & 0 \\
\hline 0 & 1 & 0.00 & 0 \\
\hline 0 & 2 & 0.00 & 0 \\
\hline 10 & 146 & 0.07 & 5339 \\
\hline 0 & 5 & 0.00 & 0 \\
\hline 0 & 186 & 0.00 & 0 \\
\hline 0 & 3 & 0.00 & 0 \\
\hline 0 & 3 & 0.00 & 0 \\
\hline
\end{tabular}




\begin{tabular}{|c|c|c|c|c|}
\hline LPRP24WE-D & 0 & 3 & 0.00 & 0 \\
\hline LSSPLR12WS-D & 0 & 2 & 0.00 & 0 \\
\hline LSSPLR18WE-D & 0 & 2 & 0.00 & 0 \\
\hline LSSPLR18WS-C & 2 & 9 & 0.23 & 1558 \\
\hline LSSPLR6WS-C & 0 & 1 & 0.00 & 0 \\
\hline LTL30W-C & 263 & 48 & 5.52 & 66 \\
\hline PC-70711 & 120 & 50 & 2.39 & 153 \\
\hline PL-30301 & 0 & 82 & 0.00 & 0 \\
\hline PL-30401 & 0 & 154 & 0.00 & 0 \\
\hline PL-40301 & 100 & 6517 & 0.02 & 23787 \\
\hline PL-40403 & 0 & 164 & 0.00 & 0 \\
\hline PL-50301 & 100 & 6841 & 0.01 & 24969 \\
\hline PL-60600 & 0 & 288 & 0.00 & 0 \\
\hline PL-60601 & 0 & 15165 & 0.00 & 0 \\
\hline PS18WE-D & 813 & 380 & 2.14 & 171 \\
\hline PS6WE-D & 265 & 678 & 0.39 & 934 \\
\hline RL100W-D & 0 & 3 & 0.00 & 0 \\
\hline ZM536B & 0 & 4 & 0.00 & 0 \\
\hline
\end{tabular}


Anexo III. Indicadores de política de revisión continua de inventarios.

\begin{tabular}{|c|c|c|c|}
\hline Artículo & Stock de seguridad & $\mathrm{EOQ}$ & Punto de re-orden \\
\hline \multicolumn{4}{|l|}{ ESENCIALES } \\
\hline \multicolumn{4}{|l|}{ BULBOS ALTA POTENCIA } \\
\hline T15060W-D & 31 & 520 & 214 \\
\hline T15080W-D & 45 & 557 & 317 \\
\hline \multicolumn{4}{|l|}{ BULBOS FILAMENT } \\
\hline G1258WF-C & 108 & 1538 & 754 \\
\hline \multicolumn{4}{|l|}{ BULBOS LED } \\
\hline A6012W-C & 245 & 3724 & 1714 \\
\hline A6012W-D & 947 & 6973 & 6626 \\
\hline A606W-C & 158 & 2987 & 1107 \\
\hline A606W-D & 899 & 9392 & 6290 \\
\hline A6518W-D & 297 & 3328 & 2080 \\
\hline \multicolumn{4}{|l|}{ DICROICOS LED } \\
\hline L39MR16B-C & 585 & 8143 & 4096 \\
\hline L39MR16B-D & 702 & 8188 & 4912 \\
\hline L7G1B-C & 389 & 5408 & 2721 \\
\hline L7G1B-D & 190 & 3588 & 1332 \\
\hline L7MR16B-C & 584 & 5159 & 4089 \\
\hline L7MR16B-D & 493 & 6168 & 3451 \\
\hline LD10G1C-C & 584 & 4337 & 4085 \\
\hline LD10G1C-D & 292 & 3670 & 2044 \\
\hline LD10MR16C-C & 548 & 4258 & 3838 \\
\hline LD10MR16C-D & 471 & 4555 & 3295 \\
\hline \multicolumn{4}{|l|}{ ECLIPSE } \\
\hline ECL18W-C & 135 & 1793 & 945 \\
\hline ECL18W-D & 648 & 4053 & 4538 \\
\hline ECL36W-C & 83 & 1059 & 582 \\
\hline ECL36W-D & 452 & 3008 & 3161 \\
\hline ECL48W-C & 69 & 883 & 482 \\
\hline ECL48W-D & 427 & 2543 & 2987 \\
\hline \multicolumn{4}{|l|}{ GLOBOS LED } \\
\hline FG19W-D & 210 & 2059 & 1468 \\
\hline FG26W-D & 98 & 1074 & 686 \\
\hline \multicolumn{4}{|c|}{ OCTOGONALES PRESS \& FIT } \\
\hline APFDOR & 44 & 1613 & 309 \\
\hline APFNICK & 61 & 2247 & 427 \\
\hline APFPLAT & 20 & 740 & 140 \\
\hline LPD10WEO-C & 112 & 1701 & 781 \\
\hline LPD10WEO-D & 210 & 2384 & 1468 \\
\hline LPD6WEO-C & 153 & 2248 & 1070 \\
\hline LPD6WEO-D & 325 & 3340 & 2277 \\
\hline
\end{tabular}


PANEL CLASICO

LPB12WS-C

LPB12WS-D

LPB18WE-D

LPB18WS-C

LPB18WS-D

LPB24WS-C

LPB24WS-D

LPB6WS-D

LPC12WS-C

LPC12WS-D

LPC18WS-C

LPC18WS-D

LPC24WS-C

LPC24WS-D

LPC6WS-C

LPC6WS-D

\begin{tabular}{|c|c|c|}
\hline 83 & 1695 & 578 \\
\hline 303 & 3363 & 2123 \\
\hline 145 & 1824 & 1014 \\
\hline 48 & 1321 & 333 \\
\hline 610 & 3907 & 4272 \\
\hline 68 & 957 & 478 \\
\hline 335 & 2278 & 2346 \\
\hline 120 & 2162 & 837 \\
\hline 10 & 0 & 70 \\
\hline 49 & 820 & 341 \\
\hline 53 & 477 & 368 \\
\hline 86 & 1207 & 599 \\
\hline 13 & 214 & $8 \varepsilon$ \\
\hline 59 & 1073 & 411 \\
\hline 17 & 314 & 117 \\
\hline 16 & 396 & 113 \\
\hline 63 & 1024 & 438 \\
\hline 483 & 2847 & 3381 \\
\hline 83 & 973 & 578 \\
\hline 438 & 2241 & 306 \\
\hline 153 & 1681 & 1068 \\
\hline 118 & 1254 & 823 \\
\hline 92 & 870 & 641 \\
\hline 356 & 2657 & 2489 \\
\hline 358 & 2314 & 2506 \\
\hline 239 & 1509 & 1670 \\
\hline
\end{tabular}

PHR36WS-D

LSN18WS-C

LSN18WS-D

LSN24WS-C

LSN24WS-D

PANEL HIELO

PHC18WS-D

PHC24WS-D

PHC36WS-D

PHR18WS-D

PHR24WS-D

RISMA

PRI30WC-C

14

PRI30WC-D

PRI30WR-C

PRI30WR-D

LLAVES TERMICAS

LLAVES TERMICAS

R103100

R103125

$\mathrm{R} 10380$

$\mathrm{R} 6 \mathrm{C} 102$

$\mathrm{R} 6 \mathrm{C} 110$

$\mathrm{R} 6 \mathrm{C} 132$

$\mathrm{R} 6 \mathrm{C} 210$

R6C216

36

20

42

7

5

9

12

6

12

12

47
2123

1014

333

4272

478

346

837

70

341

368

599

88

411

117

113

438

3381

578

063

1068

823

641

489

1670

95

249

142

291

585

51

33

61

84

42

84

82

329 


\begin{tabular}{|c|c|c|c|}
\hline R6C220 & 59 & 1405 & 412 \\
\hline R6C225 & 26 & 844 & 181 \\
\hline R6C232 & 60 & 1486 & 417 \\
\hline $\mathrm{R} 6 \mathrm{C} 240$ & 16 & 605 & 113 \\
\hline R6C250 & 4 & 263 & 30 \\
\hline R6C263 & 10 & 504 & 71 \\
\hline $\mathrm{R} 6 \mathrm{C} 310$ & 5 & 1132 & 35 \\
\hline R6C316 & 4 & 183 & 25 \\
\hline R6C320 & 5 & 368 & 33 \\
\hline $\mathrm{R} 6 \mathrm{C} 325$ & 4 & 357 & 26 \\
\hline R6C332 & 8 & 540 & 57 \\
\hline $\mathrm{R} 6 \mathrm{C} 340$ & 9 & 363 & 65 \\
\hline R6C350 & 4 & 167 & 26 \\
\hline R6C363 & 9 & 497 & 60 \\
\hline RC6K220 & 3 & 834 & 18 \\
\hline RC6K232 & 2 & 589 & 16 \\
\hline RD30216 & 10 & 268 & 69 \\
\hline RD30220 & 12 & 161 & 82 \\
\hline RD30225 & 49 & 704 & 341 \\
\hline RD30232 & 10 & 369 & 70 \\
\hline RD30240 & 17 & 324 & 118 \\
\hline RD30263 & 4 & 111 & 25 \\
\hline RD30425 & 2 & 494 & 14 \\
\hline RD30440 & 1 & 65 & 4 \\
\hline TEPDG & 10 & 199 & 67 \\
\hline \multicolumn{4}{|l|}{ EMIUM } \\
\hline \multicolumn{4}{|c|}{ TOGONALES PREMIUM } \\
\hline LPR12WEO-C & 313 & 3359 & 2193 \\
\hline LPR12WEO-D & 707 & 4990 & 4951 \\
\hline LPR8WEO-C & 824 & 5804 & 5766 \\
\hline LPR8WEO-D & 864 & 5552 & 6046 \\
\hline \multicolumn{4}{|l|}{ NEL SLIM 4} \\
\hline SPC12WS-C & 109 & 1085 & 763 \\
\hline SPC12WS-D & 175 & 1374 & 1225 \\
\hline SPR12WS-C & 145 & 1328 & 1015 \\
\hline SPR12WS-D & 282 & 1852 & 1974 \\
\hline \multicolumn{4}{|l|}{ NEL SLIM 4 PRO } \\
\hline HSSPR40WS & 249 & 1974 & 1743 \\
\hline SPR40WS-C & 361 & 845 & 2527 \\
\hline SPR40WS-D & 837 & 1207 & 5859 \\
\hline \multicolumn{4}{|l|}{ OFESIONAL } \\
\hline \multicolumn{4}{|l|}{ WNLIGHT } \\
\hline DL30W-C & 21 & 298 & 149 \\
\hline DL30W-D & 45 & 493 & 312 \\
\hline
\end{tabular}




\begin{tabular}{lrrr} 
DL30W-I & 25 & 345 & 177 \\
DL42W-C & 18 & 314 & 129 \\
DL42W-D & 58 & 607 & 405 \\
DL42W-I & 24 & 301 & \\
FIXTURES LED & & & 523 \\
LF18W-D & 75 & 1498 & 702 \\
LF36W-D & 100 & 1215 & 3427 \\
LUCES DE EMERGENCIA & & & \\
LE10W & 490 & 1782 & 986 \\
PAR LED & & & 330 \\
PAR3040W-D & 141 & 959 & 414 \\
PAR3040W-I & 47 & 557 & \\
PROPANEL & & & 637 \\
LPC48W-D & 59 & 464 & 177 \\
REFLECTORES LED SLIM IP65 & & & 420 \\
RFS100W-D & 91 & 597 & 345 \\
RFS150W-D & 25 & 253 & 286 \\
RFS200W-D & 60 & 324 \\
RFS20W-D & 49 & 830 & 967 \\
RFS30W-D & 41 & 618 & 766 \\
RFS50W-D & 138 & 995 & \\
TUBOS LED T5 & & & \\
T514WS-D & 109 & 1564 & 1432 \\
T518WS-D & 102 & 1535 & \\
T59WS-D & 88 & & \\
\hline
\end{tabular}




\section{Anexo IV: Pruebas estadísticas del Ratio Entregas Perfectas Pre-Test}

\begin{tabular}{|c|c|c|c|c|c|c|}
\hline \multicolumn{7}{|c|}{ Resumen de procesamiento de casos } \\
\hline & \multicolumn{6}{|c|}{ Casos } \\
\hline & \multicolumn{2}{|c|}{ Válido } & \multicolumn{2}{|c|}{ Perdidos } & \multicolumn{2}{|c|}{ Total } \\
\hline & $\mathrm{N}$ & Porcentaje & $\mathrm{N}$ & Porcentaje & $\mathrm{N}$ & Porcentaje \\
\hline Ratio Entrega Perfecta & 22 & $100,0 \%$ & 0 & $0,0 \%$ & 22 & $100,0 \%$ \\
\hline
\end{tabular}

\begin{tabular}{|c|c|c|c|c|}
\hline \multicolumn{5}{|c|}{ Descriptivos } \\
\hline & & & & \\
\hline \multirow[t]{13}{*}{ Ratio Entrega Perfecta } & Media & & .813636 & .0474526 \\
\hline & $95 \%$ de intervalo de & Límite inferior & .714953 & \\
\hline & confianza para la media & Límite superior & .912319 & \\
\hline & Media recortada al $5 \%$ & & .836364 & \\
\hline & Mediana & & .870000 & \\
\hline & Varianza & & ,050 & \\
\hline & Desv. Desviación & & .2225725 & \\
\hline & Mínimo & & .2000 & \\
\hline & Máximo & & 1.0000 & \\
\hline & Rango & & .8000 & \\
\hline & Rango intercuartil & & .2875 & \\
\hline & Asimetría & & $-1,325$ & ,491 \\
\hline & Curtosis & & 1,436 &, 953 \\
\hline
\end{tabular}

\begin{tabular}{|c|c|c|c|c|c|c|}
\hline \multicolumn{7}{|c|}{ Pruebas de normalidad } \\
\hline & \multicolumn{3}{|c|}{ Kolmogorov-Smirnova } & \multicolumn{3}{|c|}{ Shapiro-Wilk } \\
\hline & Estadístico & $\mathrm{gl}$ & Sig. & Estadístico & $\mathrm{gl}$ & Sig. \\
\hline Ratio Entrega Perfecta & ,208 & 22 & 014 & ,824 & 22 & 001 \\
\hline \multicolumn{7}{|c|}{ a. Corrección de significación de Lilliefors } \\
\hline
\end{tabular}



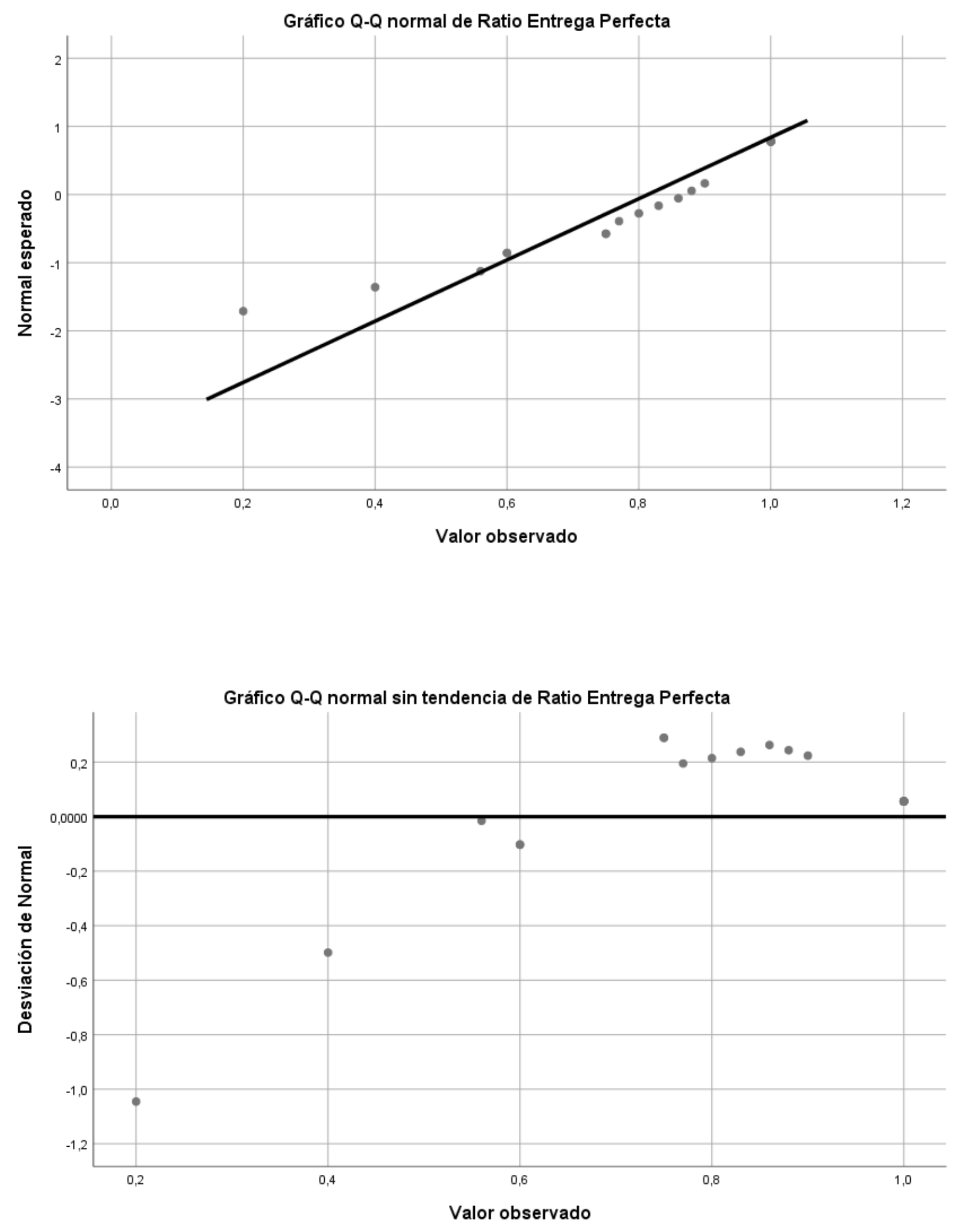


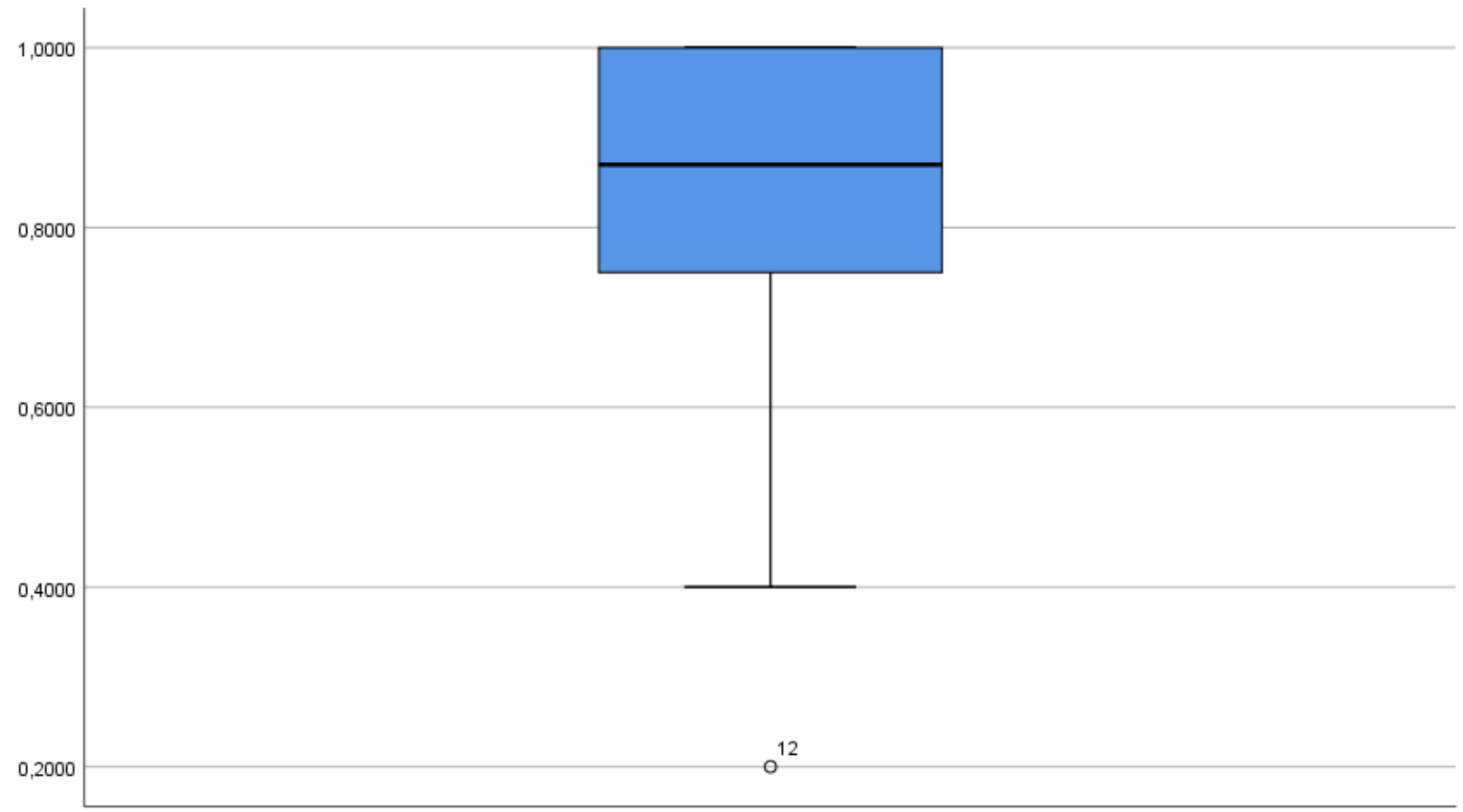

Ratio Entrega Perfecta 


\section{Anexo V: Pruebas estadísticas del Ratio Entregas Perfectas Post-Test}

\begin{tabular}{|c|c|c|c|c|c|c|}
\hline \multicolumn{7}{|c|}{ Resumen de procesamiento de casos } \\
\hline & \multicolumn{6}{|c|}{ Casos } \\
\hline & \multicolumn{2}{|c|}{ Válido } & \multicolumn{2}{|c|}{ Perdidos } & \multicolumn{2}{|c|}{ Total } \\
\hline & $\mathrm{N}$ & Porcentaje & $\mathrm{N}$ & Porcentaje & $\mathrm{N}$ & Porcentaje \\
\hline Ratio Entrega Perfecta & 22 & $100,0 \%$ & & $0,0 \%$ & 22 & $100,0 \%$ \\
\hline
\end{tabular}

\begin{tabular}{|c|c|c|c|c|}
\hline \multicolumn{5}{|c|}{ Descriptivos } \\
\hline & & & Estadístico & Desv. Error \\
\hline \multirow[t]{13}{*}{ Ratio Entrega Perfecta } & Media & & .945909 & .0235916 \\
\hline & $95 \%$ de intervalo de & Límite inferior & .896848 & \\
\hline & confianza para la media & Límite superior & .994970 & \\
\hline & Media recortada al $5 \%$ & & .965758 & \\
\hline & Mediana & & 1.000000 & \\
\hline & Varianza & & 012 & \\
\hline & Desv. Desviación & & .1106543 & \\
\hline & Mínimo & & .5000 & \\
\hline & Máximo & & 1.0000 & \\
\hline & Rango & & .5000 & \\
\hline & Rango intercuartil & & .0875 & \\
\hline & Asimetría & & $-3,383$ & ,491 \\
\hline & Curtosis & & 13,318 & ,953 \\
\hline
\end{tabular}

\section{Pruebas de normalidad}

Kolmogorov-Smirnova

Shapiro-Wilk

\begin{tabular}{lcccccc} 
& Estadístico & gl & Sig. & Estadístico & gl & Sig. \\
\hline Ratio Entrega Perfecta &, 324 & 22 &, 000 &, 530 & 22 &, 000 \\
\begin{tabular}{l} 
a. Corrección de significación de Lilliefors \\
\hline
\end{tabular}
\end{tabular}



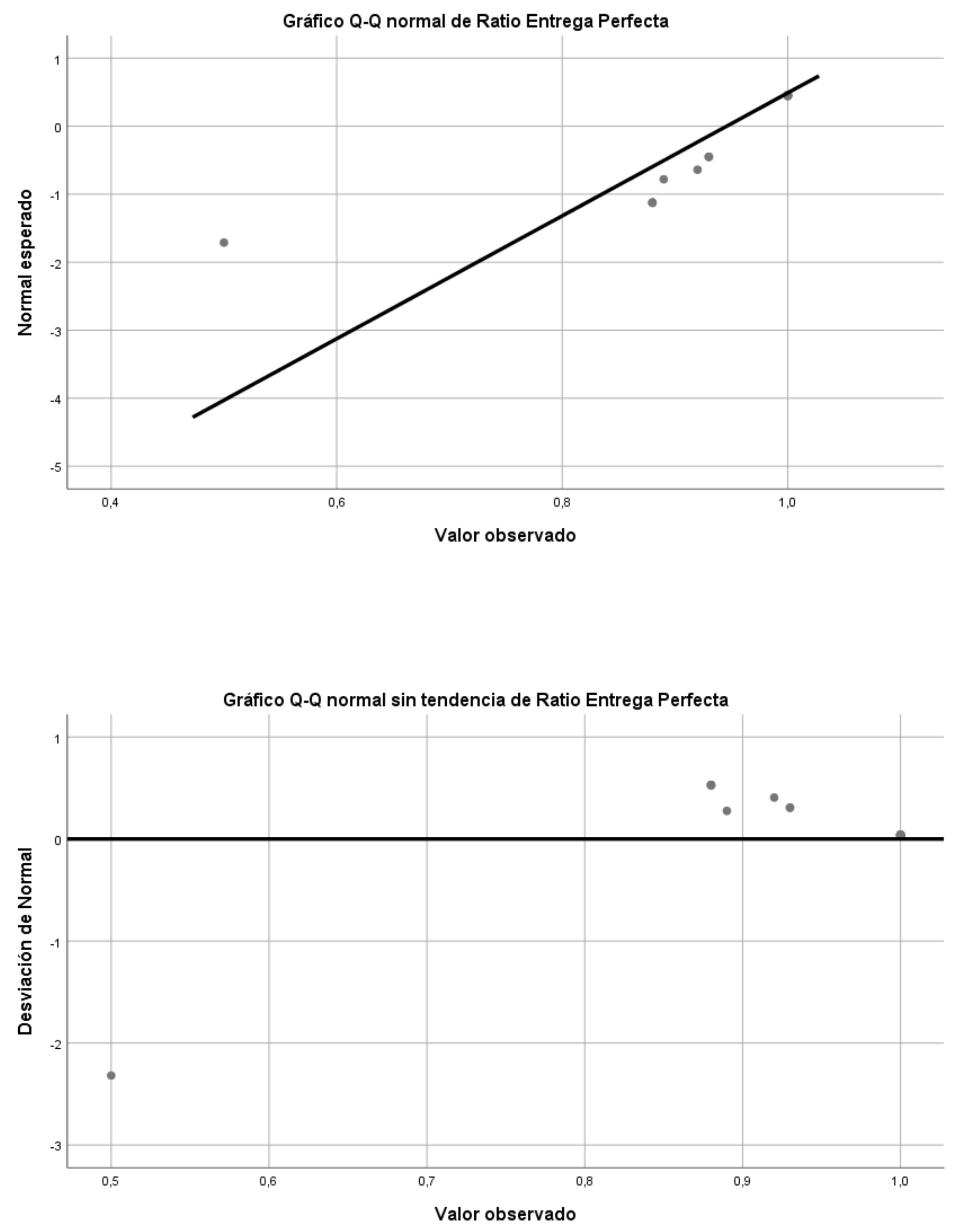


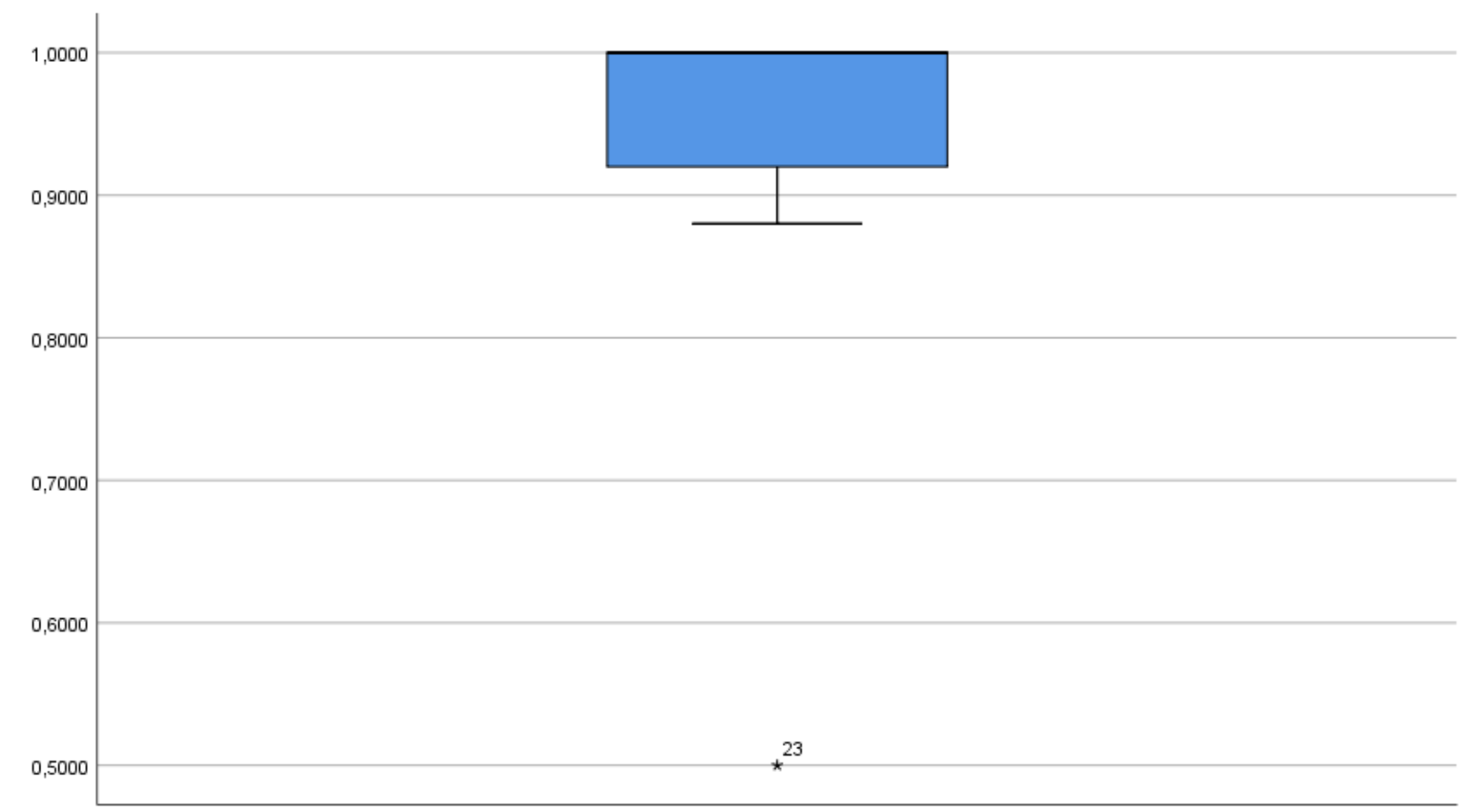

Ratio Entrega Perfecta 


\section{Anexo VI: Pruebas estadísticas del Ratio Entregas a Tiempo Pre-Test}

\begin{tabular}{lcccccc}
\hline & \multicolumn{2}{c}{ Resumen de procesamiento de casos } \\
& \multicolumn{2}{c}{ Válido } & \multicolumn{2}{c}{ Casos } & \multicolumn{2}{c}{} \\
& $\mathrm{N}$ & Porcentaje & $\mathrm{N}$ & Perdidos & \multicolumn{2}{c}{ Total } \\
& 22 & $100,0 \%$ & 0 & $0,0 \%$ & 22 & $100,0 \%$ \\
\hline Ratio Entrega a Tiempo & 22 & &
\end{tabular}

\begin{tabular}{|c|c|c|c|c|}
\hline \multicolumn{5}{|c|}{ Descriptivos } \\
\hline \multirow{14}{*}{ Ratio Entrega a Tiempo } & & & & \\
\hline & Media & & .684091 & .0675440 \\
\hline & $95 \%$ de intervalo de & Límite inferior & .543626 & \\
\hline & confianza para la media & Límite superior & .824556 & \\
\hline & Media recortada al $5 \%$ & & .704545 & \\
\hline & Mediana & & .775000 & \\
\hline & Varianza & & ,100 & \\
\hline & Desv. Desviación & & .3168094 & \\
\hline & Mínimo & & .0000 & \\
\hline & Máximo & & 1.0000 & \\
\hline & Rango & & 1.0000 & \\
\hline & Rango intercuartil & & .5000 & \\
\hline & Asimetría & &,- 951 & ,491 \\
\hline & Curtosis & & ,157 & ,953 \\
\hline
\end{tabular}

\section{Pruebas de normalidad}

\begin{tabular}{lcccccc} 
& \multicolumn{3}{c}{ Kolmogorov-Smirnova } & \multicolumn{3}{c}{ Shapiro-Wilk } \\
& Estadístico & gl & Sig. & Estadístico & gl & Sig. \\
\hline Ratio Entrega a Tiempo &, 159 & 22 &, 152 &, 861 & 22 &, 005 \\
\begin{tabular}{l} 
a. Corrección de significación de Lilliefors \\
\hline
\end{tabular}
\end{tabular}



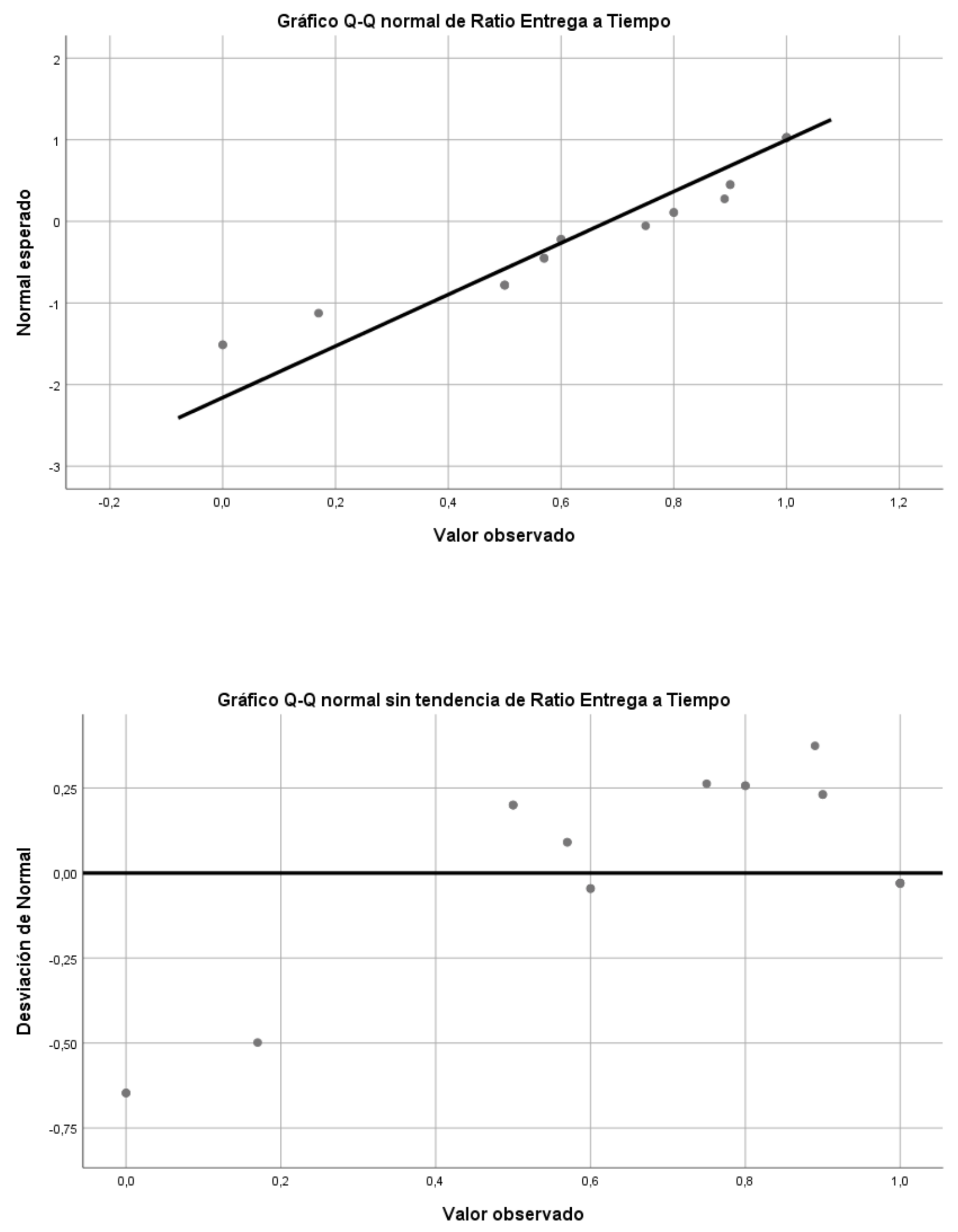


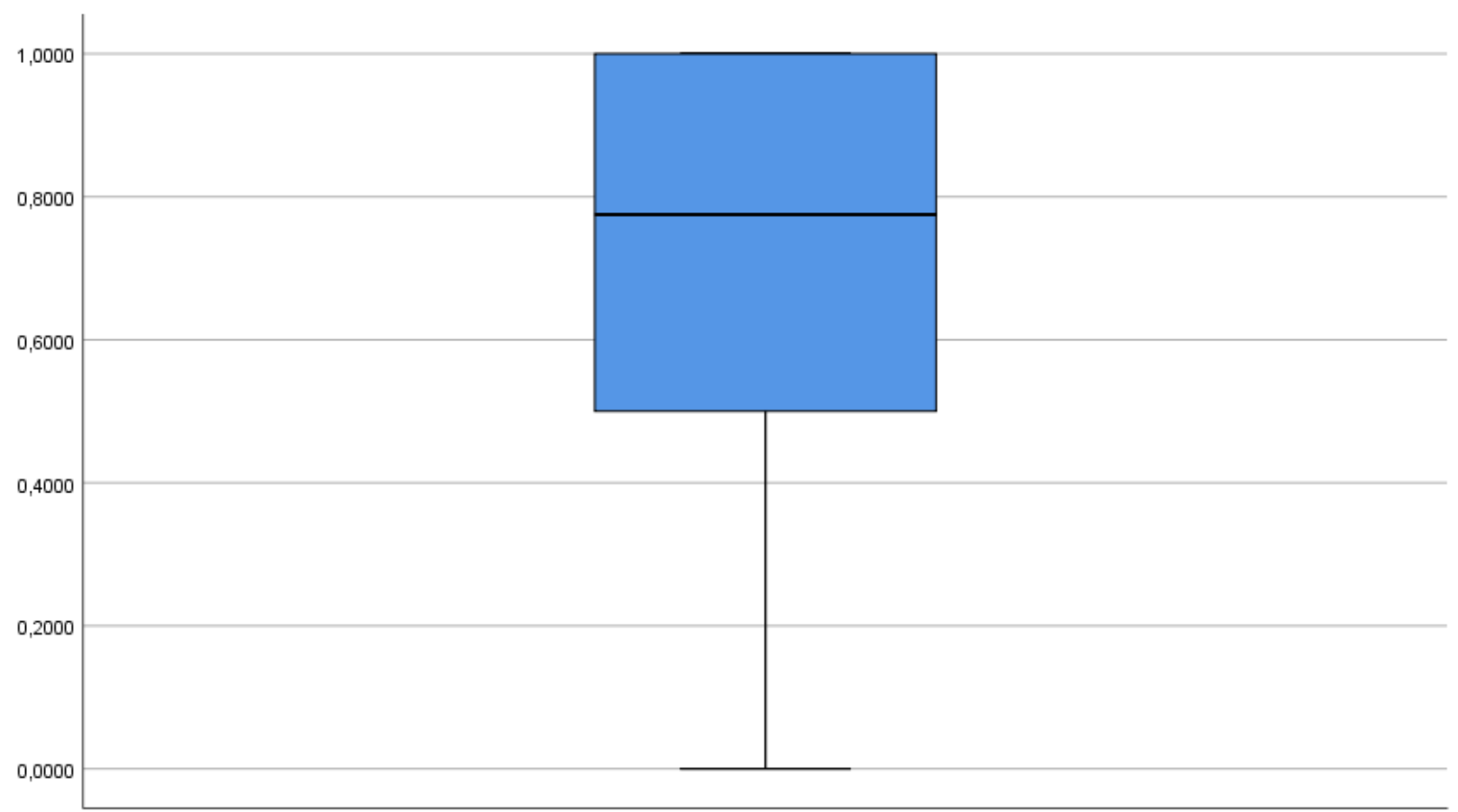

Ratio Entrega a Tiempo 


\section{Anexo VII: Pruebas estadísticas del Ratio Entregas a Tiempo Post-Test}

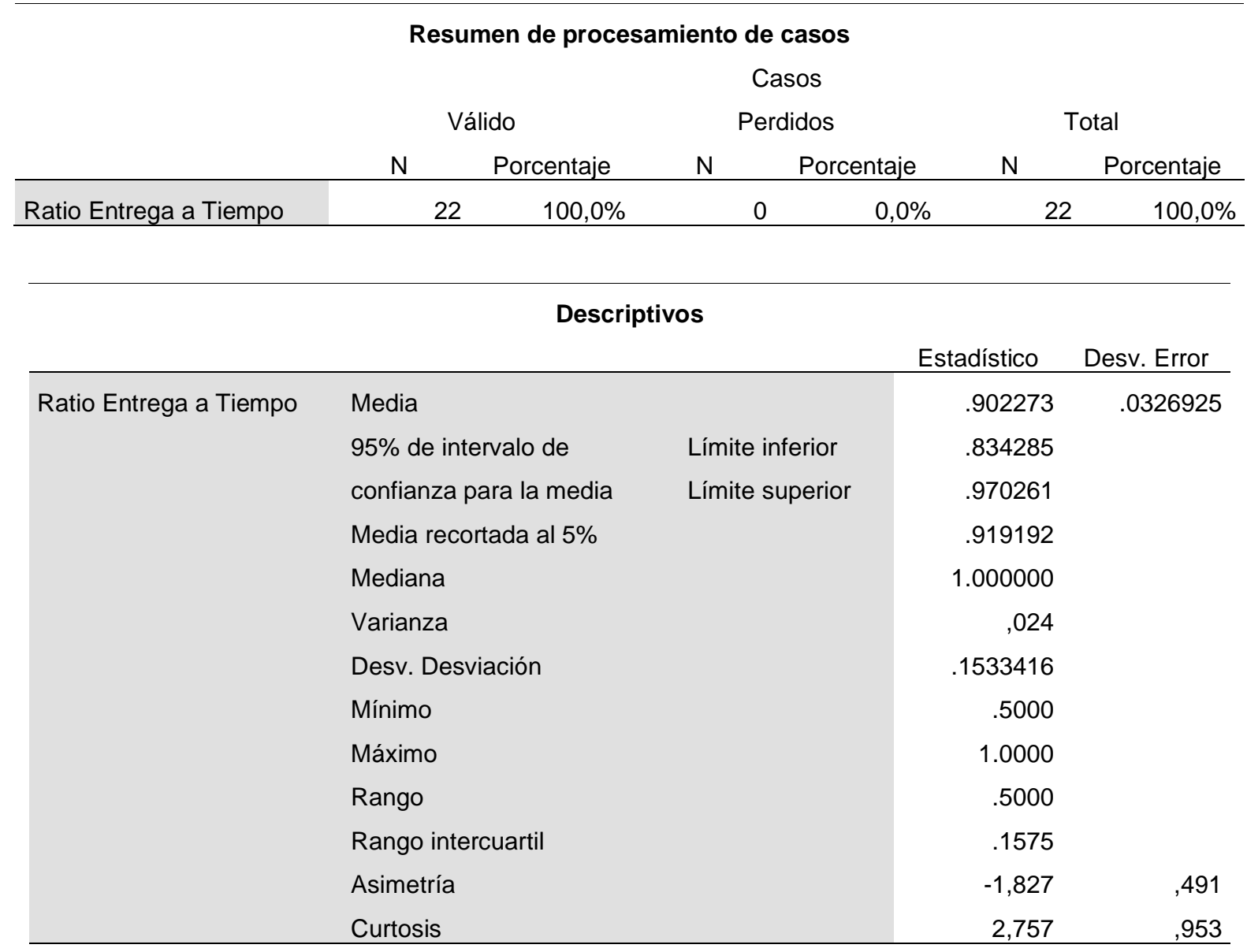

Pruebas de normalidad

Kolmogorov-Smirnova ${ }^{a} \quad$ Shapiro-Wilk

\begin{tabular}{lcccccc} 
& Estadístico & gl & Sig. & Estadístico & gl & Sig. \\
\hline Ratio Entrega a Tiempo &, 283 & 22 &, 000 &, 689 & 22 &, 000
\end{tabular}

a. Corrección de significación de Lilliefors 

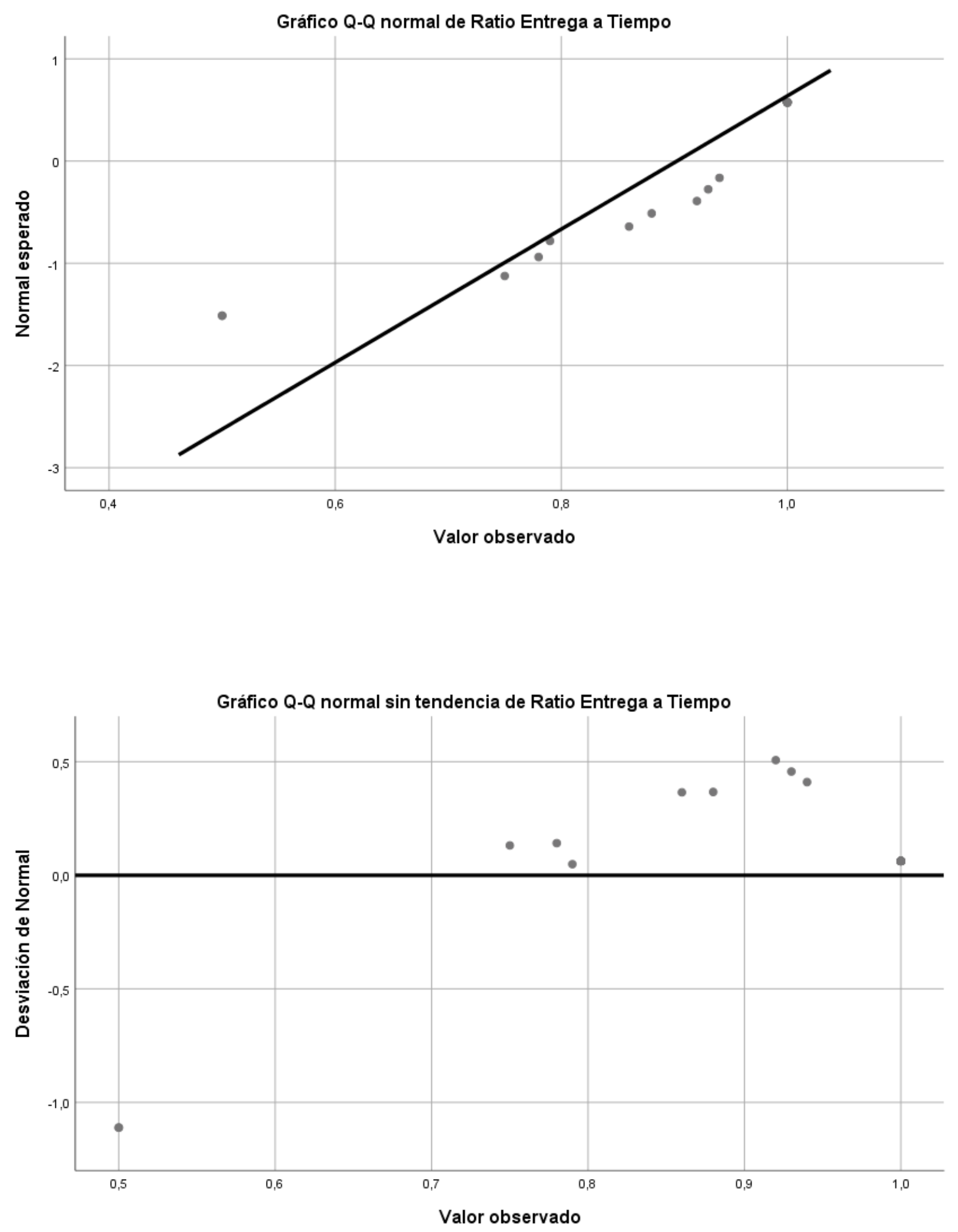


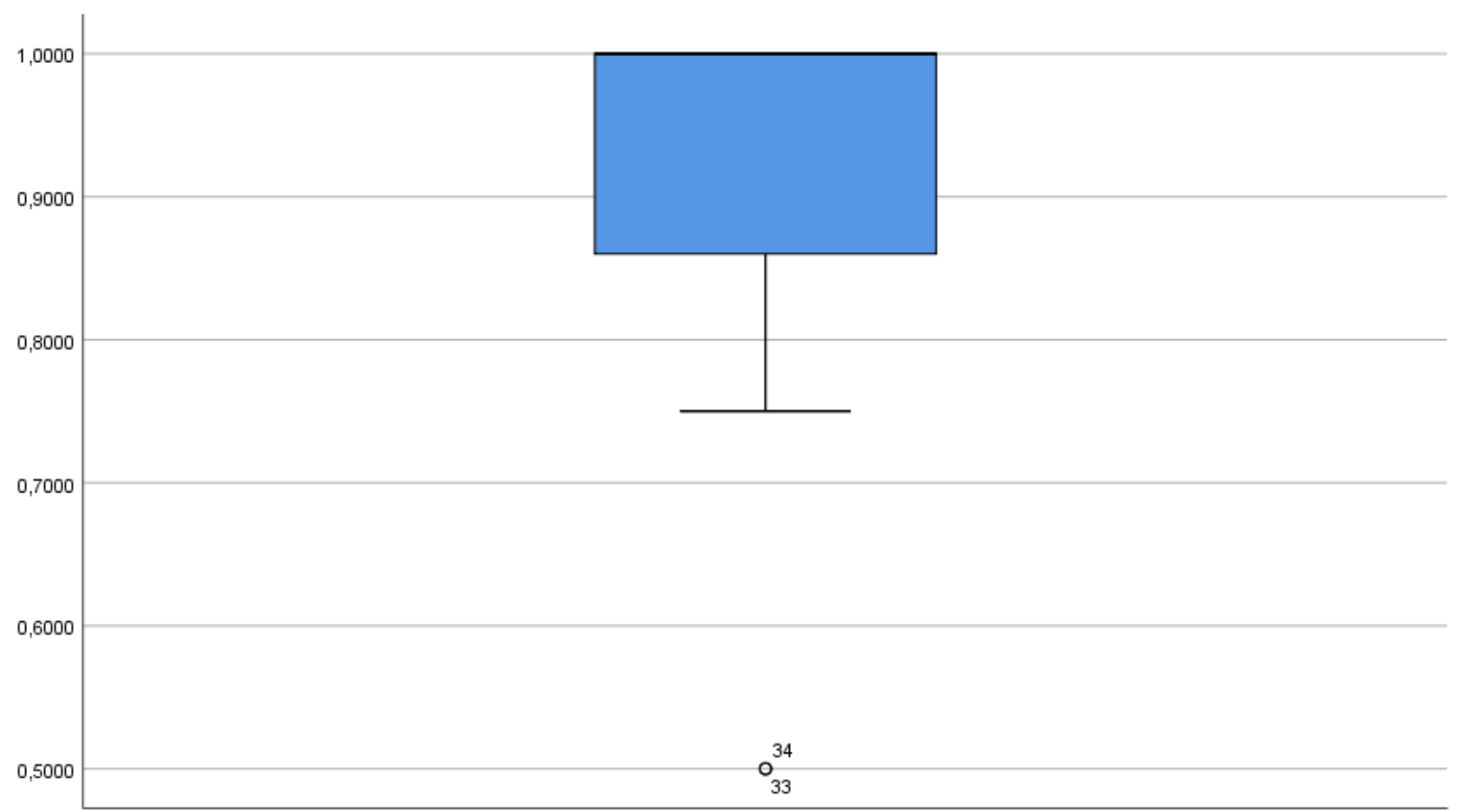

Ratio Entrega a Tiempo 


\section{Anexo VIII: Pruebas estadísticas del Ratio de Devoluciones Pre-Test}

\begin{tabular}{lcccccc}
\hline & \multicolumn{2}{c}{ Resumen de procesamiento de casos } & \multicolumn{2}{c}{ Casos } \\
& \multicolumn{2}{c}{ Válido } & \multicolumn{2}{c}{ Perdidos } & \multicolumn{2}{c}{ Total } \\
& $\mathrm{N}$ & Porcentaje & $\mathrm{N}$ & Porcentaje & $\mathrm{N}$ & Porcentaje \\
\hline Ratio Devoluciones & 22 & $100,0 \%$ & 0 & $0,0 \%$ & 22 & $100,0 \%$ \\
\hline
\end{tabular}

\begin{tabular}{llrrr}
\hline \multicolumn{2}{c}{ Descriptivos } & & \\
& & & \\
Ratio Devoluciones & & Estístico & Desv. Error \\
& Media & .148682 & .0472536 \\
& $95 \%$ de intervalo de & Límite inferior & .050413 & \\
& confianza para la media & Límite superior & .246951 & \\
Media recortada al 5\% & .123956 & \\
Mediana & .038450 & \\
Varianza & .049 & \\
Desv. Desviación & .2216392 & \\
Mínimo & .0000 & \\
Máximo & .7500 &, 491 \\
Rango & .7500 &, 953 \\
Rango intercuartil & .2000 & \\
Asimetría & 1,761 & \\
Curtosis & 2,398 & \\
\hline
\end{tabular}

\begin{tabular}{|c|c|c|c|c|c|c|}
\hline \multicolumn{7}{|c|}{ Pruebas de normalidad } \\
\hline & \multicolumn{3}{|c|}{ Kolmogorov-Smirnova } & \multicolumn{3}{|c|}{ Shapiro-Wilk } \\
\hline & Estadístico & $\mathrm{gl}$ & Sig. & Estadístico & gl & Sig. \\
\hline Ratio Devoluciones & ,251 & 22 &, 001 & ,714 & 22 &, 000 \\
\hline a. Corrección de sig & ación de Lillief & & & & & \\
\hline
\end{tabular}




\section{Gráfico Q-Q normal de Ratio Devoluciones}

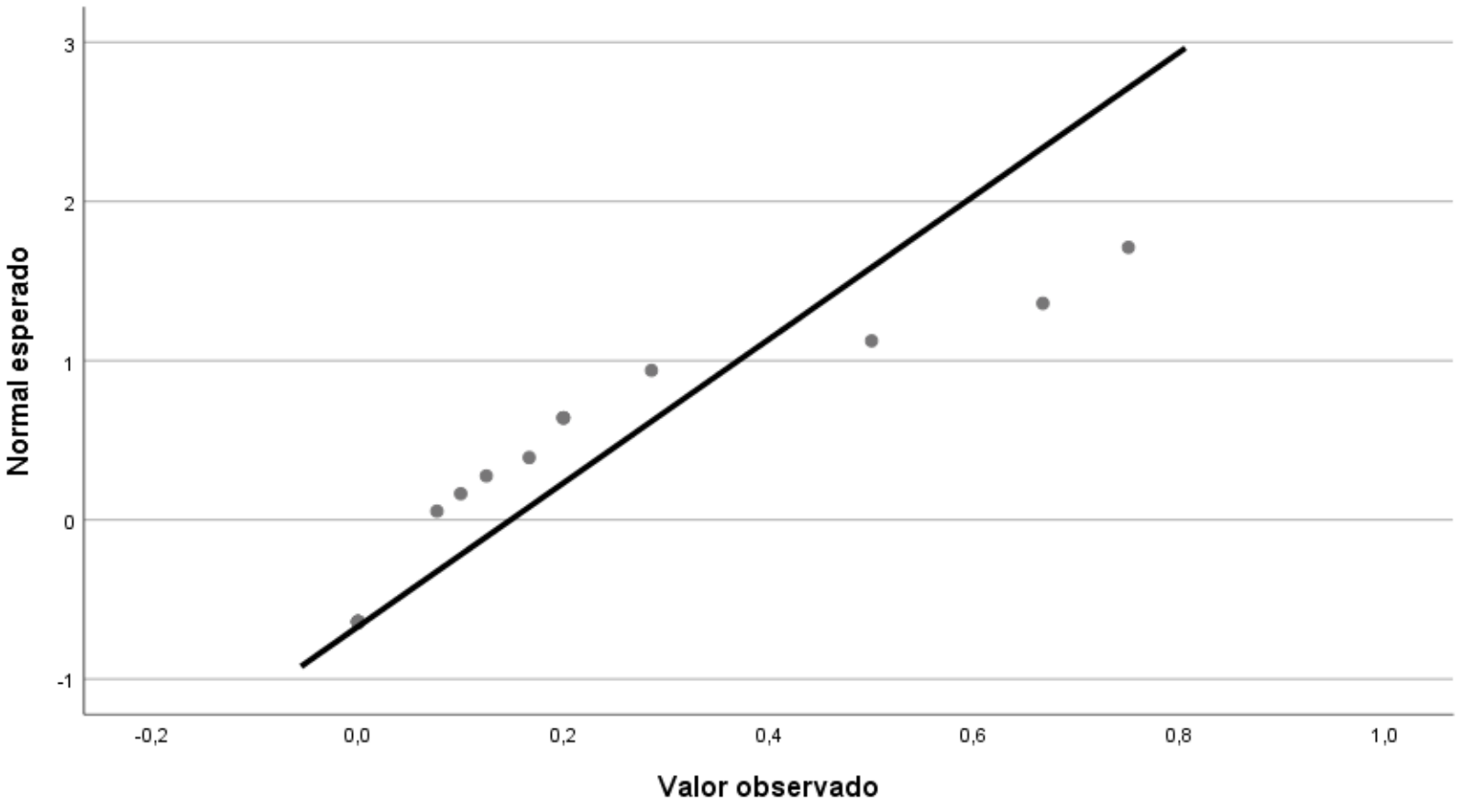

Gráfico Q-Q normal sin tendencia de Ratio Devoluciones

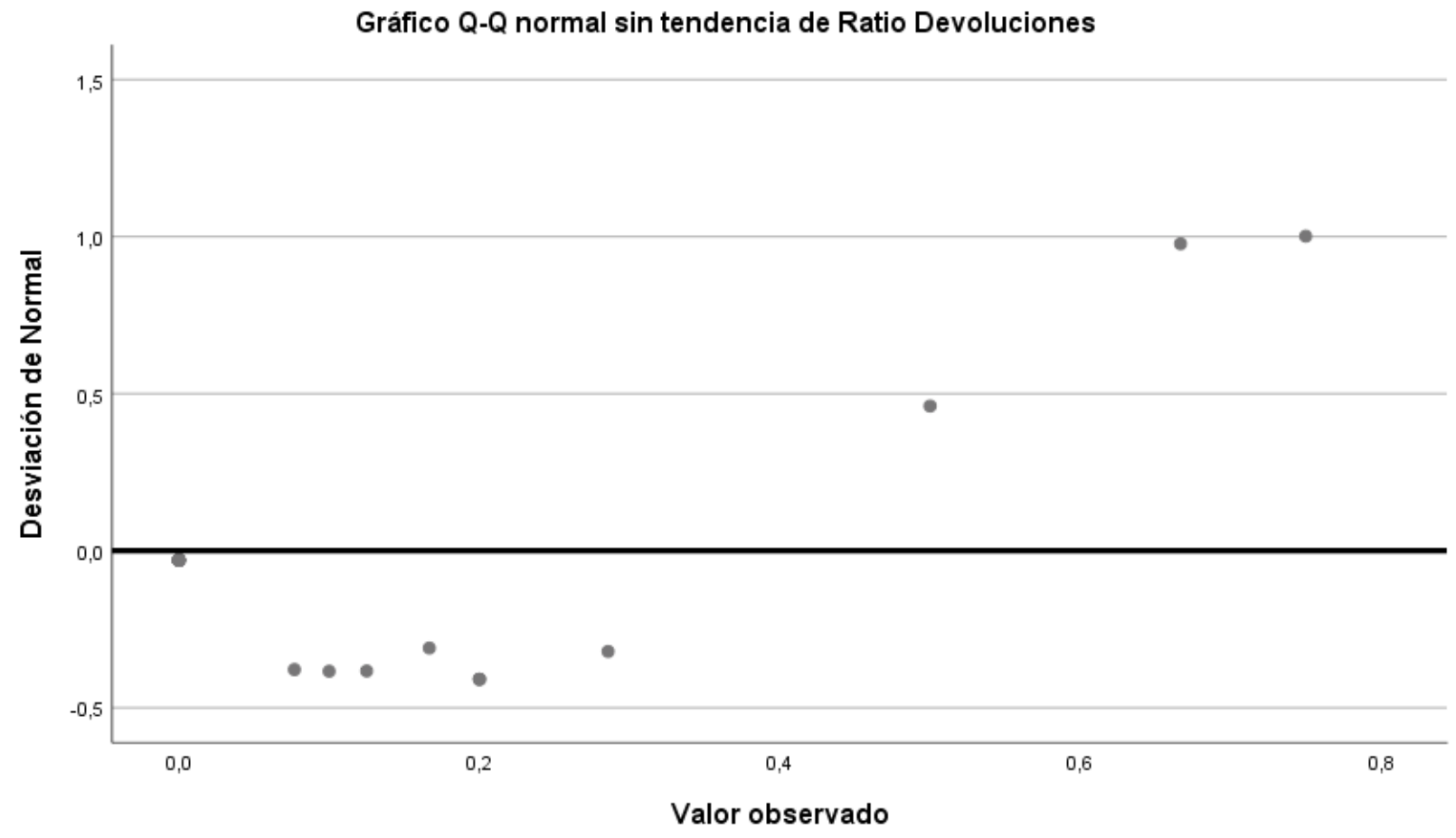




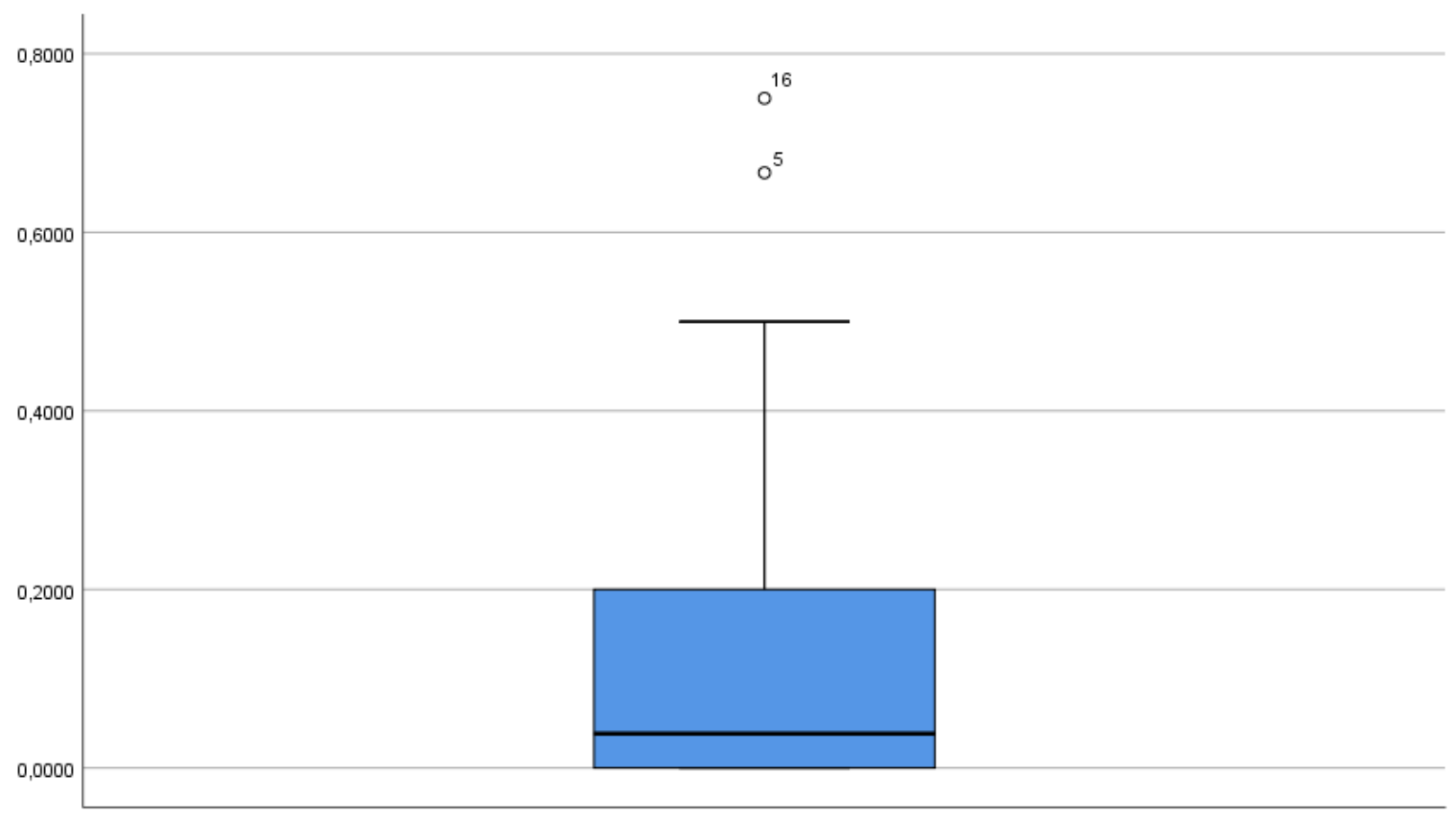

Ratio Devoluciones 


\section{Anexo IX: Pruebas estadísticas del Ratio de Devoluciones Post-Test}

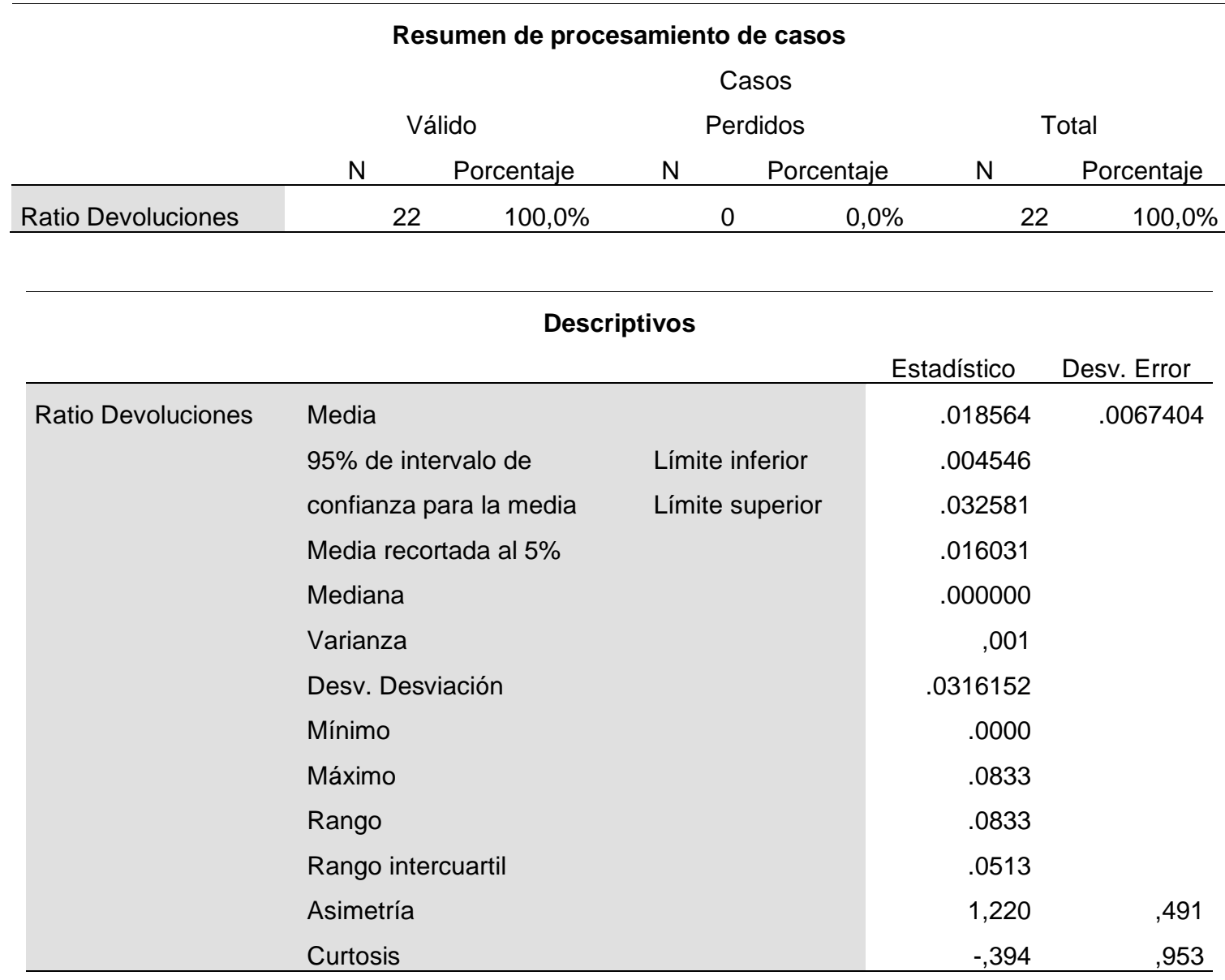

Pruebas de normalidad

Kolmogorov-Smirnova Shapiro-Wilk

\begin{tabular}{|c|c|c|c|c|c|c|}
\hline & Estadístico & gl & Sig. & Estadístico & $\mathrm{gl}$ & Sig. \\
\hline Ratio Devoluciones & 449 & 22 & , 000 & 607 & 22 & ,000 \\
\hline
\end{tabular}

a. Corrección de significación de Lilliefors 

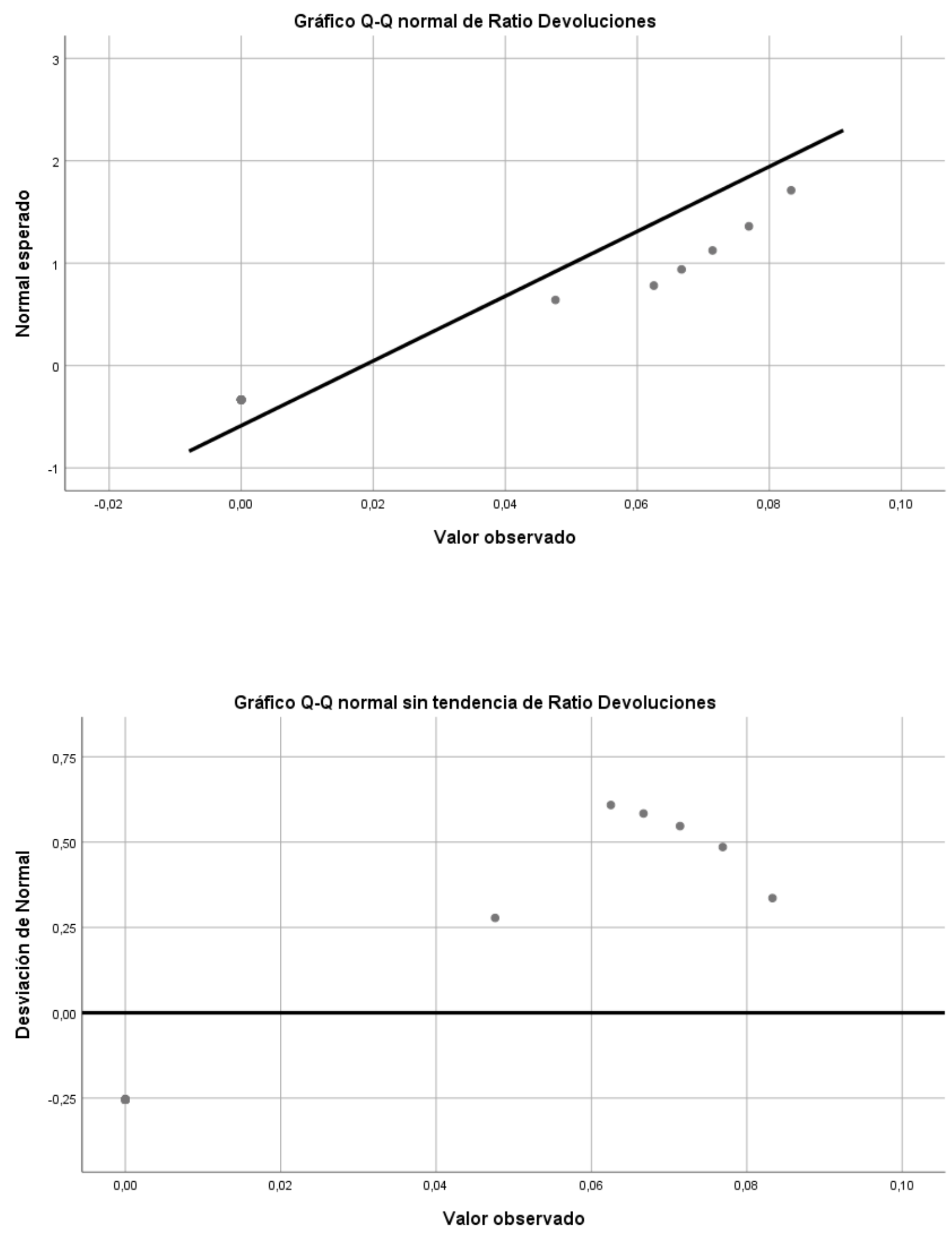


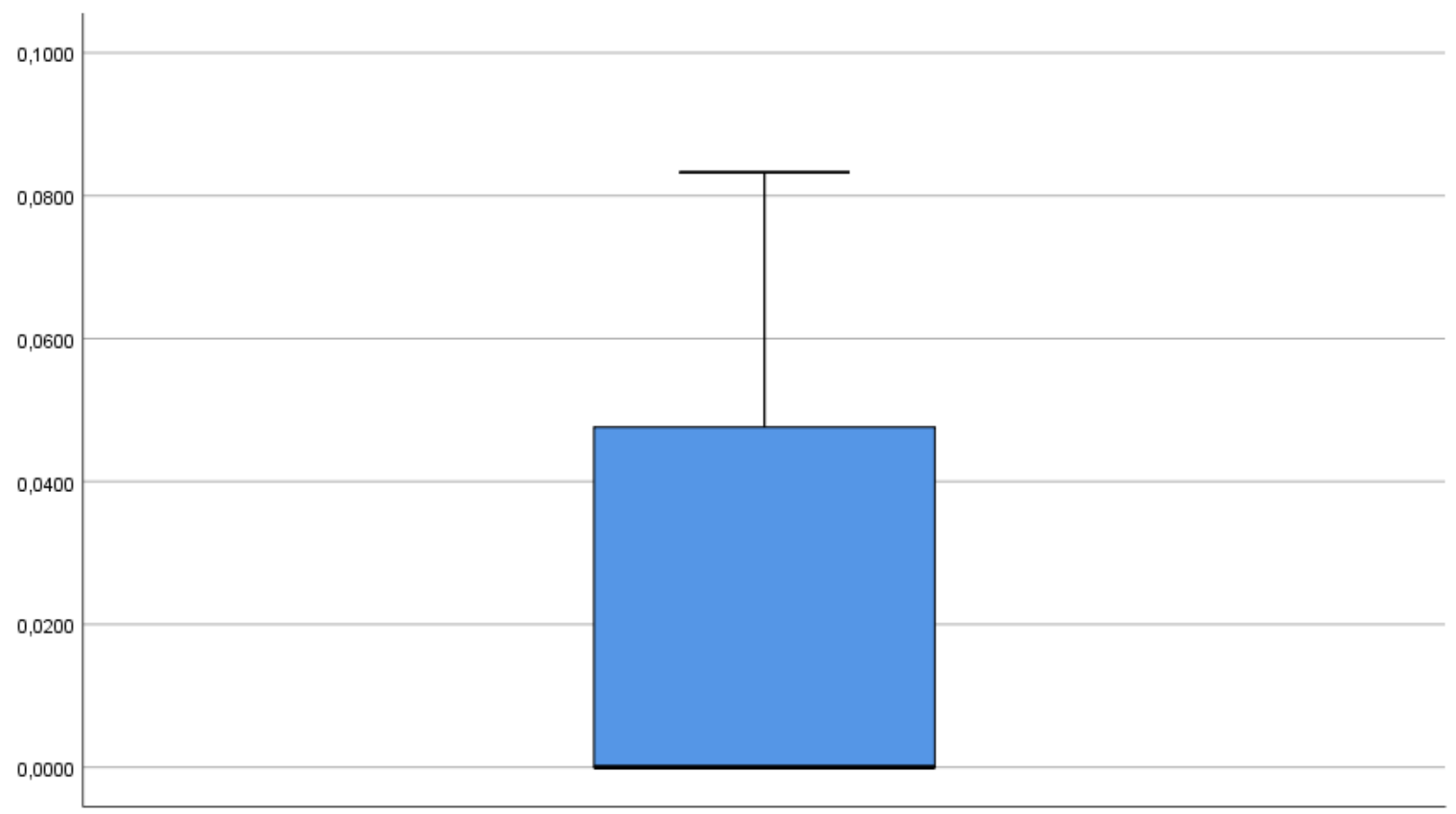

Ratio Devoluciones 
Anexo X: Data de Tiempo de Ciclo

\begin{tabular}{|c|c|c|c|c|c|c|c|c|c|}
\hline \multirow[b]{2}{*}{$\begin{array}{c}\text { Document } \\
0\end{array}$} & \multirow[b]{2}{*}{$\begin{array}{c}\text { Tiemp } \\
\text { o de } \\
\text { ciclo }\end{array}$} & \multirow[b]{2}{*}{$\begin{array}{c}\text { Document } \\
0\end{array}$} & \multicolumn{4}{|c|}{ Tiempo de Ciclo - Mayo 2019} & \multirow[b]{2}{*}{$\begin{array}{l}\text { Tiemp } \\
\text { o de } \\
\text { ciclo }\end{array}$} & \multirow[b]{2}{*}{$\begin{array}{c}\text { Document } \\
0\end{array}$} & \multirow[b]{2}{*}{$\begin{array}{c}\text { Tiemp } \\
\text { o de } \\
\text { ciclo }\end{array}$} \\
\hline & & & $\begin{array}{l}\text { Tiemp } \\
\text { o de } \\
\text { ciclo }\end{array}$ & $\begin{array}{c}\text { Document } \\
0\end{array}$ & $\begin{array}{l}\text { Tiemp } \\
\text { o de } \\
\text { ciclo }\end{array}$ & $\begin{array}{c}\text { Document } \\
0\end{array}$ & & & \\
\hline $\begin{array}{c}\text { FF0100025 } \\
3\end{array}$ & 1 & $\begin{array}{c}\text { FF0100030 } \\
1\end{array}$ & 1 & $\begin{array}{c}\text { FF0100033 } \\
1\end{array}$ & 1 & $\begin{array}{c}\text { FF0100036 } \\
1\end{array}$ & 1 & $\begin{array}{c}\text { FF0100039 } \\
3\end{array}$ & 2 \\
\hline $\begin{array}{c}\text { FF0100026 } \\
0\end{array}$ & 1 & $\begin{array}{c}\text { FF0100030 } \\
2\end{array}$ & 1 & $\begin{array}{c}F F 0100033 \\
2\end{array}$ & 3 & $\begin{array}{c}\text { FF0100036 } \\
2\end{array}$ & 1 & $\begin{array}{c}\text { FF0100039 } \\
4\end{array}$ & 2 \\
\hline $\begin{array}{c}\text { FF0100026 } \\
1\end{array}$ & 1 & $\begin{array}{c}\text { FF0100030 } \\
3\end{array}$ & 3 & $\begin{array}{c}\text { FF0100033 } \\
3\end{array}$ & 1 & $\begin{array}{c}\text { FF0100036 } \\
3\end{array}$ & 1 & $\begin{array}{c}\text { FF0100039 } \\
5\end{array}$ & 1 \\
\hline $\begin{array}{c}\text { FF0100027 } \\
5\end{array}$ & 3 & $\begin{array}{c}\text { FF0100030 } \\
4\end{array}$ & 1 & $\begin{array}{c}\text { FF0100033 } \\
4\end{array}$ & 1 & $\begin{array}{c}\text { FF0100036 } \\
4\end{array}$ & 1 & $\begin{array}{c}\text { FF0100039 } \\
6\end{array}$ & 2 \\
\hline $\begin{array}{c}\text { FF0100027 } \\
6\end{array}$ & 5 & $\begin{array}{c}\text { FF0100030 } \\
6\end{array}$ & 6 & $\begin{array}{c}\text { FF0100033 } \\
5\end{array}$ & 1 & $\begin{array}{c}\text { FF0100036 } \\
5\end{array}$ & 5 & $\begin{array}{c}\text { FF0100039 } \\
7\end{array}$ & 1 \\
\hline $\begin{array}{c}\text { FF0100027 } \\
7\end{array}$ & 1 & $\begin{array}{c}\text { FF0100030 } \\
7\end{array}$ & 4 & $\begin{array}{c}\text { FF0100033 } \\
6\end{array}$ & 1 & $\begin{array}{c}\text { FF0100036 } \\
6\end{array}$ & 1 & $\begin{array}{c}\text { FF0100039 } \\
8\end{array}$ & 1 \\
\hline $\begin{array}{c}\text { FF0100027 } \\
8\end{array}$ & 1 & $\begin{array}{c}\text { FF0100030 } \\
8\end{array}$ & 3 & $\begin{array}{c}\text { FF0100033 } \\
7\end{array}$ & 4 & $\begin{array}{c}\text { FF0100036 } \\
7\end{array}$ & 3 & $\begin{array}{c}\text { FF0100039 } \\
9\end{array}$ & 1 \\
\hline $\begin{array}{c}\mathrm{FF} 0100027 \\
9\end{array}$ & 8 & $\begin{array}{c}\text { FF0100030 } \\
9\end{array}$ & 5 & $\begin{array}{c}\text { FF0100033 } \\
8\end{array}$ & 1 & $\begin{array}{c}\text { FF0100036 } \\
8\end{array}$ & 1 & $\begin{array}{c}\mathrm{FF} 0100040 \\
0\end{array}$ & 1 \\
\hline $\begin{array}{c}\text { FF0100028 } \\
0\end{array}$ & 4 & $\begin{array}{c}\text { FF0100031 } \\
0\end{array}$ & 3 & $\begin{array}{c}\text { FF0100033 } \\
9\end{array}$ & 1 & $\begin{array}{c}\text { FF0100036 } \\
9\end{array}$ & 1 & $\begin{array}{c}\text { FF0100040 } \\
1\end{array}$ & 1 \\
\hline $\begin{array}{c}\text { FF0100028 } \\
1\end{array}$ & 3 & $\begin{array}{c}\text { FF0100031 } \\
1\end{array}$ & 3 & $\begin{array}{c}\text { FF0100034 } \\
0\end{array}$ & 1 & $\begin{array}{c}\text { FF0100037 } \\
0\end{array}$ & 1 & $\begin{array}{c}\text { FF0100040 } \\
2\end{array}$ & 1 \\
\hline $\begin{array}{c}F F 0100028 \\
2\end{array}$ & 3 & $\begin{array}{c}\text { FF0100031 } \\
2\end{array}$ & 2 & $\begin{array}{c}\text { FF0100034 } \\
1\end{array}$ & 1 & $\begin{array}{c}\text { FF0100037 } \\
1\end{array}$ & 1 & $\begin{array}{c}\mathrm{FF} 0100040 \\
3\end{array}$ & 1 \\
\hline $\begin{array}{c}F F 0100028 \\
3\end{array}$ & 3 & $\begin{array}{c}\text { FF0100031 } \\
3\end{array}$ & 2 & $\begin{array}{c}\text { FF0100034 } \\
2\end{array}$ & 1 & $\begin{array}{c}\text { FF0100037 } \\
2\end{array}$ & 1 & $\begin{array}{c}\text { FF0100040 } \\
4\end{array}$ & 1 \\
\hline $\begin{array}{c}\text { FF0100028 } \\
4\end{array}$ & 3 & $\begin{array}{c}\text { FF0100031 } \\
4\end{array}$ & 1 & $\begin{array}{c}\text { FF0100034 } \\
3\end{array}$ & 2 & $\begin{array}{c}\text { FF0100037 } \\
3\end{array}$ & 1 & $\begin{array}{c}\text { FF0100040 } \\
5\end{array}$ & 1 \\
\hline $\begin{array}{c}\text { FF0100028 } \\
5\end{array}$ & 1 & $\begin{array}{c}\text { FF0100031 } \\
5\end{array}$ & 1 & $\begin{array}{c}\text { FF0100034 } \\
4\end{array}$ & 4 & $\begin{array}{c}\text { FF0100037 } \\
4\end{array}$ & 1 & $\begin{array}{c}\text { FF0100040 } \\
6\end{array}$ & 1 \\
\hline $\begin{array}{c}\text { FF0100028 } \\
6\end{array}$ & 3 & $\begin{array}{c}\text { FF0100031 } \\
6\end{array}$ & 1 & $\begin{array}{c}\text { FF0100034 } \\
6\end{array}$ & 5 & $\begin{array}{c}\text { FF0100037 } \\
5\end{array}$ & 1 & $\begin{array}{c}\text { FF0100040 } \\
7\end{array}$ & 2 \\
\hline $\begin{array}{c}\text { FF0100028 } \\
7\end{array}$ & 1 & $\begin{array}{c}\text { FF0100031 } \\
7\end{array}$ & 3 & $\begin{array}{c}\text { FF0100034 } \\
7\end{array}$ & 5 & $\begin{array}{c}\text { FF0100037 } \\
6\end{array}$ & 2 & $\begin{array}{c}\text { FF0100040 } \\
9\end{array}$ & 1 \\
\hline $\begin{array}{c}\text { FF0100028 } \\
8\end{array}$ & 1 & $\begin{array}{c}\text { FF0100031 } \\
8\end{array}$ & 3 & $\begin{array}{c}\text { FF0100034 } \\
8\end{array}$ & 3 & $\begin{array}{c}\text { FF0100037 } \\
7\end{array}$ & 2 & $\begin{array}{c}\mathrm{FF} 0100041 \\
0\end{array}$ & 1 \\
\hline $\begin{array}{c}\text { FF0100028 } \\
9\end{array}$ & 3 & $\begin{array}{c}\text { FF0100031 } \\
9\end{array}$ & 3 & $\begin{array}{c}\text { FF0100034 } \\
9\end{array}$ & 3 & $\begin{array}{c}\text { FF0100037 } \\
8\end{array}$ & 1 & $\begin{array}{c}\mathrm{FF} 0100041 \\
1\end{array}$ & 1 \\
\hline $\begin{array}{c}\text { FF0100029 } \\
0\end{array}$ & 4 & $\begin{array}{c}\text { FF0100032 } \\
0\end{array}$ & 2 & $\begin{array}{c}\text { FF0100035 } \\
0\end{array}$ & 3 & $\begin{array}{c}\text { FF0100038 } \\
0\end{array}$ & 1 & $\begin{array}{c}\text { FF0100041 } \\
2\end{array}$ & 2 \\
\hline $\begin{array}{c}\mathrm{FF} 0100029 \\
1\end{array}$ & 1 & $\begin{array}{c}\text { FF0100032 } \\
1\end{array}$ & 1 & $\begin{array}{c}\text { FF0100035 } \\
1\end{array}$ & 3 & $\begin{array}{c}\mathrm{FF} 0100038 \\
3\end{array}$ & 3 & $\begin{array}{c}\mathrm{FF} 0100041 \\
3\end{array}$ & 1 \\
\hline $\begin{array}{c}F F 0100029 \\
2\end{array}$ & 1 & $\begin{array}{c}\text { FF0100032 } \\
2\end{array}$ & 1 & $\begin{array}{c}\text { FF0100035 } \\
2\end{array}$ & 1 & $\begin{array}{c}\text { FF0100038 } \\
4\end{array}$ & 3 & $\begin{array}{c}\text { FF0100041 } \\
4\end{array}$ & 1 \\
\hline $\begin{array}{c}\text { FF0100029 } \\
3\end{array}$ & 1 & $\begin{array}{c}\mathrm{FF} 0100032 \\
3\end{array}$ & 1 & $\begin{array}{c}\text { FF0100035 } \\
3\end{array}$ & 1 & $\begin{array}{c}\text { FF0100038 } \\
5\end{array}$ & 1 & $\begin{array}{c}\text { FF0100041 } \\
5\end{array}$ & 2 \\
\hline $\begin{array}{c}\text { FF0100029 } \\
4\end{array}$ & 1 & $\begin{array}{c}\text { FF0100032 } \\
4\end{array}$ & 3 & $\begin{array}{c}\text { FF0100035 } \\
4\end{array}$ & 1 & $\begin{array}{c}\text { FF0100038 } \\
6\end{array}$ & 1 & $\begin{array}{c}\text { FF0100041 } \\
6\end{array}$ & 1 \\
\hline $\begin{array}{c}\text { FF0100029 } \\
5\end{array}$ & 1 & $\begin{array}{c}\text { FF0100032 } \\
5\end{array}$ & 1 & $\begin{array}{c}\text { FF0100035 } \\
5\end{array}$ & 3 & $\begin{array}{c}\text { FF0100038 } \\
7\end{array}$ & 1 & $\begin{array}{c}\text { FF0100041 } \\
7\end{array}$ & 2 \\
\hline $\begin{array}{c}\text { FF0100029 } \\
6\end{array}$ & 3 & $\begin{array}{c}\text { FF0100032 } \\
6\end{array}$ & 1 & $\begin{array}{c}\text { FF0100035 } \\
6\end{array}$ & 1 & $\begin{array}{c}\text { FF0100038 } \\
8\end{array}$ & 1 & $\begin{array}{c}\text { FF0100041 } \\
8\end{array}$ & 1 \\
\hline $\begin{array}{c}\text { FF0100029 } \\
7\end{array}$ & 3 & $\begin{array}{c}\text { FF0100032 } \\
7\end{array}$ & 1 & $\begin{array}{c}\text { FF0100035 } \\
7\end{array}$ & 1 & $\begin{array}{c}\text { FF0100038 } \\
9\end{array}$ & 1 & $\begin{array}{c}\text { FF0100041 } \\
9\end{array}$ & 1 \\
\hline $\begin{array}{c}F F 0100029 \\
8\end{array}$ & 1 & $\begin{array}{c}\text { FF0100032 } \\
8\end{array}$ & 1 & $\begin{array}{c}\text { FF0100035 } \\
8\end{array}$ & 1 & $\begin{array}{c}\text { FF0100039 } \\
0\end{array}$ & 1 & $\begin{array}{c}\text { FF0100042 } \\
0\end{array}$ & 2 \\
\hline
\end{tabular}




\begin{tabular}{|c|c|c|c|c|c|c|c|c|}
\hline $\begin{array}{c}\text { FF0100029 } \\
9 \\
\text { FF0100030 } \\
0\end{array}$ & 1 & $\begin{array}{c}\text { FF0100032 } \\
9 \\
\text { FF0100033 } \\
0\end{array}$ & 1 & $\begin{array}{c}\text { FF0100035 } \\
9 \\
\text { FF0100036 } \\
0\end{array}$ & 1 & $\begin{array}{c}\text { FF0100039 } \\
1 \\
\text { FF0100039 } \\
2\end{array}$ & 1 & \\
\hline \multicolumn{8}{|l|}{ 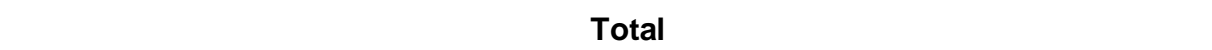 } & 143 \\
\hline
\end{tabular}




\begin{tabular}{|c|c|c|c|c|c|c|c|c|c|}
\hline \multirow[b]{2}{*}{$\begin{array}{c}\text { Document } \\
0\end{array}$} & \multirow[b]{2}{*}{$\begin{array}{l}\text { Tiemp } \\
\text { o de } \\
\text { ciclo }\end{array}$} & \multirow[b]{2}{*}{$\begin{array}{c}\text { Document } \\
0\end{array}$} & \multicolumn{4}{|c|}{ Tiempo de Ciclo - Octubre 2019} & \multirow[b]{2}{*}{$\begin{array}{l}\text { Tiemp } \\
\text { o de } \\
\text { ciclo }\end{array}$} & \multirow[b]{2}{*}{$\begin{array}{c}\text { Document } \\
0\end{array}$} & \multirow[b]{2}{*}{$\begin{array}{c}\text { Tiemp } \\
\text { o de } \\
\text { ciclo }\end{array}$} \\
\hline & & & $\begin{array}{l}\text { Tiemp } \\
\text { o de } \\
\text { ciclo }\end{array}$ & $\begin{array}{c}\text { Document } \\
0\end{array}$ & $\begin{array}{l}\text { Tiemp } \\
\text { o de } \\
\text { ciclo }\end{array}$ & $\begin{array}{c}\text { Document } \\
0\end{array}$ & & & \\
\hline $\begin{array}{c}\text { BB0100001 } \\
2\end{array}$ & 1 & $\begin{array}{c}\text { FF0100100 } \\
2\end{array}$ & 2 & $\begin{array}{c}\text { FF0100103 } \\
9\end{array}$ & 2 & $\begin{array}{c}\text { FF0100107 } \\
5\end{array}$ & 3 & $\begin{array}{c}\text { FF0100111 } \\
0\end{array}$ & 3 \\
\hline $\begin{array}{c}\text { BB0100001 } \\
3\end{array}$ & 1 & $\begin{array}{c}\text { FF0100100 } \\
3\end{array}$ & 2 & $\begin{array}{c}\text { FF0100104 } \\
0\end{array}$ & 2 & $\begin{array}{c}\text { FF0100107 } \\
6\end{array}$ & 3 & $\begin{array}{c}\text { FF0100111 } \\
1\end{array}$ & 1 \\
\hline $\begin{array}{c}\text { FF0100096 } \\
6\end{array}$ & 2 & $\begin{array}{c}\text { FF0100100 } \\
4\end{array}$ & 1 & $\begin{array}{c}\text { FF0100104 } \\
1\end{array}$ & 1 & $\begin{array}{c}\text { FF0100107 } \\
7\end{array}$ & 1 & $\begin{array}{c}\text { FF0100111 } \\
2\end{array}$ & 1 \\
\hline $\begin{array}{c}\text { FF0100096 } \\
7\end{array}$ & 2 & $\begin{array}{c}\text { FF0100100 } \\
5\end{array}$ & 2 & $\begin{array}{c}\text { FF0100104 } \\
2\end{array}$ & 1 & $\begin{array}{c}\text { FF0100107 } \\
8\end{array}$ & 1 & $\begin{array}{c}\text { FF0100111 } \\
3\end{array}$ & 1 \\
\hline $\begin{array}{c}\text { FF0100096 } \\
8\end{array}$ & 2 & $\begin{array}{c}\text { FF0100100 } \\
6\end{array}$ & 1 & $\begin{array}{c}\text { FF0100104 } \\
3\end{array}$ & 1 & $\begin{array}{c}\text { FF0100107 } \\
9\end{array}$ & 2 & $\begin{array}{c}\text { FF0100111 } \\
4\end{array}$ & 1 \\
\hline $\begin{array}{c}\text { FF0100096 } \\
9\end{array}$ & 1 & $\begin{array}{c}\text { FF0100100 } \\
8\end{array}$ & 1 & $\begin{array}{c}\text { FF0100104 } \\
4\end{array}$ & 1 & $\begin{array}{c}\text { FF0100108 } \\
0\end{array}$ & 1 & $\begin{array}{c}\text { FF0100111 } \\
6\end{array}$ & 1 \\
\hline $\begin{array}{c}\text { FF0100097 } \\
0\end{array}$ & 2 & $\begin{array}{c}\text { FF0100100 } \\
9\end{array}$ & 1 & $\begin{array}{c}\text { FF0100104 } \\
5\end{array}$ & 1 & $\begin{array}{c}\text { FF0100108 } \\
1\end{array}$ & 1 & $\begin{array}{c}\text { FF0100111 } \\
7\end{array}$ & 1 \\
\hline $\begin{array}{c}\text { FF0100097 } \\
1\end{array}$ & 1 & $\begin{array}{c}\text { FF0100101 } \\
0\end{array}$ & 1 & $\begin{array}{c}\text { FF0100104 } \\
6\end{array}$ & 1 & $\begin{array}{c}\text { FF0100108 } \\
2\end{array}$ & 1 & $\begin{array}{c}\text { FF0100111 } \\
8\end{array}$ & 3 \\
\hline $\begin{array}{c}\mathrm{FF} 0100097 \\
2\end{array}$ & 2 & $\begin{array}{c}\text { FF0100101 } \\
1\end{array}$ & 4 & $\begin{array}{c}\text { FF0100104 } \\
7\end{array}$ & 1 & $\begin{array}{c}\text { FF0100108 } \\
3\end{array}$ & 1 & $\begin{array}{c}\text { FF0100111 } \\
9\end{array}$ & 1 \\
\hline $\begin{array}{c}\text { FF0100097 } \\
3\end{array}$ & 2 & $\begin{array}{c}\text { FF0100101 } \\
2\end{array}$ & 1 & $\begin{array}{c}\text { FF0100104 } \\
8\end{array}$ & 1 & $\begin{array}{c}\text { FF0100108 } \\
4\end{array}$ & 3 & $\begin{array}{c}\text { FF0100112 } \\
0\end{array}$ & 1 \\
\hline $\begin{array}{c}\text { FF0100097 } \\
4\end{array}$ & 2 & $\begin{array}{c}\text { FF0100101 } \\
3\end{array}$ & 1 & $\begin{array}{c}\text { FF0100104 } \\
9\end{array}$ & 1 & $\begin{array}{c}\text { FF0100108 } \\
5\end{array}$ & 1 & $\begin{array}{c}\text { FF0100112 } \\
1\end{array}$ & 1 \\
\hline $\begin{array}{c}\text { FF0100097 } \\
5\end{array}$ & 1 & $\begin{array}{c}\text { FF0100101 } \\
4\end{array}$ & 1 & $\begin{array}{c}\text { FF0100105 } \\
0\end{array}$ & 1 & $\begin{array}{c}\text { FF0100108 } \\
6\end{array}$ & 1 & $\begin{array}{c}\text { FF0100112 } \\
2\end{array}$ & 1 \\
\hline $\begin{array}{c}\text { FF0100097 } \\
6\end{array}$ & 1 & $\begin{array}{c}\text { FF0100101 } \\
5\end{array}$ & 1 & $\begin{array}{c}\text { FF0100105 } \\
1\end{array}$ & 1 & $\begin{array}{c}\text { FF0100108 } \\
7\end{array}$ & 1 & $\begin{array}{c}F F 0100112 \\
3\end{array}$ & 1 \\
\hline $\begin{array}{c}\text { FF0100097 } \\
7\end{array}$ & 2 & $\begin{array}{c}\text { FF0100101 } \\
7\end{array}$ & 1 & $\begin{array}{c}\text { FF0100105 } \\
2\end{array}$ & 3 & $\begin{array}{c}\text { FF0100108 } \\
8\end{array}$ & 1 & $\begin{array}{c}\text { FF0100112 } \\
4\end{array}$ & 3 \\
\hline $\begin{array}{c}\text { FF0100097 } \\
8\end{array}$ & 1 & $\begin{array}{c}\text { FF0100101 } \\
8\end{array}$ & 1 & $\begin{array}{c}\text { FF0100105 } \\
3\end{array}$ & 2 & $\begin{array}{c}\text { FF0100108 } \\
9\end{array}$ & 1 & $\begin{array}{c}\text { FF0100112 } \\
5\end{array}$ & 1 \\
\hline $\begin{array}{c}\text { FF0100097 } \\
9\end{array}$ & 1 & $\begin{array}{c}\text { FF0100101 } \\
9\end{array}$ & 1 & $\begin{array}{c}\text { FF0100105 } \\
4\end{array}$ & 2 & $\begin{array}{c}\text { FF0100109 } \\
0\end{array}$ & 3 & $\begin{array}{c}\text { FF0100112 } \\
6\end{array}$ & 1 \\
\hline $\begin{array}{c}\text { FF0100098 } \\
0\end{array}$ & 1 & $\begin{array}{c}\text { FF0100102 } \\
0\end{array}$ & 1 & $\begin{array}{c}\text { FF0100105 } \\
5\end{array}$ & 2 & $\begin{array}{c}\text { FF0100109 } \\
1\end{array}$ & 1 & $\begin{array}{c}\text { FF0100112 } \\
7\end{array}$ & 1 \\
\hline $\begin{array}{c}\text { FF0100098 } \\
1\end{array}$ & 1 & $\begin{array}{c}\text { FF0100102 } \\
1\end{array}$ & 2 & $\begin{array}{c}\text { FF0100105 } \\
6\end{array}$ & 3 & $\begin{array}{c}\text { FF0100109 } \\
2\end{array}$ & 1 & $\begin{array}{c}\text { FF0100112 } \\
8\end{array}$ & 1 \\
\hline $\begin{array}{c}\text { FF0100098 } \\
2\end{array}$ & 1 & $\begin{array}{c}\text { FF0100102 } \\
2\end{array}$ & 2 & $\begin{array}{c}\text { FF0100105 } \\
7\end{array}$ & 1 & $\begin{array}{c}F F 0100109 \\
3\end{array}$ & 1 & $\begin{array}{c}F F 0100112 \\
9\end{array}$ & 1 \\
\hline $\begin{array}{c}\text { FF0100098 } \\
3\end{array}$ & 1 & $\begin{array}{c}\text { FF0100102 } \\
3\end{array}$ & 1 & $\begin{array}{c}\text { FF0100105 } \\
8\end{array}$ & 3 & $\begin{array}{c}\text { FF0100109 } \\
4\end{array}$ & 1 & $\begin{array}{c}\text { FF0100113 } \\
0\end{array}$ & 1 \\
\hline $\begin{array}{c}\mathrm{FF} 0100098 \\
4\end{array}$ & 1 & $\begin{array}{c}\text { FF0100102 } \\
4\end{array}$ & 2 & $\begin{array}{c}\text { FF0100105 } \\
9\end{array}$ & 1 & $\begin{array}{c}\text { FF0100109 } \\
5\end{array}$ & 1 & $\begin{array}{c}\text { FF0100113 } \\
1\end{array}$ & 1 \\
\hline $\begin{array}{c}\text { FF0100098 } \\
6\end{array}$ & 1 & $\begin{array}{c}\text { FF0100102 } \\
5\end{array}$ & 1 & $\begin{array}{c}\text { FF0100106 } \\
1\end{array}$ & 1 & $\begin{array}{c}\text { FF0100109 } \\
6\end{array}$ & 1 & $\begin{array}{c}\text { FF0100113 } \\
2\end{array}$ & 2 \\
\hline $\begin{array}{c}\text { FF0100098 } \\
7\end{array}$ & 1 & $\begin{array}{c}\text { FF0100102 } \\
6\end{array}$ & 2 & $\begin{array}{c}\text { FF0100106 } \\
2\end{array}$ & 1 & $\begin{array}{c}\text { FF0100109 } \\
7\end{array}$ & 1 & $\begin{array}{c}\text { FF0100113 } \\
3\end{array}$ & 1 \\
\hline $\begin{array}{c}\text { FF0100098 } \\
9\end{array}$ & 1 & $\begin{array}{c}\text { FF0100102 } \\
7\end{array}$ & 1 & $\begin{array}{c}\text { FF0100106 } \\
3\end{array}$ & 1 & $\begin{array}{c}\text { FF0100109 } \\
8\end{array}$ & 1 & $\begin{array}{c}\text { FF0100113 } \\
4\end{array}$ & 1 \\
\hline $\begin{array}{c}\text { FF0100099 } \\
0\end{array}$ & 1 & $\begin{array}{c}\text { FF0100102 } \\
8\end{array}$ & 1 & $\begin{array}{c}\text { FF0100106 } \\
4\end{array}$ & 1 & $\begin{array}{c}\text { FF0100109 } \\
9\end{array}$ & 1 & $\begin{array}{c}\text { FF0100113 } \\
5\end{array}$ & 1 \\
\hline $\begin{array}{c}\text { FF0100099 } \\
1\end{array}$ & 1 & $\begin{array}{c}\text { FF0100102 } \\
9\end{array}$ & 1 & $\begin{array}{c}\text { FF0100106 } \\
5\end{array}$ & 1 & $\begin{array}{c}\text { FF0100110 } \\
0\end{array}$ & 1 & $\begin{array}{c}\text { FF0100113 } \\
6\end{array}$ & 1 \\
\hline $\begin{array}{c}\text { FF0100099 } \\
2\end{array}$ & 1 & $\begin{array}{c}\text { FF0100103 } \\
0\end{array}$ & 1 & $\begin{array}{c}\text { FF0100106 } \\
6\end{array}$ & 1 & $\begin{array}{c}\text { FF0100110 } \\
1\end{array}$ & 1 & $\begin{array}{c}\text { FF0100113 } \\
7\end{array}$ & 1 \\
\hline
\end{tabular}




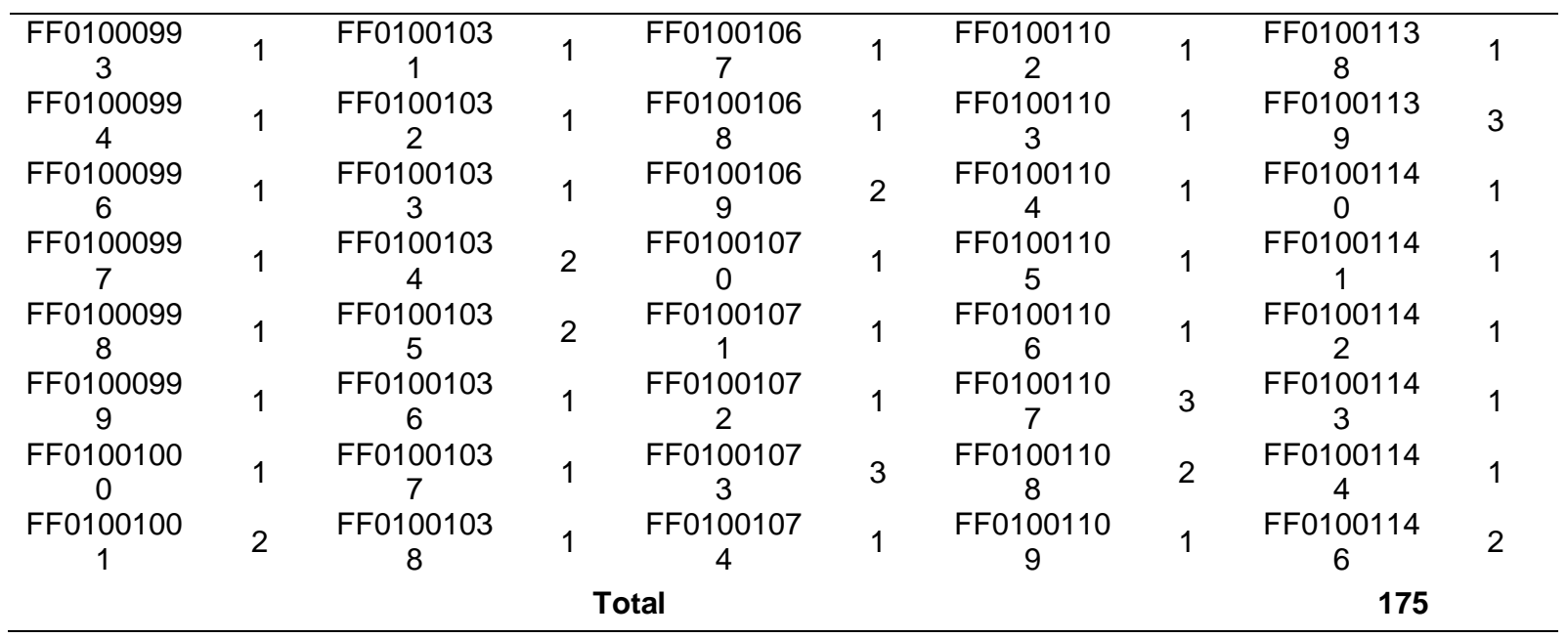


Anexo XI: Pruebas estadísticas del Tiempo de Ciclo Pre-Test

\begin{tabular}{|c|c|c|c|c|c|c|}
\hline \multicolumn{7}{|c|}{ Resumen de procesamiento de casos } \\
\hline & \multicolumn{6}{|c|}{ Casos } \\
\hline & \multicolumn{2}{|c|}{ Válido } & \multicolumn{2}{|c|}{ Perdidos } & \multicolumn{2}{|c|}{ Total } \\
\hline & $\mathrm{N}$ & Porcentaje & $\mathrm{N}$ & Porce & $\mathrm{N}$ & Porcentaje \\
\hline \multirow[t]{3}{*}{ Tiempo de Ciclo } & 30 & $100,0 \%$ & & & 30 & $100,0 \%$ \\
\hline & \multirow{2}{*}{\multicolumn{4}{|c|}{ Descriptivos }} & & \\
\hline & & & & & Estadístico & Desv. Error \\
\hline \multirow[t]{13}{*}{ Tiempo de Ciclo } & Media & & & & 2.466667 & .3277697 \\
\hline & $95 \%$ de int & valo de & Lím & ferior & 1.796302 & \\
\hline & confianza $\mathrm{p}$ & ra la media & Lím & perior & 3.137031 & \\
\hline & Media reco & ada al $5 \%$ & & & 2.277778 & \\
\hline & Mediana & & & & 2.000000 & \\
\hline & Varianza & & & & 3,223 & \\
\hline & Desv. Dest & ación & & & 1.7952684 & \\
\hline & Mínimo & & & & 1.0000 & \\
\hline & Máximo & & & & 8.0000 & \\
\hline & Rango & & & & 7.0000 & \\
\hline & Rango inte & uartil & & & 2.2500 & \\
\hline & Asimetría & & & & 1,265 & ,427 \\
\hline & Curtosis & & & & 1,672 & ,833 \\
\hline
\end{tabular}

Pruebas de normalidad

Kolmogorov-Smirnova Shapiro-Wilk

\begin{tabular}{|c|c|c|c|c|c|c|}
\hline & Estadístico & $\mathrm{gl}$ & Sig. & Estadístico & $\mathrm{gl}$ & Sig. \\
\hline Tiempo de Ciclo & 293 & 30 & ,000 & 786 & 30 & ,000 \\
\hline a. Corrección de & ificación de Lill & & & & & \\
\hline
\end{tabular}



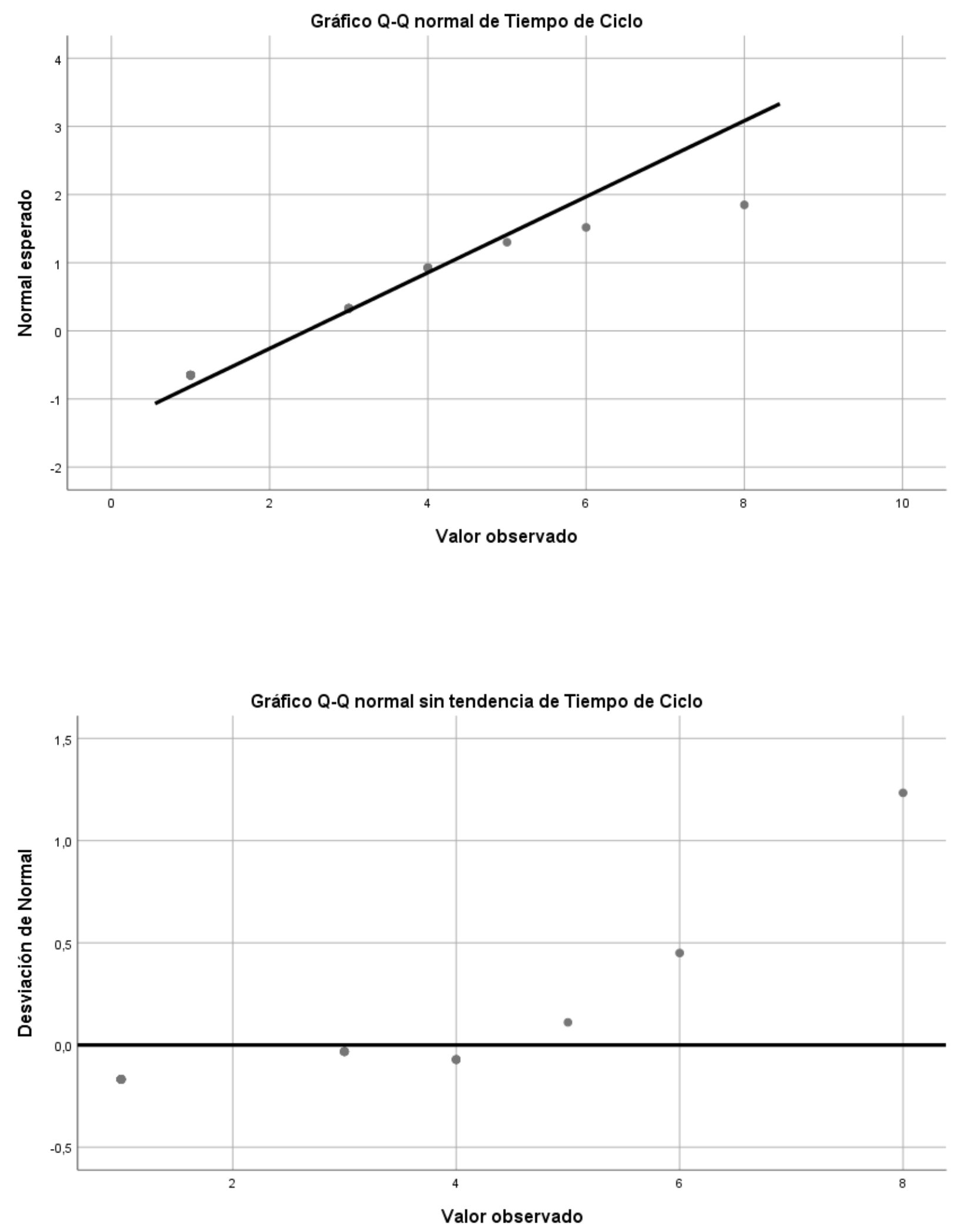


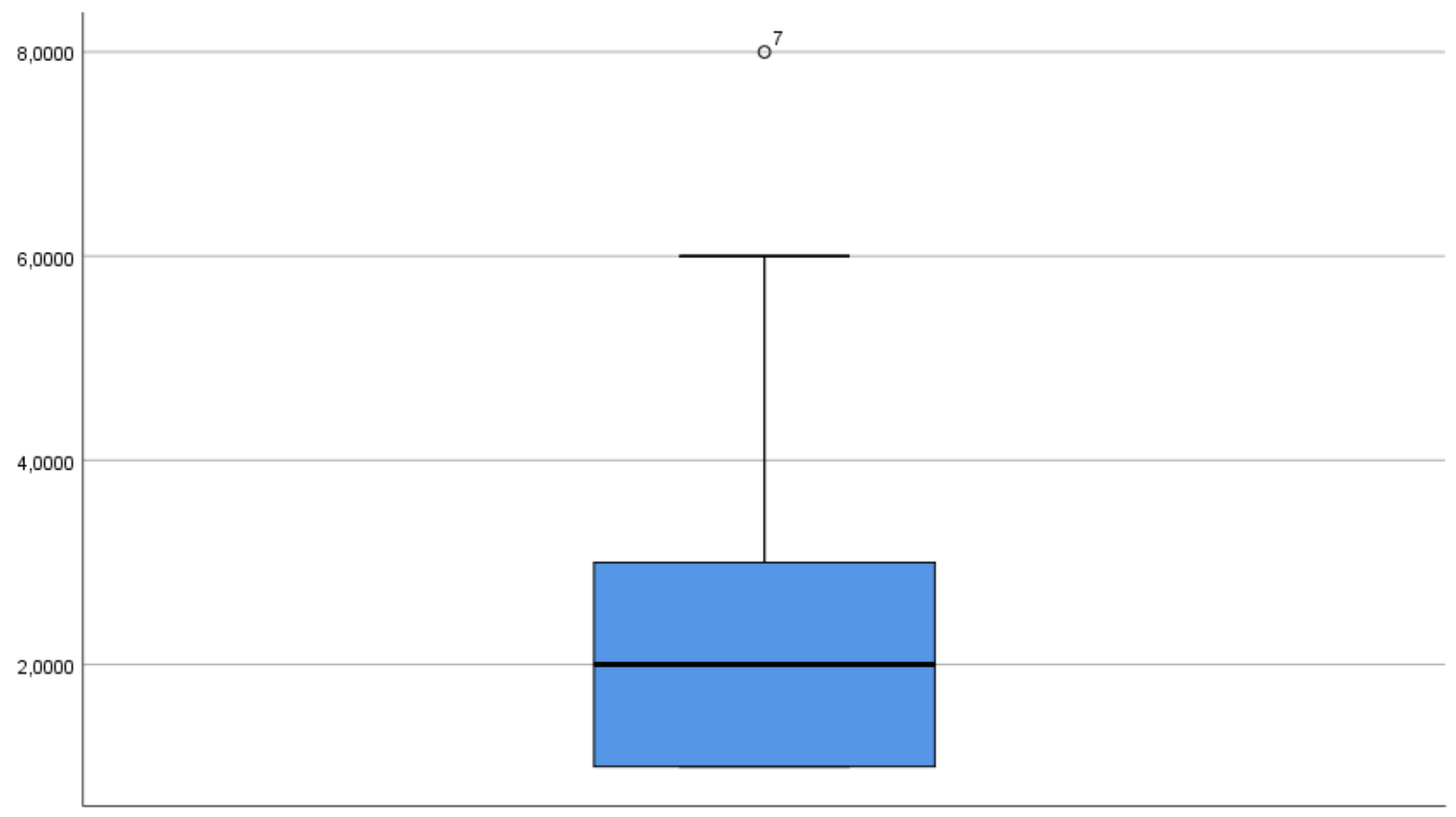

Tiempo de Ciclo 


\section{Anexo XII: Pruebas estadísticas del Tiempo de Ciclo Post-Test}

\begin{tabular}{|c|c|c|c|c|c|c|}
\hline \multicolumn{7}{|c|}{ Resumen de procesamiento de casos } \\
\hline & \multicolumn{6}{|c|}{ Casos } \\
\hline & \multicolumn{2}{|c|}{ Válido } & \multicolumn{2}{|c|}{ Perdidos } & \multicolumn{2}{|c|}{ Total } \\
\hline & $\mathrm{N}$ & Porcentaje & $\mathrm{N}$ & Porcentaje & $\mathrm{N}$ & Porcentaje \\
\hline Tiempo de Ciclo & 30 & $100,0 \%$ & & $0,0 \%$ & 30 & $100,0 \%$ \\
\hline
\end{tabular}

\begin{tabular}{|c|c|c|c|c|}
\hline \multicolumn{5}{|c|}{ Descriptivos } \\
\hline & & & Estadístico & Desv. Error \\
\hline \multirow[t]{13}{*}{ Tiempo de Ciclo } & Media & & 1.300000 & .0850963 \\
\hline & $95 \%$ de intervalo de & Límite inferior & 1.125959 & \\
\hline & confianza para la media & Límite superior & 1.474041 & \\
\hline & Media recortada al $5 \%$ & & 1.277778 & \\
\hline & Mediana & & 1.000000 & \\
\hline & Varianza & & ,217 & \\
\hline & Desv. Desviación & & .4660916 & \\
\hline & Mínimo & & 1.0000 & \\
\hline & Máximo & & 2.0000 & \\
\hline & Rango & & 1.0000 & \\
\hline & Rango intercuartil & & 1.0000 & \\
\hline & Asimetría & & 920 & , 427 \\
\hline & Curtosis & & $-1,242$ & ,833 \\
\hline
\end{tabular}

\section{Pruebas de normalidad}

Kolmogorov-Smirnova

Shapiro-Wilk

\begin{tabular}{lrrrrrrr} 
& \multicolumn{3}{c}{ Kolmogorov-Smirnova $^{\mathrm{a}}$} & \multicolumn{4}{c}{ Shapiro-Wilk } \\
& Estadístico & gl & Sig. & Estadístico & gl & \multicolumn{1}{c}{ Sig. } \\
\hline Tiempo de Ciclo &, 440 & 30 &, 000 &, 577 & 30 &, 000
\end{tabular}

a. Corrección de significación de Lilliefors 

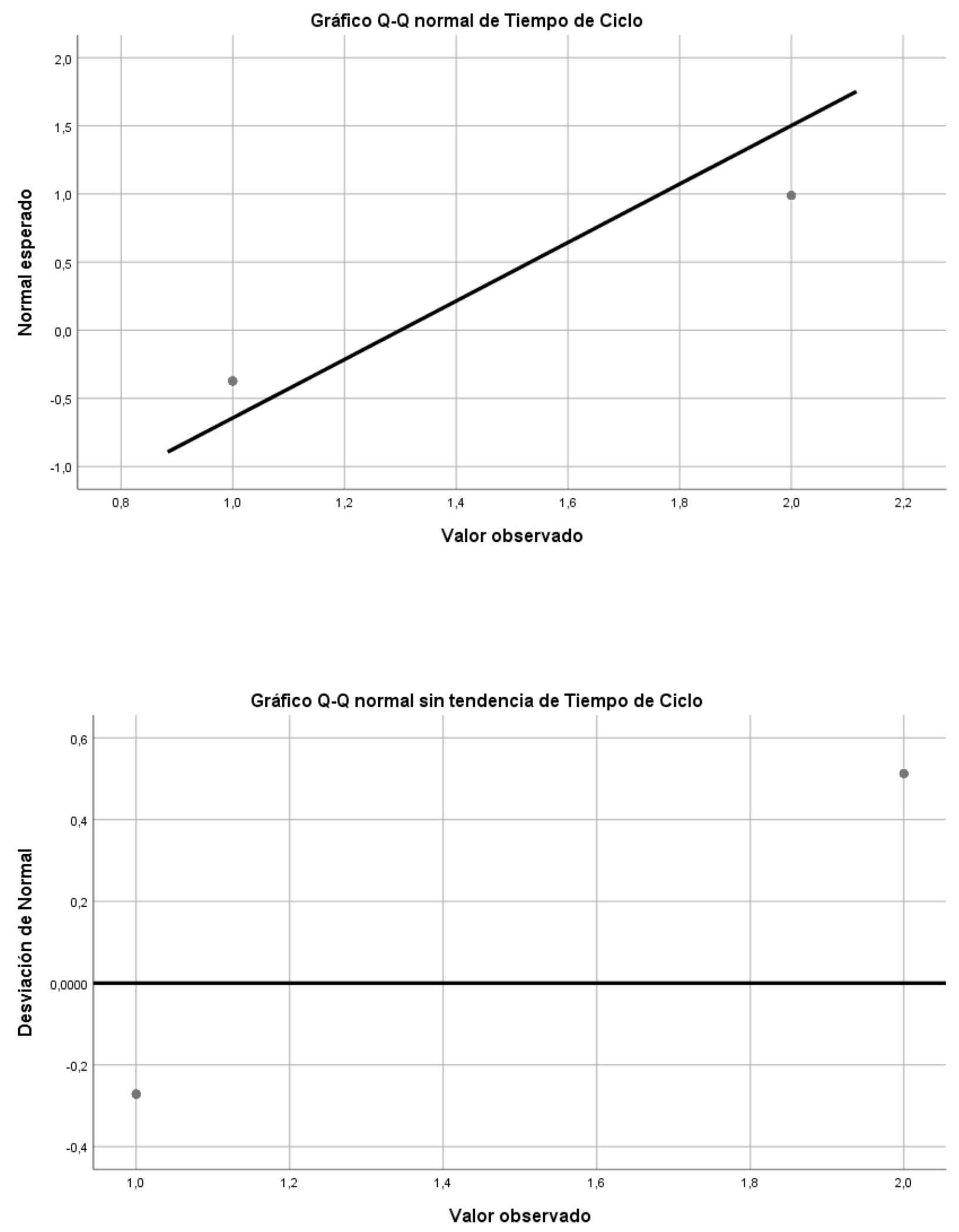


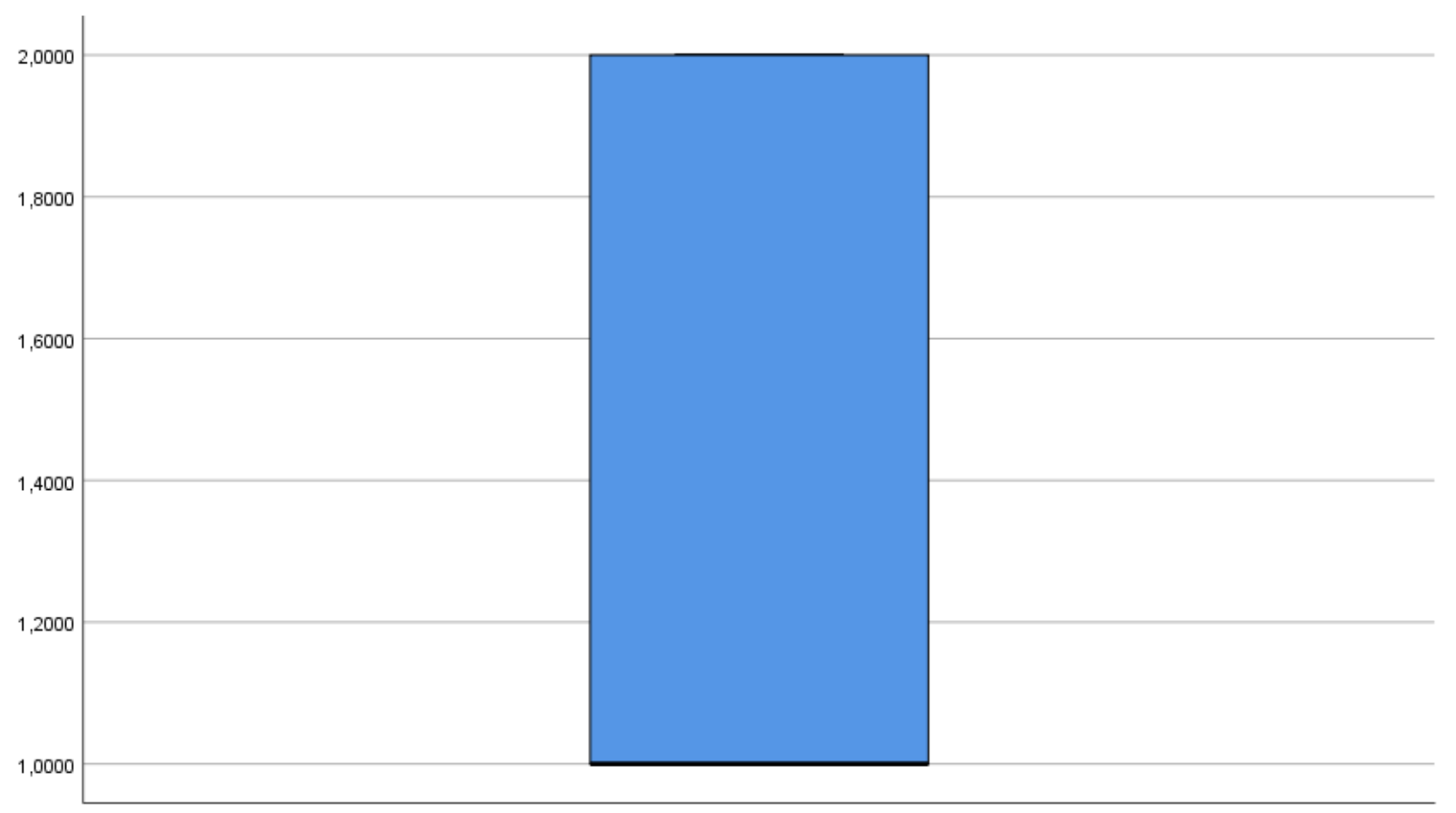

Tiempo de Ciclo 